\title{
Power Play: Visualising Electricity Use as Emoji
}

\author{
By
}

Ariel Reyes

\begin{abstract}
A thesis
submitted to the Victoria University of Wellington in fulfilment of the requirements for the degree of

Master of Design Innovation
\end{abstract}

Victoria University Wellington

2018 


\section{Abstract}

With the prevalence of emoji, digital pictographs in computer mediated communication, this thesis investigates the suitability of using emoji to represent energy use. With research participants and in partnership with a New Zealand electricity retailer and a meter equipment provider, a selection of emoji was identified to represent low or high daily electricity usage. A chatbot was developed to replace an In-Home Display (IHD) usage monitor. The chatbot is used as an agent for presenting interpreted consumption both as text and emoji. The resulting interactions and observations were documented, along with changes in consumption. 


\section{Acknowledgements}

First, I would like to thank Kala, Marius and Alex for being patient with me, and for encouraging me to finish what I've started. Lola Aida and Lolo Newton, for inspiring me to pursue higher education.

I'd also like to thank my Supervisor Walter Langelaar, who has stuck with me, and for giving me sound advice on completing my study. I wouldn't have developed the technical bits without his prodding. Thanks to Donald Cruz as well for proof reading.

Thanks to the faculty, staff and fellow students of the School of Architecture and Design, Flick Electric Co. and Vector AMS for contributing to this body of work.

To my family and friends here and across the globe, thanks for your unwavering support.

And finally, to the Big Man Above, it has been more than two years of learning, hard work, frustration, self-doubt, self-affirmation, grit, determination, and now finally completion. You have always told me everything happens in its own sweet time. Something I should constantly keep in mind. Thanks for everything! 


\section{Table of Contents}

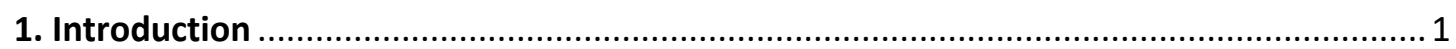

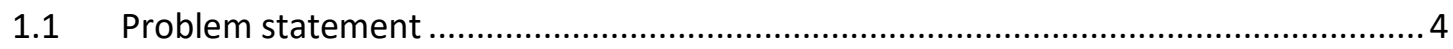

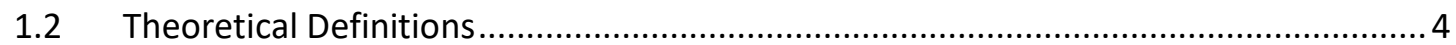

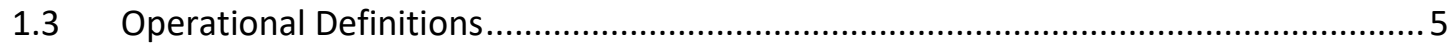

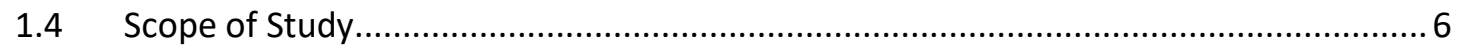

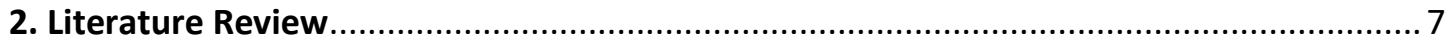

2.1 New Zealand Electricity Market ........................................................................... 7

2.2 Eco-Visualization and Eco-Feedback ................................................................... 12

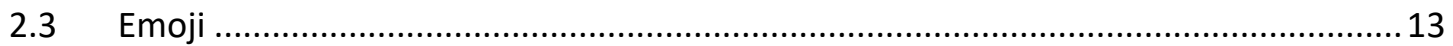

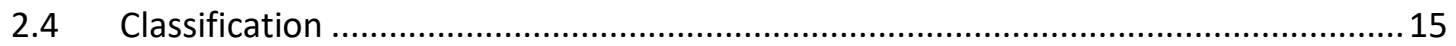

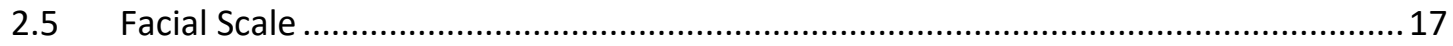

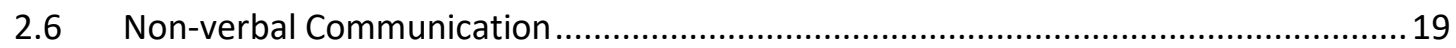

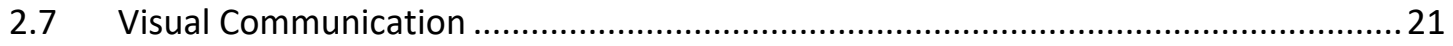

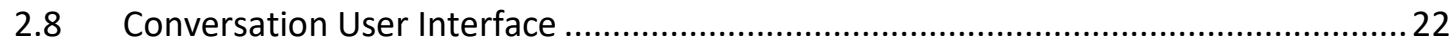

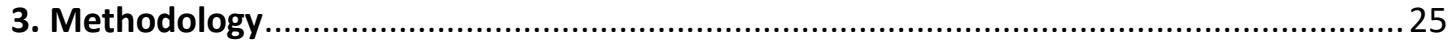

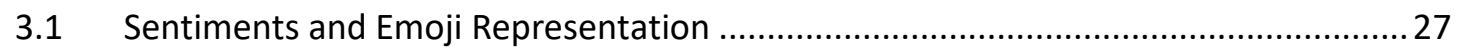

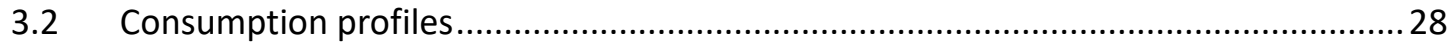

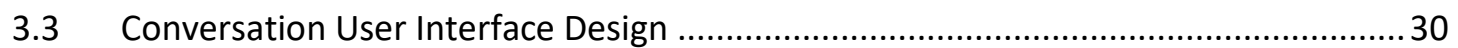

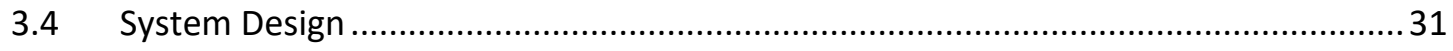

3.4.1 Versions of the Conversation User Interface................................................. 32

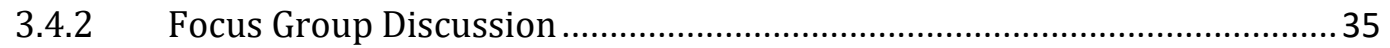

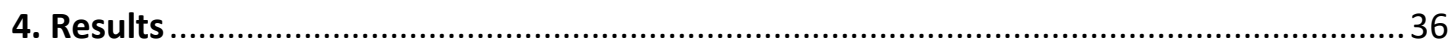

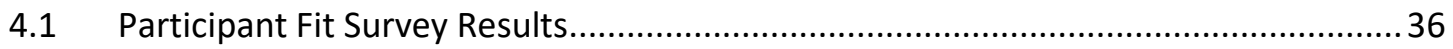

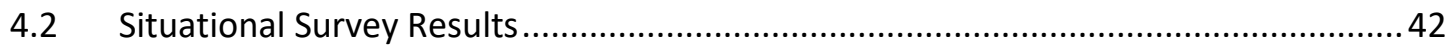

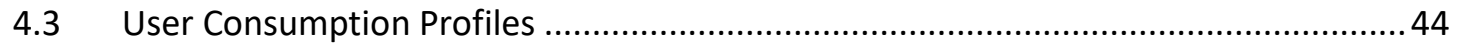

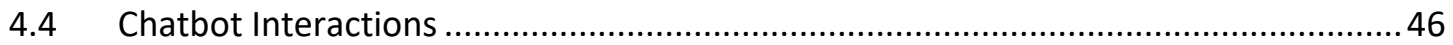

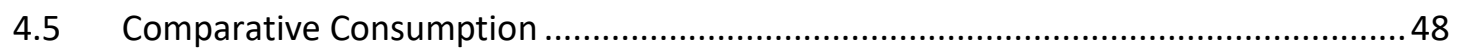

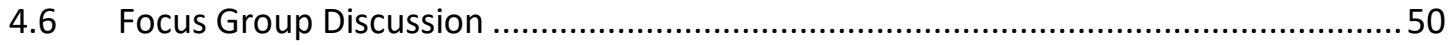

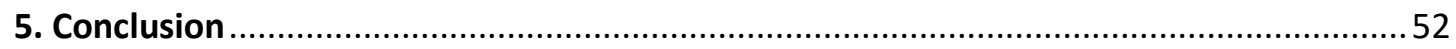

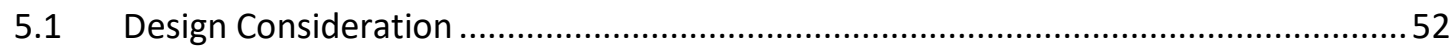




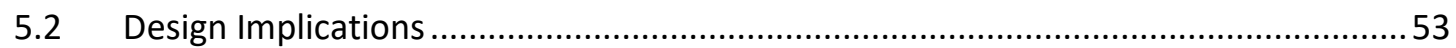

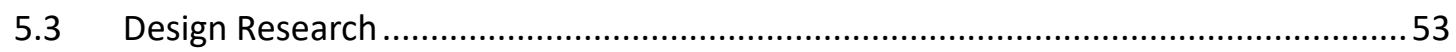

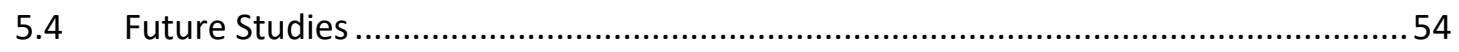

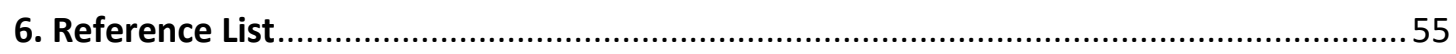

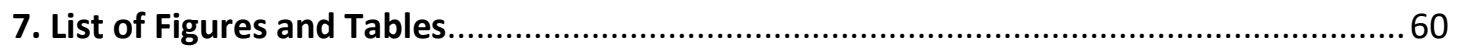

8. Appendix A: Questions and Responses from First Design Expert......................................61

9. Appendix B: Questions and Responses from Second Design Expert .................................62

10. Appendix C: Participant Fit Survey Questions and Results ..............................................64

11. Appendix D: Application Architecture and Technical References ..................................67

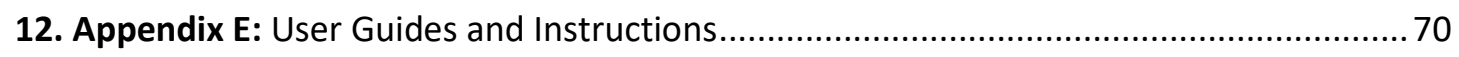

13. Appendix F: Situational Survey Questions and Results ................................................. 72

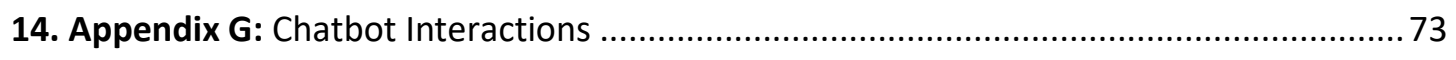

15. Appendix H: Comparison of Participants Daily Cumulative Reads .................................77

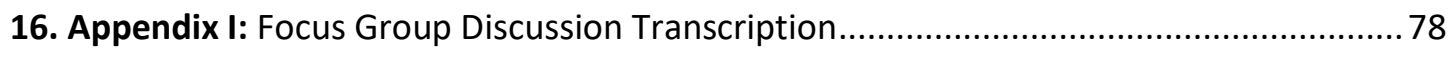

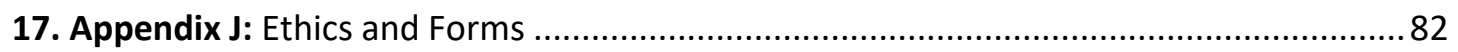




\section{Introduction}

According to the UN Foundation for Climate Change "Reducing the amount of energy the world wastes is the first and best step toward fighting global warming. The International Energy Agency estimates that almost one-half of the necessary climate mitigation will need to come from improved energy efficiency. Eliminating energy waste also provides financial resources to sustainably grow strong economies around the world" (United Nations Foundation, 2013).

Furthermore, in the Conference of the Parties under the United Nations Framework Convention on Climate Change in Paris, 2015, participants agreed that greenhouse gas (GHG) emissions will be reduced to as close to zero as possible. It was pointed out that the energy sector--- electricity generation, transmission and distribution comprises the vast majority of GHG emission. It follows that by reducing electricity demand, increasing efficiency and shifting to renewable resources can help in achieving the set goal.

The push for promoting environmental awareness and energy conservation, has motivated advocates in the field of Human-Computer Interaction ( $\mathrm{HCI}$ ) to come up with concepts like Eco-Feedback and Eco-Visualization. What is Eco-Feedback? It is defined as feedback on individual or group behaviours with a goal of reducing environmental impact. While Eco-Visualization, coined by Tiffany Holmes, is primarily the use of art and technology to promote environmental awareness. A lot of environmental organizations have been successful in using HCI to promote energy awareness initiatives. As described by Holmes in 2007, her primary research question was "Can creative visualizations of real time energy consumption patterns trigger more ecologically responsible behaviour? Media art that displays the real time usage of key resources such as electricity offers new strategies to conserve energy in the home and workplace". Holmes further pointed out that Eco-Visualization can be used to shed awareness of one's own energy consumption and as an incentive to change one's consumption (Venables, 2007).

Based on the literature reviewed and case studies done on Eco-Visualisation, it provided a view of the effort required to setup methods for representing electricity consumption data. Previous research work done on Eco-Visualization took advantage of predominant technologies like web and mobile applications. Some even went as far as doing public digital installation (Holmes, 7000 Oaks, 2007).

Still, it is worthwhile to consider that whenever there is research on technology, it is mostly directed towards practicability and with lesser emphasis on applicability. As professor of sociology, Elisabeth Shove argues: there is a tendency "to pay greater attention to the invention and acquisition of the new things than to the way such novelties are subsequently deployed in practice" (Holmes, 2007, p. 2).

This lends us to trace the roots of Eco-Feedback and Eco-Visualization which is environmental psychology. Defined as the complex interactions between humans and the environment. More specifically, the field is about understanding roots of environmental degradation and the connections between environmental attitudes and proenvironmental behaviours (Froehlich, Findlater and Landay, 2010). For an Eco-Feedback or Eco-Visualization project to be successful we also need to assess successful models that worked towards encouraging pro-environmental behaviours. 
Evaluating the different platforms available for undertaking Eco-Feedback and EcoVisualization projects--- check what is readily available, cost effective and most applicable. Previous studies have tested solutions using web and mobile applications, with varying degrees of success.

To date, the primary investigator has not seen any study that attempted to do EcoFeedback and Eco-visualisation using messaging bots, more commonly called chat bots, computer programs that mimic human conversation with people using artificial intelligence (Wong, 2016).

Statistics indicate there are approximately 2.16 billion people with smart phones globally (eMarketer, 2014). And according to Juniper research, mobile and online messaging traffic will reach 160 trillion per annum by 2019, up from 94.2 trillion this year - equating to approximately 438 billion messages sent and received by users on a daily basis by 2019 . And Facebook statistics alone indicate that on WhatsApp an average of 42 billion messages are sent daily (Smith, 2018). With the availability of mobile and pervasiveness of instant messaging, it strongly supports considering mobile messaging as an option.

It is also important to note that Eco-Feedback and Eco-Visualization may at times be discussed as separate or combined concepts throughout the research. The primary investigator would like to emphasize Eco-Feedback in this study is the practice of providing energy usage information directed towards an individual or a group in the attempt to promote energy conservation. While Eco-Visualization in the context of this study is the method of interpreting the energy consumption data using art and technology to promote environmental awareness. Furthermore, background studies have proven, with the help of feedback mechanisms like computer interactive displays or energy usage monitoring devices, household energy consumption can be reduced considerably (Darby, 2006, p.17).

Looking further into the social aspect of environmental psychology, once it is framed in the context of social media, it allows for several users to share and interact regarding online content and to connect with like-minded individuals who share similar environmental views and concerns. Reaching a wider audience, building an online community or even a critical mass. Like other Eco-visualisation projects (7000 Oaks, Power Ballads), social media was essential for promotion. In the context of using instant messaging as the medium to facilitate Eco-Feedback and Eco-Visualization we also have to look at how social media plays a part. As there are numerous debates online on the idea that instant messaging does not fall under social media, even if most instant messaging applications are capable of sending messages, images and videos. This research project needs to establish an online network and connect the research participants so sentiments regarding Eco-Feedback can be freely shared.

The limitations of multiplatform instant messaging applications like WhatsApp and Viber is that messaging using these applications can only work and communicate with agents in your contact list. Unlike social media sites wherein new connections can be established even if agents are not in your list of contacts. Furthermore, this requires an online community of research participants to be able to socialize their views and experience in relation to the Eco-Feedback received. With the aim to make the research more participatory and engaging. Most multiplatform messaging applications do not have features like community or group pages by default, unlike most social media sites. To further disambiguate the idea on which platform to use, and in following other studies 
that have worked in promoting Eco-Visualisation, the primary investigator will focus on instant messaging application services that are provided by social media sites.

We know that social media has become so popular that it is now part of our everyday life. Platforms like Facebook, Twitter and Instagram are so predominant that for businesses to be competitive they need to have an effective social media strategy (Burke, M. \& Kraut R., 2011). In essence, these social media sites try to reach as many users as possible. Due to the fact that one of the key revenue streams of these social media sites is mobile advertising. Advertising has always been geared towards tapping into consumer's emotions rather than reason. Even for consumer products, it has always been about the feeling we derive from the products rather than the material itself. The emotional value being endorsed by these social media sites is what BJ Fogg considers as Captology, the use of computers as a persuasive technology. Still on advertising. Fogg further qualifies that social media sites, particularly Facebook, embodies core elements of Captology, wherein content is tailored based on a user's online activity and preferences. We look at Captology in this study as a concept we can apply to encourage pro-environmental behaviour.

With the platform identified, we then need to look into the language or medium for providing Eco-Feedback. To reiterate, this study is evaluating visual messages as an alternative to representing electricity usage data. In following the theme of EcoVisualization, one of the popular art forms that have emerged recently are emoji. Emoji are defined as digital pictographs used commonly in mobile and computer mediated communication as a replacement for words. These pictographs have exploded in use in 2011 when Apple came out with the emoji keyboard for the iPhone in the aim to penetrate the Japanese market. More recently, the Museum of Modern Art (MoMA) in Manhattan acquired the original 176 emoji created by Shigetaka Kurita as part of their collection. According to Paul Galloway, collection specialist in MoMA's Department of Architecture and Design, "These 12x12 pixel humble masterpieces of design planted the seeds for the explosive growth of a new visual language." (Pierson, 2016).

Emoji are actual pictures embedded in text as opposed to emoticons which are face imitations created using ASCII characters (Hallsmar and Palm, 2016, p. 1). Through the emoji keyboard available in most smartphones it has been integral in mobile communications. At present, there is a Unicode consortium that governs the creation of emoji. As of 20 August 2016, there are actually 1791 emojis available across platforms unique for every device or operating systems ("Full Emoji List", n.d.).

Emoji were selected as the visual language for Eco-Feedback due to its prevalence in social media and intrinsic emotive value (Stark and Crawford, 2015, p.8). One study pointed out that in 2 years, out of 12 billion tweets around 4 billion have emoji (Novak, Smailović, Sluban and Mozetič, 2015). Some background studies also give evidence that the combination of energy consumption feedback and the pervasiveness of social media can help consumers become more energy aware (Foster, Linehan, Lawson and Kirman, 2011, p. 2222-2226). This supports the idea of selecting social media sites, particularly Facebook as the proper communication platform (Burke and Kraut, 2011, p. 8), as it embodies elements that allow behavioural change to occur --- motivation, ability and triggers (Persuasive Tech, n.d.).

It is still of interest if emoji can work to represent energy use, particularly electricity consumption. One study conducted by Azuma and Ebner in 2008, trialled an online community blog site allowing students in Japan and Austria to communicate to each other 
through transliteration--- using emoji in lieu of text for specific keywords (e.g. "My 圈 broke down"). Focus was lexical rather than emphatic use of emoji. Also, the students were only asked to communicate in English. Results showed even with the language differences, students were generally able to communicate ideas, with some cases of misinterpretation due to emoji selection. What the study confirmed was that with the aid of a dictionary there was lesser room for misinterpretation (Azuma and Ebner, 2008).

With the significant popularity of faces emoji, the primary investigator is also seeking to simplify the interpretation of electricity usage by either a personal selection of emoji or trialling if a lexicon emoji can represent varying degrees of energy use. This is relative to a participant's historical consumption data. The same concept is taken from the study on comes from how the Wong-Baker pain scale was developed and how a visual scale can be used to represent a physical experience or condition (Wong and Baker, 1988).

To draw things together, the research aims to facilitate Eco-Feedback using a messaging bot on Facebook Messenger, but instead of numerical data a lexicon of emoji will be used as a medium.

\subsection{Problem statement}

This project investigates whether a messaging bot aided by emoji, can be used as a channel and medium to provide Eco-Feedback. With the vast selection of emoji available, the aim is to trial if a lexicon of emoji can be used represent electricity usage data. Various studies have established the emotive value of emoji, but with aid of persuasive technology, it is hypothesized that emoji can also be used to visualize electricity usage and perhaps encourage pro-environmental behaviour.

\subsection{Theoretical Definitions}

Emoji - Defined as digital pictographs which were initially created by Shigetaka Kurita for NTT Docomo in Japan to replace words in text messaging. The word "emoji" is Japanese for "picture character" (Pierson, 2016). The Unicode Consortium defines emoji as pictographs (pictorial symbols) that are typically presented in a colorful form and used inline in text. They represent things such as faces, weather, vehicles and buildings, food and drink, animals and plants, or icons that represent emotions, feelings, or activities. This is in keeping with the Unicode Consortium objective of allowing people around the world to use computers in any language. The consortium provides specifications and data that help form the foundation for software internationalization in all major operating systems, search engines, applications, and the World Wide Web ("The Unicode Consortium", n.d.).

Emoticons - It is a contraction of the words "emotional icons". Glyphs used in computermediated communications and are meant to represent facial expressions (Kelly, 2015, p. 14).

Eco-Visualization - Is defined as a novel approach to display the real time consumption statistics of key environmental resources for the goal of promoting ecological literacy. Holmes (2007) defined it as any data-driven visualization that displays ecological information of any form in real-time. 
Eco-Feedback - Is defined as technology that provides feedback on individual or group behaviours with a goal of reducing environmental impact (Froehlich, Findlater and Landay, 2010, p. 1999).

Conversation User Interface - Or the Spoken Dialogue systems have been defined as computer systems with which humans interact on a turn-by-turn basis and in which spoken natural language plays an important part in the communication. The main purpose of a spoken dialogue system is to provide an interface between a user and a computer based application such as a database or expert system (McTear, 2002, p. 92). The term Conversation User Interface or CUI, is used interchangeably with messaging bot or chatbot in the research discussion.

\subsection{Operational Definitions}

Meter Data Collection - With deregulation brought about by the New Zealand Energy Efficiency and Conservation Act of 2000, the Meter Equipment Providers or MEPs are now responsible for collecting, storing and providing meter consumption data to electricity retailers. With smart meters, meter consumption data measured in half-hourly intervals, can now be collected on demand or on schedule. The meter communicates with the MEPs backend system either through a Global Packet Relay System (GPRS) or a Mesh Network.

RESTful API - RESTful services follow the REST model which is defined as "REpresentational State Transfer, is a communications paradigm for distributed systems such as the World Wide Web. REST-style architectures include clients and servers, where clients send requests to the servers that in turn process these requests and return appropriate responses back to the clients". Further to this patent US 20160092173 A1, states that "Web service APIs (Application Programming Interfaces) that adhere to the architectural constraints of REST are called RESTful. HTTP-based RESTful APIs may be defined using a base URI for a resource, an Internet media type for the data (e.g., JSON, XML, Atom, etc.), HTTP methods (e.g., GET, PUT, POST, DELETE), hypertext links to reference state, and/or hypertext links to reference related resources. "(Rodrigues, Souza and Chan, 2016).

AI Service - Are callable Web APIs that provide artificial intelligence function such as Conversation User Interface or Personal Assistance, Computer Vision, Speech Recognition and Text to Speech. These services are made available by cloud service providers like Amazon Web Services, Microsoft Azure and Google.

Intent - In the context of the AI Service used in developing the messaging bot, an Intent represents a map between what a user says and what actions the software behind the messaging bot will take.

Webhooks - Also called web callbacks or HTTP push API, is a method for a Web application to pass-on information to other applications. A webhook delivers data to other applications instantaneously. Unlike typical APIs where frequent polling is needed to get real-time or close to real-time data.

Half Hourly Reads - The half hourly interval meter consumption data recorded and transmitted by the smart meter. It is comprised of 48 intervals which represents all half hour intervals for 24 hours. When DST starts in summer only 46 intervals are recorded for that day. While in fall when DST ends 50 intervals are recorded. 
Midnight Reads - The sum of all interval reads recorded for a day. The time stamp of the cumulative meter read is at 11:59:59 PM.

\subsection{Scope of Study}

The study will primarily be conducted in Wellington, New Zealand. There are four main data sources: 1) online surveys that will help identify research participants, 2) interview with at least two professional designers to probe their thoughts on alternative uses of emoji, and 3) themes arising from interactions with the messaging bot and 4) results from a Focus Group Discussion with the research participants. The electricity industry participants that have helped are Flick Electric Co. as the retailer, with Vector AMS as the MEP.

This research already takes into account that there are now more than 1 million smart meters in New Zealand. Having smart meters are now standard for most homes. Remote meter reading is the only functionality this study depends on. This service is provided by MEPs.

Utilizing an existing social media platform, Facebook and its instant messaging service, Facebook Messenger, allowed for developing a chatbot that will act as an Eco-Feedback agent. This agent will be comprised of an AI Service that will be used for communicating with the research participants. Along with an API that will ingest consumption data. Then process, interpret and present the consumption data as text or emoji to the research participants.

It is necessary that historical consumption data is retrieved to set a baseline for comparing changes in consumption during the period of user testing and data gathering.

In order to come up with the emoji set, the primary investigator will present the most popular emoji ranked based on occurrences on Twitter with the aid of a real-time emoji tracker (http://emojitracker.com/). Alternatively, research participants can opt to use non-popular emoji, selecting two emoji that will represent low and high energy use. Somewhat similar to the Wong-Baker pain scale, but instead of pain, comparative consumption is represented.

The research participants can freely respond to all messages coming from the chatbot. Research participants are expected to communicate with the messaging bot in English using both text and emoji. 


\section{Literature Review}

The previous chapter presented an overview of the research. The literature review provides the theoretical background to support it. Some insights on the importance of energy information for New Zealand is given, and how this research may contribute to this domain of knowledge. This is followed by a discussion on emoji as a visual language, and some background on visual communication. Studies on Eco-Feedback and EcoVisualisation are also provided. Finally, the idea of using Conversation User Interface (CUI), specifically a chatbot, along with AI Services is also presented.

\subsection{New Zealand Electricity Market}

According to the New Zealand Ministry of Business, Employment and Innovation one of the key objectives of the New Zealand Energy Efficiency and Conversation Strategy of 2017 to 2022 is to help "individuals, households and community institutions choose energy efficient technologies, adopt energy efficient behaviours and make greater use of renewable energy". To be economically competitive, it is necessary for New Zealand to adopt policies that will encourage efficient energy use, conservation and shift to renewable energy (Ministry of Business, Innovation and Employment, 2017).

The New Zealand Energy Efficiency and Conservation Act of 2000 provided policies that paved the way for advances in energy infrastructure, wherein smart metering has allowed for easier access to electricity usage information. Only through measurement can efficiency and conservation be achieved. Figure 2.1 provides a comparison of conventional and advanced metering data flows.

Figure 2.1 Comparison Between Conventional and Advanced Metering Data Flows

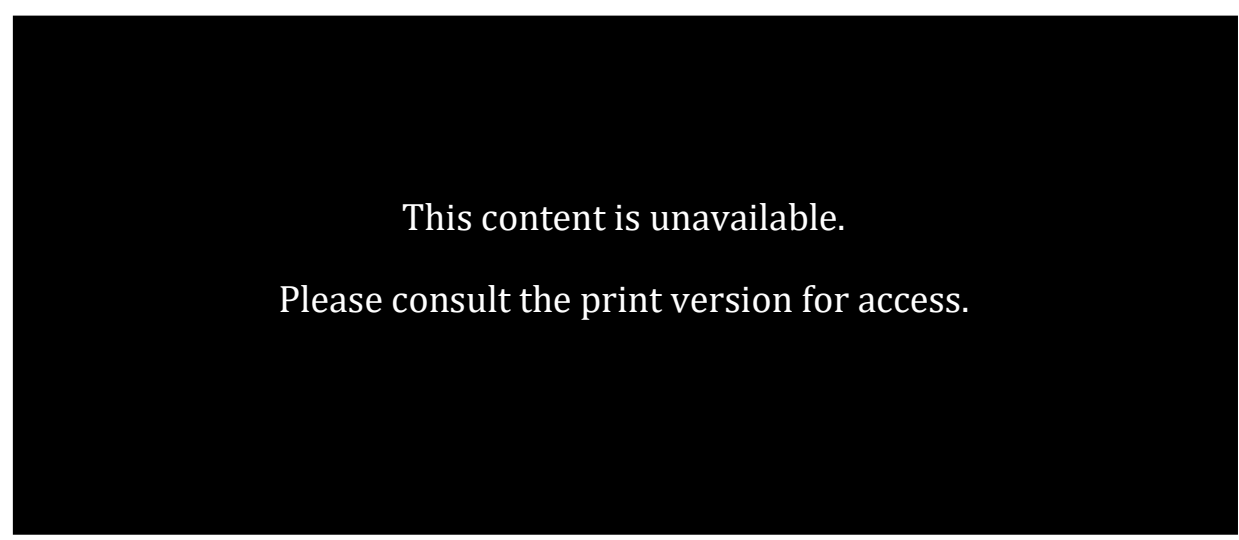

Source: Advanced Metering Infrastructure Based on Smart Meters in Smart Grid, Trong Nghia et. al., 2016

Conventional metering was significantly reliant on estimating usage, unlike smart metering which enables actual meter reads.

Smart metering is only a segment of New Zealand's energy infrastructure. The national electricity grid, owned and operated by Transpower, is made up of over 12,000 km of transmission lines and more than 170 substations. Electricity is transmitted over the grid 
at high voltages (up to 220,000 volts) from power stations to local lines companies and major industries. It is a network of transmission lines, substations, transformers and more that deliver electricity from the power plant to homes and businesses.

In New Zealand, the electricity industry was deregulated with the intention of encouraging competition among electricity retailers and distributors to reduce prices for the benefit of consumers. Deregulation divided the industry into four sectors: generators, distributors, retailers and transmission companies. In other countries the electricity industry is vertical wherein utilities generate, distribute and retail electricity. The Electricity Authority which governs the industry has prescribed that retailers participate in the electricity market and allow for residential consumers to purchase electricity at spot market prices. This along with other incentives have encouraged innovations in trading and retail products like different tariffs and pricing schemes.

It is necessary to mention Transpower, as an efficient national grid allows for market competition and ensures electricity demands are met. Transpower is also mandated to promote conservation as stated on their website "Energy conservation is important and highly desirable. However, it takes time and a lot of education to get people to change their habits and for new and more efficient technologies to replace existing ones". Transpower also provides information services to all market participants ranging from usage quantities, trading information to generation mix (percentage from coal, solar, hydro, etc.). Market participants use the information for trading, settlements and demand forecasting. Still, there is not much innovation for promoting energy conservation. According to Bolt (2015) "In a market where innovation is hard to come by, there are a few retailers challenging the status quo. Flick Electric, which launched last year, developed technology allowing customers with any type of smart meter to take advantage of electricity spot prices and shift their usage to when power is cheapest. This is a good start, but Flick isn't offering meters with home area network functionality or In-Home Displays (IHDs) - you have to log on to a personalised online portal to check your power use and spot prices". Scanning existing products and services, electricity retailers offer consumers with mobile and web applications to view pricing and generation mix. While some provide usage information for only a limited period.

Bolt (2015) also mentioned that the Electricity Authority released a report to the New Zealand Ministry of Energy and Resources stating that the cost of setting up home area networks (HANs) which would allow smart meters to interact with smart appliances, and IHDs that show real-time energy use which can identify power hungry appliances far outweighed the benefits. As a result, electricity retailers installed meters capable only of recording your power use and nothing more. Bolt argued that with online energy monitoring programmes being opt-in, making it less accessible than IHDs.

With the opt-in nature of existing retailer energy monitoring programmes, on both web and mobile, adoption is largely dependent on consumer interest. According to Darby (2006), economic incentives help encourage reduction in consumption. Still, without the IHD in most households, consumers do not actively monitor their usage. In New Zealand, consumers with retailers that provide spot market prices are more consciously monitoring their usage to avoid "bill shocks" due to market price surges (Williams and George, 2017).

The most comprehensive study on energy consumption patterns in New Zealand, was done by Otago University in 2006 through the Household Energy End-use Project (HEEP). 
The HEEP project identified that $44 \%$ of the household carbon emissions from household appliances comes from hot water heating. With the average electricity consumption for New Zealand homes account for around 7,700 kWh/year, which has remained constant for more than 30 years.

Figure 2.1.2 Energy Usage in New Zealand Homes

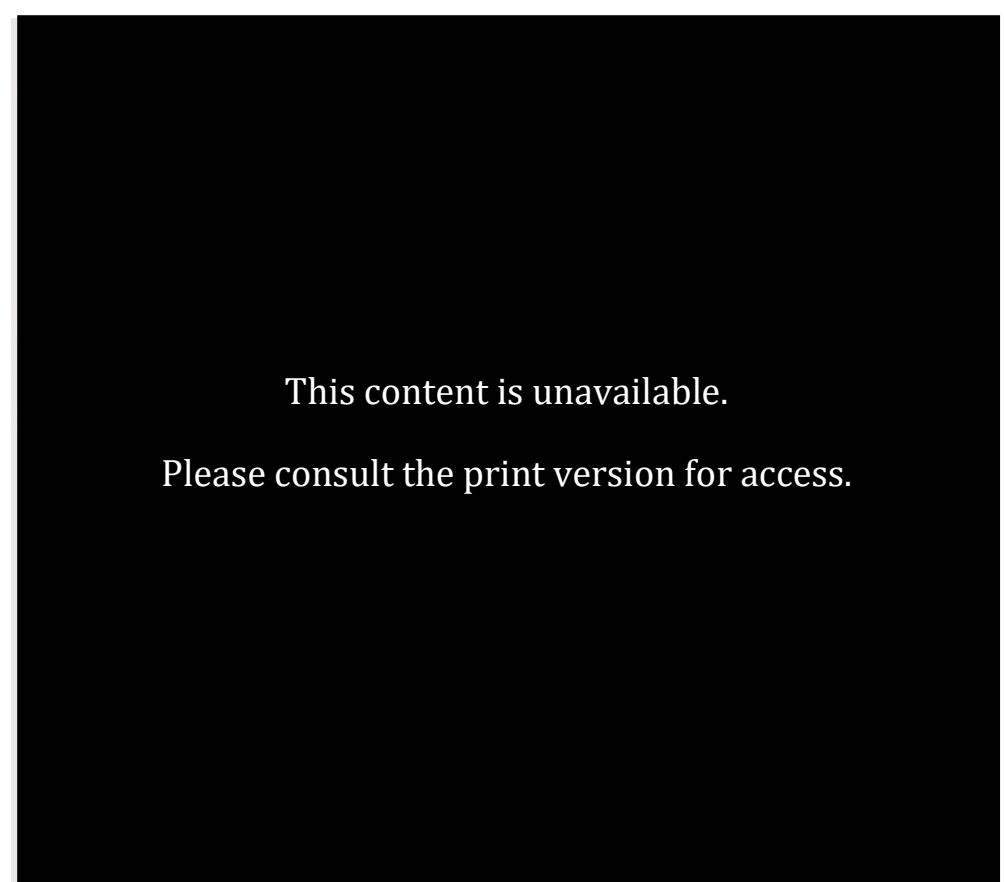

Source: http://www.physics.otago.ac.nz/eman/hew/ehome/energyuse.html\#

According to Kollmuss and Agyeman (2002), in the United States where studies on proenvironmental behaviour started, common practice in public communication campaigns follow the linear progression model which assumes that environmental knowledge leads to environmental awareness and concern (environmental attitudes), which in turn was thought to lead to pro-environmental behaviour. They argued that various government and non-government organizations continue to follow the same framework believing that information alone is sufficient, thinking once people are more environmentally aware proenvironmental behaviour follows. The model is depicted in Figure 2.3.

Figure 2.3 Environmental Knowledge Linear Progression Model

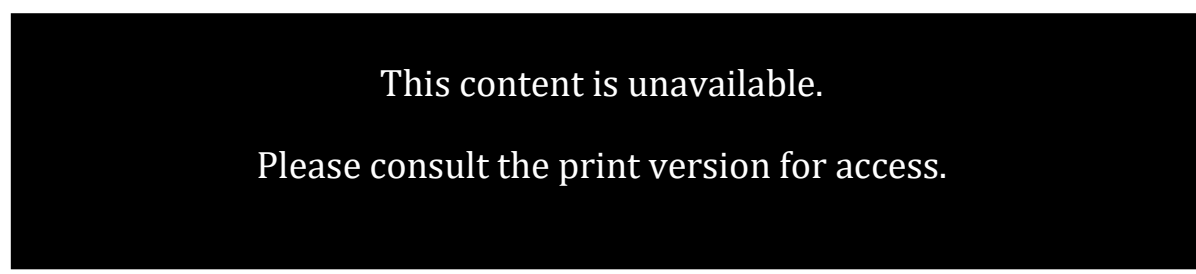

Source: Mind the Gap, Kollmuss and Agyeman, p. 241, 2002

Kollmuss and Agyeman further argued that environmental knowledge, values, and attitudes, together with emotional involvement makeup a complex called 'proenvironmental consciousness'. This complex in turn is embedded in broader personal values and shaped by personality traits and other internal as well as external factors. Where social and cultural factors are considered as external factors. These factors along with education help contribute to the development of environmental awareness. They 
have identified several barriers to pro-environmental behaviour ranging from lack of knowledge, feedback, incentives and environmental consciousness to existing values, knowledge and contradicting environmental values. For them the biggest barrier are old behaviour patterns. These barriers are identified as black boxes in the Kollmuss and Agyeman model for pro-environmental behaviour in Figure 2.4.

Figure 2.4 Kollmuss and Agyeman Pro-Environmental Consciousness

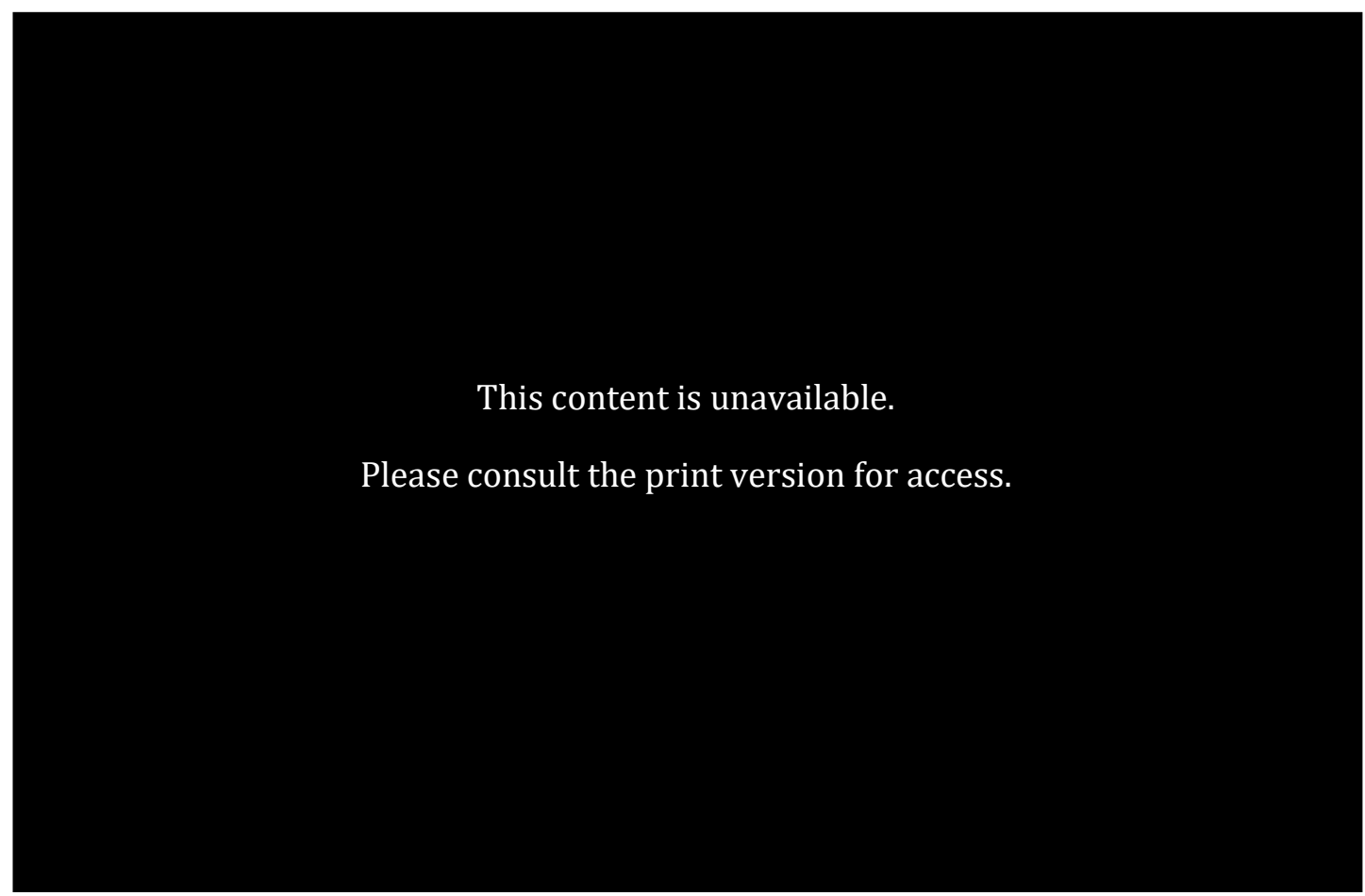

Source: Mind the Gap, Kollmuss and Agyeman, p. 257, 2002

In support of Kollmus and Agyeman's argument that environmental knowledge alone is insufficient, Allcot and Mullainathan (2010) further pointed out that along with information, behavioural programs like social comparison has significant benefits. Emphasizing that rational choice model of combining price and information alone does not ensure behavioural changes. What they noted was for a study done in the United States--- by providing energy use report to households and comparing it with similar households, providing energy saving tips helped reduce consumption by over $2 \%$. Still, behavioural research points out that “... people procrastinate; attention wanders. Peripheral factors subconsciously influence perceptions and decisions. These behavioural tendencies influence real-world outcomes". For them, behavioural programs that directly interact with consumers that go beyond pricing has proven to reduce consumption.

The New Zealand Energy Efficiency and Conservation Act encourages participants to promote conservation. Looking at the existing communication model between retailers and consumers, we can consider that information is unidirectional, from the retailers to the consumers. New Zealand electricity retailers broadcast energy information like pricing, generation mix and usage through mobile and web applications. Consumers who choose to receive the energy information can either ignore or act on the information. Still, there is no facility for consumers to provide instant feedback on the information provided. The only way consumers can provide feedback is by coursing messages through the retailer's customer service channels. This presents a gap for how energy information is 
communicated from retailers to consumers. This also provides opportunities for evaluating if other methods of providing energy information would eventuate to proenvironmental behaviour change. As existing formats provided by retailers to consumers span from paper based (monthly power bills) to digital formats (email, mobile or web applications).

In view of energy information being provided using different platforms and formats, this affords opportunity to explore other methods of visualizing energy information. Following on the premise that visual images, like other forms of data can help affect behavioural changes. This concept of visual persuasion is supported by research from Duke University whereby 341 university students performed what they believe was a visual acuity test, unknowingly being exposed to both Apple and IBM logos, and asked to list different uses of a brick, besides wall building. The students exposed to the Apple logo provided far more creative uses of the brick compared to those exposed with the IBM logo. A second experiment was done comparing Disney and E! Channel logos and the results showed participants who were exposed to the Disney logo behaved more honestly compared to those exposed to the E! Channel logo (Fitzsimmons, et.al, 2008).

Another study that supports the idea of representing complex concepts through visual information is the study done by Jeong, Wang and Lee (2012) wherein they collected images associated with complex concepts from the Web. They treated complex concepts as having both an adjective and noun, similar to attributes associated with images. Through image and word clustering, they could measure the visualness of certain concept and develop a matrix of images and words, which they called a synonym set. Quite similar, but smaller in comparison to the ImageNet project (http://www.image-net.org), an image dataset organized according to the Princeton WordNet hierarchy. This emphasizes that complex concepts can be communicated with the aid of a lexicon of images. This lends to exploring how visual communication can influence behavioural changes. Still, various studies point out that visual communication alone is insufficient to stimulate proenvironmental behaviour. We need to evaluate how visual communication can be effective if given the right messages, medium, timing and audience.

There are other concepts that are being reframed to provide a new view on how to design environmental visual messages. As discussed, 'Captology' is the field of study on persuasion using computers. It gives us a view on how computers can influence our behaviour. One example is how addicted we are with social media sites like Facebook. According to one such study Facebook has the 3 elements of an effective persuasion tool --- 1) connectivity, we subscribe to news feeds from people we know, even our extended network. 2) Easy access to information e.g. new feeds and status updates. 3) Ability to respond, when we hit like or post comments we fulfil our desire to interact and give our opinions (Fogg, 1998). So, with the crux of all 3 elements we know Facebook is highly effective in getting people's attention. We can also note that a lot of companies invest in social media to reach new customers and retain them as well. With the functional triad of tools, media, and social actors, 'Captology' appropriately fit as a framework to test visual elements that might help promote pro-environmental behaviour (Sears and Jacko, 2007, p.137). 


\subsection{Eco-Visualization and Eco-Feedback}

There are several studies that define Eco-Visualization and Eco-Feedback, all publications reviewed have cited two foremost studies on the topics. For Eco-Visualisation the term was first introduced by Tiffany Holmes (2007) in her study "Eco-Visualization: Combining Art and Technology to Reduce Energy Consumption", she emphasizes that media arts and interdisciplinary studies can promote sustainable design of the 21st century by merging art, technology, and environmental stewardship. For her displaying electricity consumption in real time has the potential to not only reveal usage patterns and provide a visual reminder to conserve.

Other relevant studies define Eco-Visualization (EVs) as "any kind of interactive device targeted at revealing energy use in order to promote more sustainable behaviours or foster positive attitudes towards sustainable practices." and "Eco-Visualization offers a new approach to visualize real time consumption with the goal of promoting ecological literacy. Eco-Visualization provides new strategies for energy conservation that combines both artistic and scientific information to produce new forms of real time data representation" (Pierce, Odom and Blevis, 2008).

Olsen (2014) argued that Eco-Visualisation is the method of using visual cues to promote environmental awareness. She pointed out that according to Edward Tufte "the most effective way to describe, explore and summarize large sets of numbers is to actually look at pictures of those numbers. By utilizing visual representations of abstract data, one can enable the remarkable human perceptual abilities that are greatly underutilized in most current interface design". Further indicating that visualization and sustainability is the interdisciplinary topic of Eco-Visualization. Originating from environmental art in the 1960s, Eco-Visualization combines art and information visualization to confer visibility to usually invisible environmental data through visual dynamic feedback.

On a related note, Eco-Feedback is based on the hypothesis "that most people lack awareness and understanding about how their everyday behaviours such as driving to work or showering affect the environment; technology may bridge this "environmental literacy gap" by automatically sensing these activities and info feeding related information back through computerized means. Eco-Feedback can be considered as the merging of Human Computer Interaction with Environmental Psychology. With the aid of ubiquitous computing, Eco-Feedback is aimed at persuading people to reduce or alter energy consumption behaviours. This can also be viewed as an extension of research in persuasive technology, and that there are two behavioural models when looking into EcoFeedback designs. First is the Norm-activation model which is based on the premise that moral or personal norms are direct determinants of pro-social behaviour. And the Rational-Economic model which assumes that people act to maximize rewards and minimize costs. With respect to the environment, this model is often simplified to suggest that people will adopt environmentally responsible behaviours that are economically advantageous. (Froehlich, Findlater and Landay, 2010).

Olsen also attributed the study done by Petkov (2008) which argued that applications promoting sustainable behaviour should contain more than one kind of feedback to motivate users and that "visualization of real time energy consumption alone may not be sufficient to inspire change". Many complex factors influence the individual's desire and 
ability to conserve resources. Conservation behaviour can therefore be connected to perceptions of nature, economies of resource availability, and individual environmental ethics. She also recognizes Holmes argument that "there are no easy solutions for designing applications that may promote conservation behaviour". She did recognize the study done by Pallak and Cummings (1976) which showed that public recognition of conservation resulted in decreased consumption.

To better understand how Eco-Visualization works, below is an excerpt for Holme's publication "Concrete consequences-figures such as number of trees to offset $\mathrm{CO} 2$ emissions are more meaningful when they are large, aggregate figures (e.g. per building, campus). However, even if they provoke reflection, their potential to motivate action is still questionable, particularly without prescriptive suggestions for actions or social motivation. Abstract quantities (e.g. KWh, pounds of CO2) are more meaningful when presented on a per person basis, where they appeared to make people feel like their actions are having an impact. With large numbers, people felt hopeless to effect change. Numbers and statistics are generally not motivating- narratives or data-driven photographic visualizations may be more meaningful. Relevant Instructive Informationeven if people are surprised by their consumption impact, they are unlikely to take actions if they do not know what to do; offering people the ability to calculate estimated savings from a variety of energy-saving behaviour suggestions could provide more engaging alternatives" (Odom, Pierce and Roedl, 2008).

While the field of Eco-Visualization is becoming increasingly diverse, at present the dominant approach to designing EVs is to create consumption monitors that clearly present consumption patterns. Past studies have indicated that this approach can lead to decreased consumption, it is considered that instant feedback from IHDs, may lead to more engaging experiences and further reduce consumption.

At times it can also be difficult to distinguish between Eco-Visualisation and Eco-Feedback when trying to promote pro-environmental behaviour. It is necessary to clarify that EcoFeedback is used to increase awareness by automatically sensing peoples' activities and feeding related information back through computerized means (Darby, 2006). While, EcoVisualizations reveals hidden environmental information and behaviour patterns, and create more readily comprehensible and accessible information for a population or target group, with the goal of promoting sustainable behaviours or fostering positive attitudes towards sustainable practices. From a designer's point of view, and tying both ideas into this research, we can evaluate Eco-Feedback as a method for providing electricity consumption data through an alternative channel, and with the aid of digital design, interpret the data as a form of Eco-Visualisation to promote pro-environmental behaviour.

\subsection{Emoji}

In the process of identifying other methods for promoting pro-environmental behaviour, background research showed various Eco-Feedback and Eco-Visualization projects having varying degrees of success. The primary investigator, did not want replicate existing studies. The decision was to try, to the best of his knowledge, something that has not been done. Borrowing elements from previous studies, like using social media platforms and ubiquitous computing, the primary investigator looked at computer 
mediated communication particularly mobile computing due to the fact that globally there are now 4.7 billion unique mobile users and this is forecasted to grow to 5.6 billion by 2020. And in the realm of social development, delivering digital inclusion to the still unconnected population mobile internet penetration has reached $44 \%$ as of 2015 , seen to grow to $60 \%$ by 2020 (GSMA Mobile Economy, 2018).

Based on the growth rate, we can deduce mobile communication would be an effective channel for reaching a wider audience. Still, one foreseeable limitation in communication, including mobile as well, is the language barrier. A lot of global companies invest resources to internationalize and localize products and services. This points out a need to find a language that can transcend language barriers.

When thinking of languages that spans cultures and has the widest level of adaption, we cannot ignore the fact that a predominant visual language that has exploded in usage are Emoji. One study pointed out that in 2 years, out of 10 billion tweets around 4 billion have Emoji (Novak, Smailović, Sluban and Mozetič, 2015).

In October 2016, with the original 176 emoji added to the Museum of Modern Art (MoMA) collection, Paul Galloway (2016) of MoMA stated that "The transition from desktop to mobile platforms necessitated a further rethinking of the customs long associated with written correspondence. This was especially true in Japan, where the cultural necessity of exacting salutations and complex honorifics made early devices' impractical for widespread adoption. Emoji were an ingenious shortcut around this and other problems ".

To differentiate Emoticons with Emoji, we can describe Emoticons as "A representation of a facial expression such as a smile or frown formed by various combinations of keyboard characters and used in electronic communications to convey the writer's feelings or intended tone". While Emoji can be seen as a further development of emoticons, sequences of text symbols meant to represent a face expression for example ":-)" and ":-(“. Looked at sideways the combinations of characters become a happy face and a sad face. The birthplace of the emoticon can be traced back to Carnegie Mellon University, where in the 1980's their Computer Science department needed a way to explicitly mark certain posts as not to be taken seriously on their online bulletin boards. Recent studies have shown that the usage of emoji are growing and are not only complementing emoticons but instead replacing them on social media. A recent study shows that during the period of February 2014 to August 2015 almost 14\% of all public messages on Twitter contained at least one emoji, whereas emoticons were found in roughly $2 \%$ of the messages.

In contrast to emoticons, emoji are actual pictures and have the ability to convey a wider range of emotions due to their nature. In addition to expressing facial expressions similar to emoticons such as :-:), a much wider range of concepts and ideas can be visualized such as weather, food and events. For example, the rugby ball emoji ( $(O)$ can be inserted to indicate that the text is about rugby (Hallsmar and Palm, 2016).

Even with its wide acceptance, due to the increasing number of emoji, the level of ambiguity, created by cultural differences and cross-device implementation, the problem of misinterpretation comes up. The emotional value conveyed through emoji can also be misinterpreted. What Azuma and Ebner proposed was to develop a "Visual Matrix" or a dictionary of Emoji to prevent misinterpretation (Azuma and Ebner, 2008). This can be viewed as converse to what is advocated by the Unicode consortium, but it is in fact 
appendant to it. Where the Unicode consortium prescribes how devices are to implement and represent these messages, a visual dictionary will then facilitate how people are meant to interpret these visual messages. In the context of this study, a visual dictionary or set of Emoji will have to be defined to represent low or high of energy use.

We also need to understand, that communication as we know it has evolved significantly. From the research done by Gretchen McCulloch, a distinguished Internet Linguist, she states that Emoji are part of the fourth quadrant of communication which is "Informal Written Communication". For her Emoji are necessary in Computer Mediated Communication (CMC) to humanize how we communicate. Another linguistic study points out that Emoji can be considered as non-verbal codes in CMC, somewhat similar to our bodily actions when we conduct face-to-face "Spoken Formal or Informal Communication" (Kelly, 2015).

When viewing Emoji as a visual language, we do need to consider other forms for visual communication to provide a holistic view of how it can be used to promote proenvironmental behaviour. To date and in the best of the primary investigator's knowledge, there are no emoji that have been popularly used to represent concepts like energy use and climate change. And in the field of visual communication "When considering a visual communication activity, it is therefore crucially important to consider the characteristics of a target audience and their likely range of interpretations. A person's response to an image is not simply rational, but has an emotional component that raises ethical and practical issues (Myers, 1994). Daniel and Meitner (2001) remind us of the power of visualisations to alter people's interpretations of complex concepts and to arouse positive and negative emotions" (Nicholson, 2005, P. 260). With emotional investment, similar to advertising, people would be more inclined to adopt proenvironmental behaviour.

The next section provides us a view of how Emoji can be classified according to the sentiments they evoke.

\subsection{Classification}

When looking into languages, be it written or spoken, we also have to look into sentiment analysis or opinion mining. According to Hallsmar and Palm it "is the task of determining the underlying attitude of a writer or speaker. Sentiment analysis is a subfield of Natural Language Processing (NLP) which deals with the task of processing natural languages. Natural languages are languages that people speak, such as Swedish or English, and evolve naturally by invention of new words or slang. These languages contain ambiguity and other complications such as irony or sarcasm, as opposed to formal languages such as programming languages". Along with sentiment analysis we also need to interpret valence of what is being communicated. Valence refers to the intrinsic attractiveness (positive valence) or aversiveness (negative valence) of an event, object, or situation.

With the different emotions that can be conveyed through emoji, and with a total of 1,851 emoji characters supported on current platforms, it can only mean that messages can easily be misinterpreted, which is quite similar to occurrences in natural language. Without non-verbal cues, like hand gestures, sometimes messages can get lost. From the research of Carley Durante (2016) "nonverbal cues are used deliberately to communicate and are "part and parcel" of the total message (Burgoon, et al., 1996, p. 152). With nonverbal cues dominating Face to Face interactions (researchers estimate about 80 
percent of communication is nonverbal) the likelihood of nonverbal coding elements also appearing in digital communication mediums is plausible (Alban, 2015)."

At this point we are not focusing on non-verbal communication, this will be discussed in the next section. What we are focusing on is how we can classify emoji for the purposes of this study. As mentioned earlier, valence of emotions needs to be considered when studying languages. And with 1851 possible emoji we cannot simply classify emoji as positive or negative. What Hallsmar and Palm recommends is to use a Multi-class sentiment classification, which takes in "Paul Ekman's original theory about universal emotion categories suggests that human emotions can be categorized as one out of six different classes; anger, disgust, fearful, happy, sad and surprise."

Looking at the work done by Instagram research, they were able to establish a semantic map and clustered emoji with related emotions in their study. Specific emoji were found to be representative enough of particular sentiments. The subset of Paul Ekman's original emotion categories shown in Figure 2.5 were selected in the Hallsmar and Palm study.

Figure 2.4.5 Paul Ekman's Emotional Categories

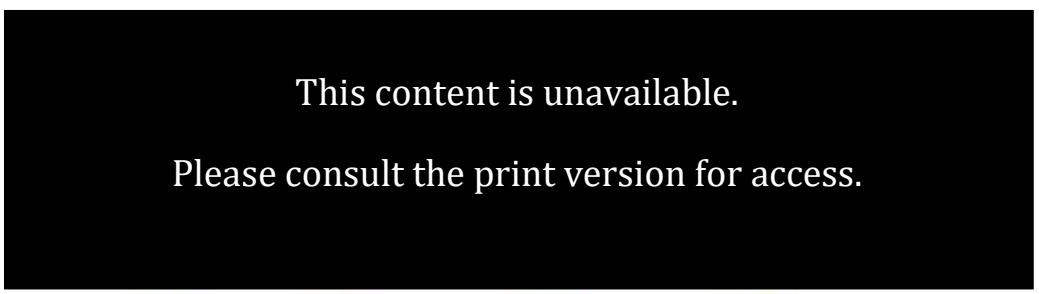

Source: Hallsmar and Palm's “Multi-class Sentiment Classification on Twitter using an Emoji Training Heuristic".

To provide structure on how sentiments can be drawn from Emoji used, it is imperative to establish the lexicon of Emoji to represent sentiment classification. With classification, it would be easier to measure opinions expressed towards an idea, object or situation. In the context of this study, it is necessary to follow a similar classification method which is the Naïve Bayes Classifier, but considering as well emotions resulting from Eco-Feedback and Eco-Visualization. Conversely, environmental information, could also be classified if attributes can be defined for the messages, both text and visual. And in reference to the Emoji research done by Instagram, the application of a specific classification method has allowed for clustering of emoji. With clustering, defining or labelling clusters would be simpler rather than doing the same for each emoji.

Emoji classification proved to be effective as well in measuring public sentiment during the recent US presidential elections. The study done by Stanford University established that by using emoji as an oracle, we can classify the sentiment of the tweet. It was still necessary to expand on measuring positive or negative sentiment towards a candidate and classifying tweets into five emotions namely happy, sad, fear, laughter, and angry. Again, multi-class sentiment analysis was applied. Still, even with sentiments geo mapped, it was not able predict the outcome of the 2016 US presidential elections (Chin, D., Zappone, A., \& Zhao, J., 2016).

Looking into classification of energy use, the primary investigator was able to retrieve simplified energy use classification practiced in the UK. An average 'low user' is defined 
in terms of energy use, as using 2,000 kWhs of electricity a year and 8,000 kWhs of gas a year. While an average 'medium user' is defined in terms of energy use, as using 3,100 kWhs of electricity a year and $12,500 \mathrm{kWh}$ of gas a year. And an average 'high user' is defined in terms of energy use, as using 4,600 kWhs of electricity a year and $18,000 \mathrm{kWhs}$ of gas a year. (USwitch, n.d.). The only comparable study here in New Zealand is the HEEP project.

The study done by Beckel, Sadamori and Santini (2012) showed that by using electricity consumption data, there exists a set of household properties that are likely to be inferable. Properties like the size of a household and the income of its occupants. In the energy market, factors like demand response and dynamic pricing based on peak usages, help retailers retain customers and attract new ones.

\subsection{Facial Scale}

SwiftKey, the company that helped Apple develop the Emoji keyboard conducted a study on 1 billion emoji in 16 languages and found out that around 58\% of emoji used are faces emoji (Swiftkey, 2016). And according to Iconfactory's Gedeon Maheux one of the designer responsible for the Twitter Emoji, people prefer faces emoji as they add the human touch to computer mediated communication (refer to Appendix A for Gedeon's response). Emotions are best expressed through facial expressions. Even the field of speech therapy, children with autism are unable to read facial expressions, and by asking children to match emoji with real faces having the same expressions, speech therapist Raj (2014) was able to break through some of their communication barrier. Abramsky

(2015) noted a Swedish organization developed battered-looking emoji to help women and children who had been abused to indicate the nature of the abuse (Harris, 2016).

Engineer Rana el Kaliouby (Adler, n.d.) states that for "Affective Computing", facial expressions communicate emotional information best. He argued that in the relation to big data, this is the next frontier. With the limitations of CMC, facial Emoji have become the top choice for expressing emotions.

Even in the fields of social research, Tchokni, Séaghdha and Quercia (2014) investigated the use of emoji and emoticons in business. The authors looked at picture word usage in online social networks to explore the use of language and evidence of social power. They found that people who use emoji and emoticons in their personal and professional lives tend to be more popular and influential than others. According to them, emoji and emoticon use is powerful predictor of social status on both Twitter and Facebook despite being a rather simplistic way of conveying emotion (Tchokni et al., 2014, p. 493).

Harris (2016) further noted that another emoji-like therapeutic tool like, is the WongBaker Faces Pain Scale. It has been used in medical settings to assess pain in children and others who are unable to communicate verbally or cognitively. Figure 2.6 presents the Wong Baker Faces Pain Scale. 


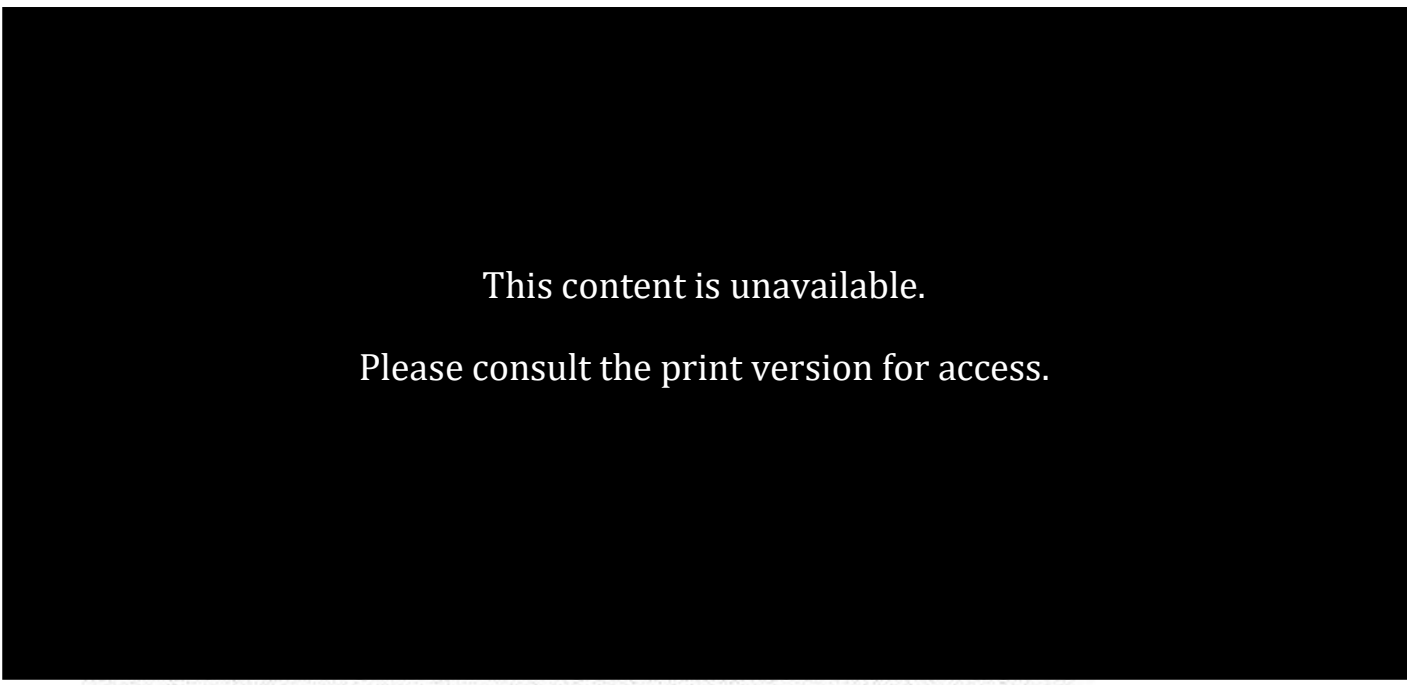

Source: Wong-Baker FACES® Foundation, 1983

One study in particular established that for older children in an emergency room department a Visual Analogue Scale (VAS) has a uniformly increasing relationship with the Wong-Baker FACES Pain Rating Scale (Garra, et. al., 1999). VAS is a measurement instrument that tries to measure a characteristic or attitude that is believed to range across a continuum of values and cannot easily be measured. For example, the amount of pain that a patient feels ranges across a continuum from none to extreme. VAS is usually a horizontal line, $100 \mathrm{~mm}$ in length, anchored by word descriptors at each end. Refer to Figure 2.7 below. The patient marks a point on the line that they feel represents their perceived degree of pain. The VAS score is determined by measuring in millimetres from the left end of the line to the point that the patient marks.

Figure 2.7 Visual Analogue Scale

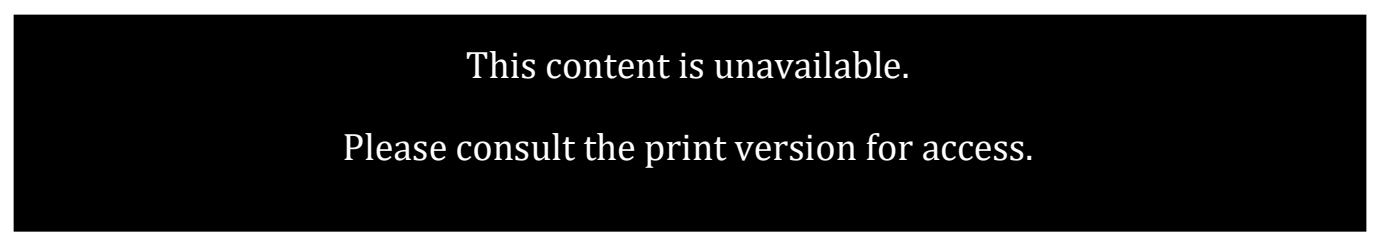

Source: Journal of Clinical Nursing, 2001, p. 706

It is important to note that the VAS and Wong Baker Scale (WBS) are two different scales of measurement (continuous and ordinal), but the study conducted by Garra, et. al. in 2009 , found out there is a uniformly increasing relation between VAS and WBS.

Another interesting study on emoji done by Ljubešić, and Fišer (2016, p. 89), provided that by performing a correlation analysis between emoji distributions across countries and some World Development Indicators show that emoji with the strongest correlation clearly describe that emoji usage is indicative of the living conditions in different parts of the world. Pointing out that by "country clustering results differentiate between the "first world" cluster the most distinctive features of which are rather emotionally empty, the "second world" cluster which is specific for highly positive emotions, the "third world" cluster which contains both positive and negative emotions, and the "fourth world" 
cluster which is predominantly negative with additional, rather basic concepts like fire, dance, music and hand gestures".

Still, visual communication needs to have context so interpretation can be closer to the actual message. It is with this premise that perhaps an ordinal scale composed of emoji, or a set of emoji, can be used to gauge and represent electricity usage data. The effectivity of the WBS in gauging pain further supports the idea that abstract concepts can indeed be measured using visual elements. With the idea that measurements are but subjects we try to communicate, and we treat emoji as a language, in theory it should apply. We also have to understand that the way we communicate is continuously evolving. And as Tchokni, et. al, pointed out "18- to 25-year olds find it easier to put their feelings across using emojis rather than words" (Tchokni et al., 2014, p. 493).

A visual scale was initially thought to be an effective way for measuring and comparing household energy consumption. The intention was to set upper and lower limits in relation to the New Zealand average household consumption. At the time of developing the design prototype the only available data was for the first quarter of 2016, and intended data gathering period was in the third quarter of 2017. Comparing average consumption between summer and winter proved infeasible. Given this limitation, a different method of measurement and comparison was undertaken which is further explained in Chapter 3.

\subsection{Non-verbal Communication}

In the SwiftKey (2016) research on Emoji, it is taken that these pictographs can now be considered part of the spectrum of informal language. And in the field of Internet Linguistics (Crystal, 2005), it is viewed as "informal written language". Somewhat similar to words that have originated from the Internet and have pervaded the English language like "cyber bullying" and "social networking". And looking at Oxford dictionary's 2015 word of the year which is ("happy face with tears of joy"), emoji have equally pervaded the English language. Referencing as well the work done by Instagram's Emojineering whereby they established that emoji have now replaced Internet slang on Instagram (Dimson, 2015). It is only appropriate that we consider emoji as a visual language.

Even with the wide and varied acceptance of emoji in Computer Mediated Communication (CMC), it is important to remember that the research pointed by Kelly and McCulloch describing emoji as non-verbal codes used in CMC. In face-to-face communication, non-verbal codes are facial expressions, body language, gesture, etc. Durante (2016) probed CMC and looked into non-verbal codes in Mobile-Mediated Communication (MMC). Durante also specified that emoji exploded because Apple (and eventually Android) developed the Emoji keyboard. Non-verbal codes were classified by Burgoon, et. al. (Burgoon, Buller \& Woodall, 1996) by functions. Defined as: kinesics (body movement, facial activity, and gaze); vocalics (vocal activity); physical appearance; haptics (touch); proxemics (space or distance); chronemics (time); and artifacts (objects). For Durante, emoji are "digital nonverbal" or kinesic code, the digital

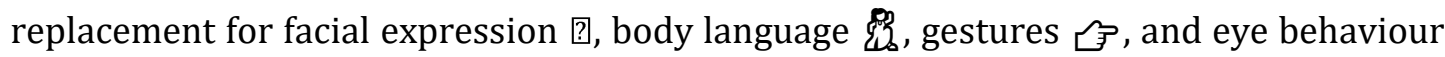
(20) in MMC (Durante, 2016, p.14).

Durante (2016) mentioned that when analysing CMC we also need to look into the "Social Presence Theory". This is the idea that a medium's social effects are caused by the degree 
of social presence which it gives to its users. Social presence means a communicator's sense of awareness of an interaction partner. This is important for the process by which man comes to know and think about other persons, their characteristics, qualities and inner states (Short et al., 1976). Thus increased social presence leads to a better communication. Along with the advancements in asynchronous digital communications, such as instant messaging, immediate response with emoji allows personalization in mediated communications. Tuten and Solomon (2015) note, "the immediate nature of the written word is perceived more like a spoken conversation...for this reason, if you communicate with a friend via AIM or Facebook chat, you may feel that you actually 'talked' to her" (p. 113).

When communicating face-to-face or through mediated means, there are certain norms and rules that we adhere to. Take for example sending instant messages in all caps is considered as shouting. Or like sending a message containing emoji like as a threat of violence if sent randomly. It is of interest as well that the pistol ( (욜) emoji has been replaced by Apple with a water pistol (Love, 2015) and Apple also opposed the introduction of a rifle emoji (Hern, 2016). Furthermore Burgoon, et al. (1996) note the presence of display rules demonstrates evidence that there are rules managing nonverbal behaviours, "each culture can easily articulate what behaviours are considered appropriate or inappropriate for use in various contexts" (p. 154). The idea that culture influences nonverbal behaviours in Face-to-Face communication, suggests the same can be true for nonverbal behaviours within MMC.

Durante (2016) further mentions that "nonverbal cues have no single meaning, which is often cited as evidence against nonverbal behaviours forming language. Yet this is no different from the property of polysemy in verbal language...one must rely on context and culture to decide which interpretation to select. Many nonverbal behaviours depend on simultaneously occurring verbal and nonverbal information for their interpretation (p.153). Closer inspection confirms communicators follow rules both in the construction of nonverbal expressions and in the interpretation. The best evidence of this is one's ability to recognize "ungrammatical" expressions, or unorthodox combinations of signals (Burgoon, et al., 1996)".

Citing culture and context being crucial in interpreting emoji correctly, the SwiftKey study also provides us a view of occurrences of popular emoji by country. This provides us a picture of how emoji can represent culture. For example, the most popular emoji in Hawaii are surf, coconut trees and the beach. While in France we have a lot of emoji coming out with reference to love, wine and hearts.

In contrast, Neil Cohn (2015), like Gretchen McCulloch, do not think emoji will replace the English language. Neil Cohn believes that with natural language we have building blocks (letters) to create the units (words), and not by searching through a collection of whole words like we do when using emoji (Cohn, 2015).

Still, the research done by Jeong, et. al., (2012) and that of Azuma and Ebner (2008) both propose that a visual dictionary will help to prevent misinterpretation when communicating using emoji. With the help of contextualization and transliteration, emoji have effectively helped enrich CMC.

Mark Davis, the president and co-founder of Unicode, believes that Emoji are best used as an "adjunct" to text-helping to make up for the lack of gestures, facial expressions 
and intonation found in speech. For him "Emojis are strongest in social media: in quick, short messages where they connect with the reader and add flavour, colour and emotion" (Stern, 2015).

\subsection{Visual Communication}

Research in social psychology has shown the effects that stem from the "priming" or situational activation of mental constructs, like environmental cues, even subtly presented, can have powerful effects on behaviour (Bargh, Chen, and Burrows 1996; Bargh et al. 2001). The experiments done by Fitzsimons, et. al., (2008) was able to determine that social priming can influence behavioural changes. It was proven that by exposing individuals with subliminal branding information, specifically Apple and IBM logos, those exposed to the Apple logo were more creative in identifying uses of a brick compared to the latter. Quite a similar case as well with Disney and E! Channel logos, participants exposed to the former we more honest compared to the latter while responding to a social desirability test. The results from Fitzsimons, et. al., (2008) study has proven that visual messages, in the context of branding can also affect consumer behaviour. Still, the study did not provide details on visual characteristics and if participants have been pre-conditioned through advertising.

Several researches have investigated the power of visualization, but of interest is the study done Nicholson-Cole (2005) on the visualization of climate change. With an abstract concept, the study noted that "People's prior perceptions, experiences, attitudes, social background, cultural orientation and behavioural dispositions influence the reactions they will have to images of climate change, the messages they take away and whether they act on the basis of the visual communication they have received" (e.g. Myers, 1994). The same idea presented by Durante (2016) citing that culture and context is essential in interpreting emoji correctly.

The primary investigator was initially looking into specific visual characteristics of popular emoji in an attempt to identify positive or negative characteristics that could help encourage pro-environmental behaviour. Finding such characteristics could help establish design patterns. But as Nicholson-Cole (2005) cited the study done by Healey and Enns (2002) "heterogeneous nature of the audiences ensure heterogeneous interpretations. Hence, we can never depend on one image appealing to everyone in the same way, let alone presume that a particular message will be delivered. When considering a visual communication activity, it is therefore crucially important to consider the characteristics of a target audience and their likely range of interpretations".

Some insight was also given on the emotive value of visualization, "The symbolism contained in a visual image can arouse emotional feelings when we look at a picture, and to some extent these elements help to bring about a meaningful experience or interpretation (Boholm, 1998; Oring, 1999). Presenting emotive imagery is therefore one way in which to attract people's attention and may motivate people to act. However, because images can trigger powerful emotional responses, we must also be careful to avoid conveying disturbing or misleading visions, or feelings of fear or unease if the point is to provide a meaningful and motivating message. This is particularly important when visual communication is being used to stimulate engagement because of the fine balance involved in using visual communication to provide an engaging message. It needs to be managed carefully because responses to emotional visual appeals can simply end up 
triggering defensive psychological responses, leaving the audience desensitised with a sense of 'issue fatigue' or leading to feelings of powerlessness to do anything to reduce the causes of climate change."(Nicholson-Cole, 2005, P. 260).

There are key characteristics of visualization according Nicholson-Cole (2005) that the research on climate change established "that people's perceptions and attitudes toward climate change are related to their visual imagery about the issue; strongly influenced by input from various visual media as well as personal experience. The results suggest that visualisations of climate change designed to engage people with the issue must have various characteristics in order to make them attention grabbing, memorable and likely to trigger some motivation to make behavioural changes: 1 . Easy to relate to and personally applicable both spatially (i.e. locally recognisable) and temporally (i.e. within a perceivable length of time, not too far in the future so as to be unrealistic), possibly involving a high level of realism. 2 . As scientifically certain as possible, representing the most sound projections from a source trusted by the target audience. 3. Instructive with a clear message in order to send the message that climate change is an important issue, and that individuals can make a difference (by doing certain things). These must come across as being easy to do, positive and feasible given other life commitments. 4 . Attention grabbing so that people notice the image and think about it."

Similar characteristics used for effectively visualizing climate change messages to motivate behavioural changes has the same applicability to other abstract concepts like electricity usage. The same model of effective communication applies--- when a simple and clear messages is sent, using the right language, through an effective channel is highly likely to be received well. Key element is that messages are directed to the appropriate audience.

\subsection{Conversation User Interface}

In NextIT's United States patent ID no. US9223537B2 documentation, Conversation User Interface (CUI) is defined as "A conversation user interface enables users to better understand their interactions with computing devices, particularly when speech input is involved. The conversation user interface conveys a visual representation of a conversation between the computing device, or virtual assistant thereon, and a user. The conversation user interface presents a series of dialog representations that show input from a user (verbal or otherwise) and responses from the device or virtual assistant. Associated with one or more of the dialog representations are one or more graphical elements to convey assumptions made to interpret the user input and derive an associated response. The conversation user interface enables the user to see the assumptions upon which the response was based, and to optionally change the assumption(s). Upon change of an assumption, the conversation GUI is refreshed to present a modified dialog representation of a new response derived from the altered set of assumptions" (Brown, et. al., 2015).

The patent provides a sufficient description of a CUI. The main idea presented is that a CUI will be a Graphical Conversation User Interface wherein a Virtual Assistant will accept inputs for a user (typed, audio or voice), and with the help of Natural Language Processing system, respond to the inputted query or instruction. Focusing on having a graphical interface has somewhat limited the CUI definition. Considering that ubiquitous computing has given us "Smart Speakers" like Amazon Echo and Google Home, this has taken out the necessity of a graphical interface as inputs are primarily voice driven. 
As a patent, it seems to disagree with some established studies in the field of Human Computer Interaction (HCI). Research in $\mathrm{HCI}$ have qualified that basic human inputs and resulting machine outputs, given a set instruction, can already be considered a conversation. HCI originally focused on computer programming, requiring strict syntax, but since then has spread to other areas (Myers and Ko, 2009).

Computer use has gained wide acceptance primarily due to the advances in the Graphical User Interface. With visual cues, it helped ease the way we interacted with computers. According to Ron Kaplan “It wasn't just cost and Moore's law. The graphical user interface - now known as the GUI ("gooey") — is what really made computing widespread, personal and ubiquitous. Its friendly icons and point-and-clickability made computers approachable, enabling ordinary people to do extraordinary things on devices previously only available to military and high-powered experts. But the GUI, though it's served us well for a long time, is beginning to fray around the edges. We're now grappling with an unintended side effect of ubiquitous computing: a surge in complexity that overwhelms the graphical-only interface. It can take as many as 18 clicks on 10 different screens to make one simple airline reservation while we're faced with an unwieldy array of buttons, ads, drop-downs, text boxes, hierarchical menus and more... What we need now is to be able to simply talk with our devices. That's why I believe it's finally time for the conversational user interface, or CUI" (Kaplan, 2013).

In the same context, due to mobile computing and the proliferation of mobile applications, people spend more time using mobile devices rather than traditional desktop computers. Still with mobile applications, users have to contend with increasing amount of information often being compressed within limited real estate available on mobile devices. More often than not, the interface design is sacrificed in lieu of application usability and functionality.

CUI can also be defined as any User Interface (UI) that mimics conversing with a real human. The idea is that instead of communicating with a machine (with the help of a Natural Language System) through manipulation of graphical elements or by entering specific commands, we interact with computers through natural language. Currently, there are two basic types of CUI - voice assistants, where voice is the medium, and there are chat bots, where interaction is inputted by typing (Brownlee, 2016).

With ubiquitous computing aided by advances in Natural Language Processing, Artificial Intelligence and Machine Learning --- $\mathrm{HCI}$ is now leaning towards conversation triggered interactions. Again, these conversations can either be voice or text based.

Technological advances can pose conflicting views on the nature and characteristics of CUI. As NextIT's patent focuses on virtual assistants for an existing web or mobile application. A lot of interest have moved to native mobile messaging applications, a specific case is even with the Bank of America already providing virtual assistance through online banking, they are now also offering banking services through Facebook Messenger (Barba, 2016). In this regard, it would be limiting to constrain the definition of CUI as an appendant to an existing web or mobile application. As mentioned, another possible contradiction is the arrival of "Smart Speakers" like the "Amazon Echo" and "Google Home", these are cloud connected devices that can work as virtual assistants to help send communications, retrieve news and weather information, prepare grocery lists and a whole lot more, interacting with users primarily through voice commands. 
As an emerging technology, "Smart Speakers" have the potential to gain significant consumer adoption. This provides a good opportunity for evaluating voice triggered CUI. Still, these devices are not officially available in New Zealand as of this writing. The only platform that could enable CUI are mobile instant messaging applications like Facebook Messenger, Slack, WhatsApp, etc.

At present mobile messaging applications are taking over the world with high mobile application store rankings, incredible retention and engagement rates. Every community, marketplace, on-demand service, dating applications, social game or ecommerce product has or will soon have messaging as part of the experience to drive retention, engagement and transaction volume. There has been a lot of discussion around CUI and how the pattern of communicating with people and computers is blending in messaging or voice interaction with simple commands, and simple, mostly textual responses, occasionally paired with visual imagery (Štolfa, 2016).

When speaking about CUI we need to look into the pioneering work of Allan Turing, mathematician and father of Artificial Intelligence, he proposed in his paper the "Imitation Game" a test if a human interacts with a machine and cannot be certain if he is talking to machine or not has passed the Turing test. The first project that has passed the Turing test is a chatbot named A.L.I.C.E. also known as "Artificial Linguistic Internet Computer Entity". In essence what Turing proposed, and what A.L.I.C.E. has proven, is that Artificial Intelligence is not only viable through pattern matching but through finding algorithms that solve complex problems the fastest possible time. The same applies to Natural Language Processing, considered as an extension of Artificial Intelligence (AI) research, wherein computational techniques are used to analyse and synthesize natural language and speech.

This study does not attempt to focus on AI research, but rather evaluating existing AI services provided the likes of Microsoft's Cognitive Services, Google's API.AI (rebranded as DialogFlow) or Amazon's AWS AI, and using these services to help design and enrich a CUI. Still based on the idea of setting up a chatbot that will function as an agent to provide Eco-Feedback is the primary thrust of this study.

Essential to this study is a good understanding of how energy information will flow from the meter to the consumer. It is envisaged with the use of a virtual assistant via a mobile messaging application (e.g. Facebook Messenger), and with the proper messages, will encourage pro-environmental behaviour. Again, like any form of communication--- the right message, medium, agent, context and culture is essential for promoting desired responses. Last, like any standard CUI, feedback or responses on the Eco-Feedback can be recorded for future analysis. 


\section{Methodology}

As presented in the Chapter 2, modern day communication, mediated by computers, has evolved significantly. We now have a plethora of new terms and icons, symbols we use when we communicate online. This study attempts to determine if emoji can be used to represent data. This stems from studies done by Azuma and Ebner (2008), Kelly (2015), Sears and Jacko (2007) on how emoji have evolved into a visual language used predominantly in online communication.

The study of emoji as a visual representation of data, was pursued due to increased usage in Computer Mediated Communication (CMC). As provided in Chapter 2, section 2.3, a two year study on Twitter showed $40 \%$ of all messages contained emoji (Novak, Smailović, Sluban and Mozetič, 2015). Furthermore, the acceptance of emoji as a language is recognized as non-verbal communication in the field of Internet Linguistics (SwiftKey, 2016).

Aside from the language, this study also evaluates effectivity of Eco-Feedback, discussed in Chapter 2, section 2.2 as electricity usage information represented by emoji. With both language and message set, the communication agent had to be identified. The researcher came across several of eco-visualization and Eco-Feedback hardware and software projects, mostly as web or mobile applications. The researcher's adviser suggested using a messaging bot, which prompted the researcher to evaluate further.

Building a Facebook Messenger bot, capable of providing Eco-Feedback in the form emoji was considered. The reason for selecting a Facebook Messenger bot as an Eco-Feedback agent is due to the wide adoption of the instant messaging service in New Zealand. As of 23 March 2017, there are 2.9 million New Zealanders that have an active Facebook account or $61 \%$ of the population (Fyers and Cooke, 2017).

With Eco-Feedback provided on Facebook Messenger, it can be further evaluated if a user's consumption behaviour changes once they are made aware of how much electricity they are using, comparing current against historical usage. The selection of a Facebook Messenger bot also adheres to the application of the theory of Captology, which is the use of computers as persuasive technology (Fogg, 1998, p.89-100) to communicate energy usage information. In contrast, two design experts stated that emoji alone is insufficient in representing energy information (refer to Appendix B), the designer's view emoji only as complementary elements which help enrich online messages. One designer's feedback is shown in Figure 3.1. 


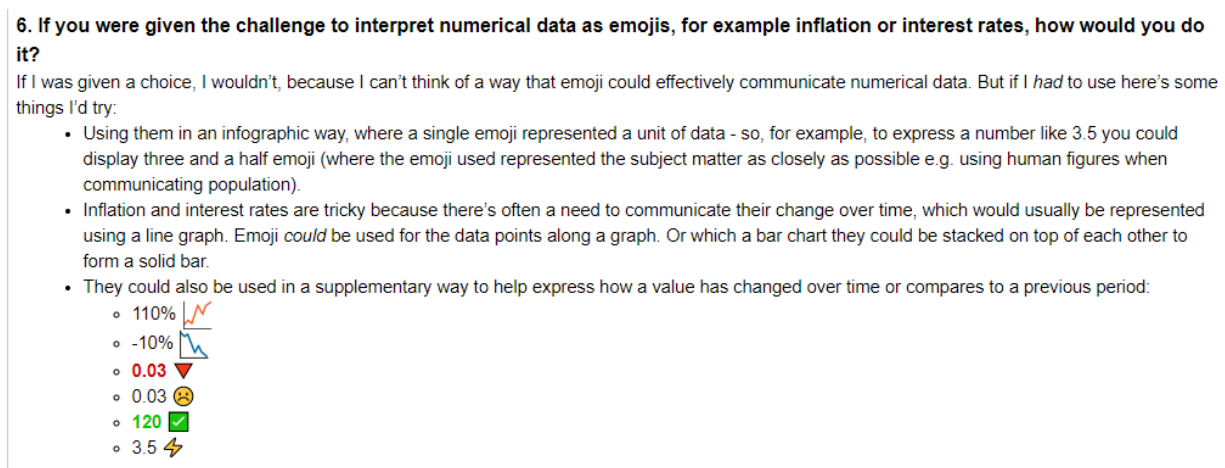

Source: Author. Designer's response to questionnaire. 2016

The researcher initially conducted literature review on the design elements of emoji. The thrust was to submit a proposal to the Unicode Consortium for a new emoji that could represent energy use. The researcher also intended to conduct a design workshop among Victoria University Wellington design students to validate if elements among popular emoji could represent the said topic.

After initial investigation, the researcher did not push through with the idea of submitting a proposal to the Unicode Consortium due to complex requirements for submissions. It was further assessed that the timeline for this research would be insufficient to submit a valid proposal. This restriction allowed for the researcher to pivot and instead use existing emoji. The same model will be applied, out of the 1851 emoji available, research participants will have to select emoji they believe best represent electricity usage.

In order to find suitable research participants, it was necessary to conduct two online surveys. The first was to identify candidates for user testing. The research required users be familiar with using emoji when communicating on social media, and environmentally aware. More importantly, were existing customers of the electricity retailer that agreed to participate in this research. As stipulated by the Electricity Authority "The Privacy Act 1993 requirements with regard to consumers rights to access data about their electricity usage was a key consideration by the Authority. The Authority considers that retailers are best placed to address and consider privacy issues because they are responsible for protecting consumer information as part of their business, and are likely to have appropriate procedures in place." (Electricity Authority, 2015).

Only with the retailer's approval and the consumer's consent can the researcher request for electricity consumption data. Refer to Appendix $C$ for survey questions and results.

After selecting research participants that fit the criteria in the first survey, the second survey was focused on detailing the living situations of the selected participants, similar to the Household Energy End-Use (HEEP) Project done by BRANZ in 2006, it is necessary to probe if participants had unusual demands for electricity due to living situations. Such as periods where the user was away, having had non-standard electrical appliances, or changes in household heating. Last, the second survey also asked the users for specific emoji they would like to use to indicate positive or negative consumption. Positive in the sense that the electricity usage, normally for the current or previous day, is lower than the usage for the other period being compared to. 
Prior to conducting user testing, the selected research participant's electricity usage will be compared to the New Zealand averages as a form of pre-testing. This will give the research participants an idea on how their energy use compares to the New Zealand average.

Given the research on emoji switched from proposing a new emoji that could represent energy use, to using existing emoji, it was considered that allowing users to select the emoji to represent positive or negative consumption, would somehow personalize their Eco-Feedback. This is seen as a method for motivating the research participants to interact more frequently with the Facebook Messenger bot.

The next section elaborates on how the Facebook Messenger bot will be designed.

\subsection{Sentiments and Emoji Representation}

The top six emoji based on the EmojiTracker as of March 2016 were presented to online survey respondents in the first survey. Of these top six emoji, four are face emoji. In comparison a study done by Instagram's engineering team recently published a study based on 50 million English Instagram comments and captions from 2015 with a visualization of how emojis appear in similar contexts. The research concluded, using a 2D semantic map, that emoji could be considered as representations of the emotions anger, fearful, happy and sad are clearly separated (Instagram, 2015). The study conducted by Instagram further supports the idea that emoji can be an effective medium for expressing emotions.

To analyse language, in both text and visual form, we also have to understand its structure. According to Kelly (2015, pp. 7-8) "Communication is based on encoding and decoding and, since Aristotle, all semiotic theories have been based on 'the code model'. 'Semiotics' is derived from the Greek word, sēmeiōtikos, which means 'observant of signs'". Kelly also noted that "Saussure developed the concept of langue (language) as a social dynamic system composed of signs, grammar, rules and codes where the sign is the basic unit and parole (speaking) - the executive linguistic act: the utterance. Saussure opined that langue and parole were closely interrelated and expressed through mutual presupposition between the signified and the signifier (K Boklund-Lagopoulou et al 2014, p.7)". The idea of mutual presupposition applies as well to semantics, which is defined as understanding the meaning of words and how they can be combined to make the meaning of a sentence or phrase. Such is the case that context, and agreed meaning of signs and words is essential to allow for proper interpretation.

Focusing on emoji, Linguist Tyler Schnoebelen (2012) found that groups fall into specific habits with certain emoticons or emoji use. Which means emoji use varies across age, gender, location and social class. For him it is essential to understand your audience for emoji use to be effective.

As highlighted in Chapter 2, emoji in CMC are the equivalent of non-verbal messages like posture and hand gestures in face to face communication. Primarily it is an expression of emotions if used in the proper context. In Kelly's (2015) study she indicated that "The sender or receiver of a message relies on the context, in combination with the requisite preknowledge, in order to understand or make the message understood. In this case, the context is dependent on either an emoticon as a symbol or a feeling as an emoji. It is thus easy to 
understand the usage of different emoticons/ emojis, depending on by whom, when and how a message should be understood."

To reiterate the research attempts to determine if an agent like a Facebook Messaging Bot can be used effectively for Eco-Feedback. Providing electricity usage information both in text and visual form of which will be emoji. This is taking into account the study done by Fitzsimons, as discussed in Chapter 2 section 2.8, that visual messages can influence consumption behaviour. With this model we can then test if the right messages, using an available channel can encourage pro-environmental behaviour.

\subsection{Consumption profiles}

Prior to conducting user testing, the electricity usage profile of the participants will be collected along with the proper approvals and consents. Not only with this be used for pre-testing, it is also viewed as a way of incentivising the user to either reduce consumption if usage is higher or maintain status quo if his usage is below the New Zealand average.

The publicly available dataset of New Zealand electricity usage is available from MBIE. Still, there is limitations as comparative data for New Zealand average is aggregated by quarter for a calendar year. Figure 3.2 shows New Zealand average household expenditure on electricity.

Figure 3.2 Average Residential Expenditure on Electricity per Household in New Zealand

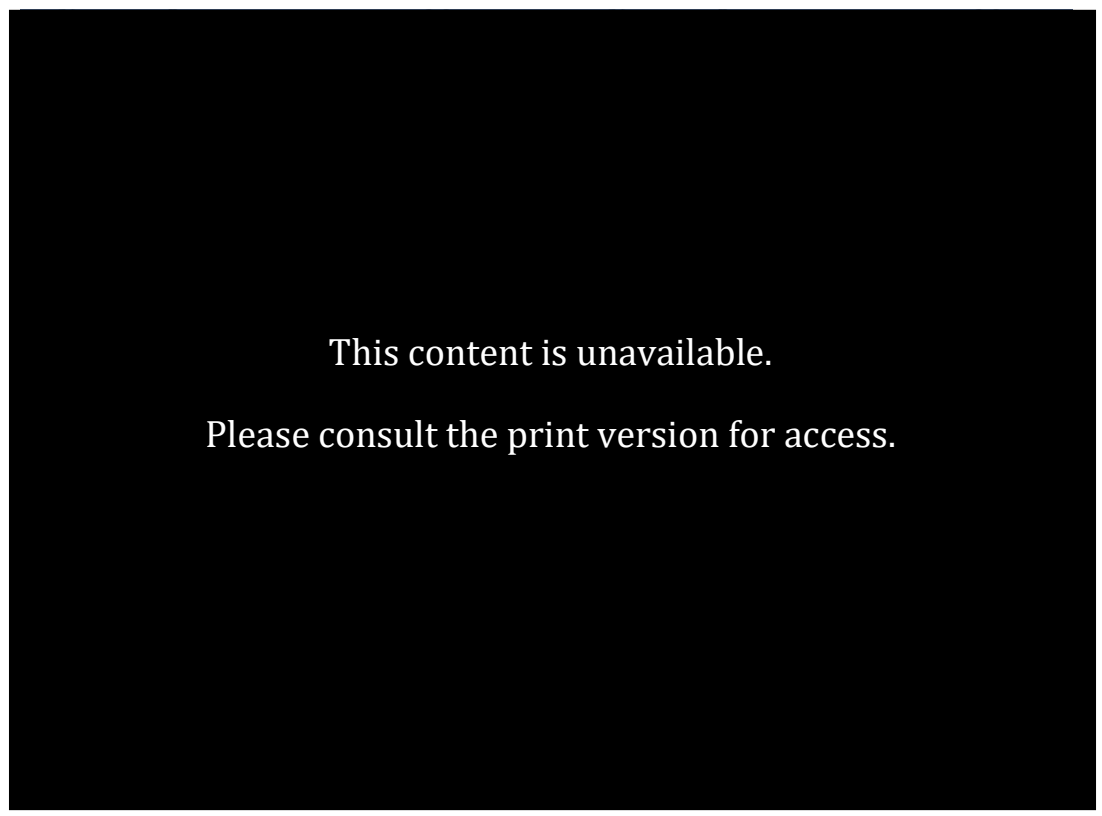

Source: https://figure.nz, 2018

Providing energy usage information while user testing is ongoing is also seen as a motivator or a reminder for the user to be conscious about his or her usage. This would appear to be duplicating what some of New Zealand's electricity retailer are doing, case in point is the mobile application developed by Flick Electric Co., Choice. Choice provides a view of the current half hourly spot market price, as well as a four hour price forecast so users can decide when it is best to use electricity. Figure 3.3 the forecasted spot market price. 


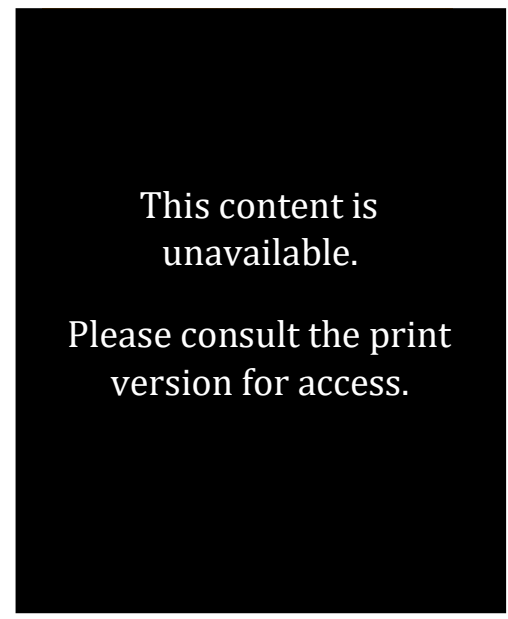

Source: Author. Flick Mobile Application Screen Capture, 2017

Choice also provides real-time carbon impact based on electricity generation sources, as shown in Figure 3.4.

Figure 3.4 Real-time Carbon Impact Screen on Choice by Flick Electric

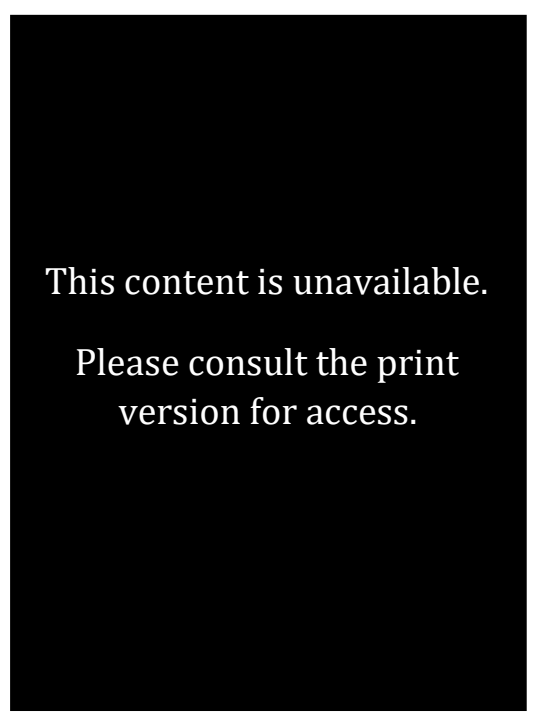

Source: Author. Flick Mobile Application Screen Capture, 2017

Even if Choice provides users with economic incentives and environmental awareness, one observed limitation is that it does not provide historical views of a user's consumption, although Choice provides historical saving of up to four months.

The Facebook Messenger bot can provide electricity usage information. It requests for meter usage data for a given day. Which can be used to compare with meter usage for a day, week, month or year ago. Making the information being presented usage focused.

It is also important to note that after user testing, meter usage data will again be extracted covering the period of user testing. The data cannot be compared to New Zealand averages, as such information is not available to date. But users can only compare consumption to the previous year. 
Although not conclusive, the comparison of electricity usage during user testing to previous year's consumption, during the same period, can be viewed as semi-structured observation due to the fact that specific dates are being compared and the only variable introduced is energy information (Martin and Hanington, 2012, p. 121). Under such conditions, it is envisaged the changes in consumption can be observed.

\subsection{Conversation User Interface Design}

It has been continuously mentioned that a Facebook Messenger bot, or simply a chatbot, will be used as an agent that will provide electricity usage data in the form of or will be enriched with an emoji, as Eco-Feedback. The researcher compared mobile and web applications provided by predominant electricity retailers in New Zealand and it was observed that a lot of retailers may provide the following information--- cost per kilowatt hour, generation sources or historical usage in graphical form, but there exists no utility yet for requesting reads for specific periods. Even the Electricity Authority stipulates that "You can request your usage information from your current power company. If you have switched your power company in the past 24 months, you will need to contact all companies you have used to get a full set of data for this time period.

To request this information contact your power company by phone, email or through their website. They must provide this information to you." (Electricity Authority, n.d.). This puts the responsibility of requesting and analysing electricity use to the end users.

New Zealand is a unique case as approximately $70 \%$ of the residential electricity consumers use smart meters (Kovacs, 2017). Hence, collecting meter data information can now be requested from the Meter Equipment Provider (MEP). With the data collection provided by the MEP, efforts will be focused on how the energy information can be fed back to the user through the chatbot. The premise that the bot will provide electricity consumption data can be considered as a machine to human type of communication. Still, the chatbot will require specific triggers and responses to provide the information needed.

Requesting consumption data from the bot requires the right data parameters and language structure, and without human intervention to guide and assist the user, it can be viewed that the chatbot acts as the Conversation User Interface (CUI) between the user and the MEP. CUI is defined by Brown (et. al, 2012, Abstract) as "A conversation user interface enables users to better understand their interactions with computing devices, particularly when speech input is involved. The conversation user interface conveys a visual representation of a conversation between the computing device, or virtual assistant thereon, and a user. The conversation user interface presents a series of dialog representations that show input from a user (verbal or otherwise) and responses from the device or virtual assistant."

The succeeding sections provides details on the CUI or hereon will be referred to as the chatbot. 


\subsection{System Design}

In order to understand how the chatbot was developed, we need describe its different components. The chatbot uses Facebook Messenger, an instant messaging service provided by Facebook, as the messaging platform. It also uses Webhooks (refer to Technical Definitions section in Chapter 1) to send and receive messages to an API hosted in DialogFlow, an AI service provided by Google, to collect the required data parameters. Once collected, DialogFlow sends an HTTP request to an API published on Heroku (another cloud provider) to processes the request. Depending on the parameters provided, the API will send one or two HTTP requests to MeterDataAPI (https://api.meterdataapi.net) or to the NZX Wholesale Information Trading System (WITS) (https://www2.electricityinfo.co.nz/price_indexes) for the latest electricity spot market prices across New Zealand. The results from the requests sent to either MeterDataAPI or WITS, are then processed --- summed up for half hourly meter reads to derive the daily consumption or formatted in the case of spot market prices. Then processed data is then sent back to DialogFlow which in turn passes it on to the chatbot which is waiting for a response.

Figure 3.5 High Level Architecture of DialogFlow

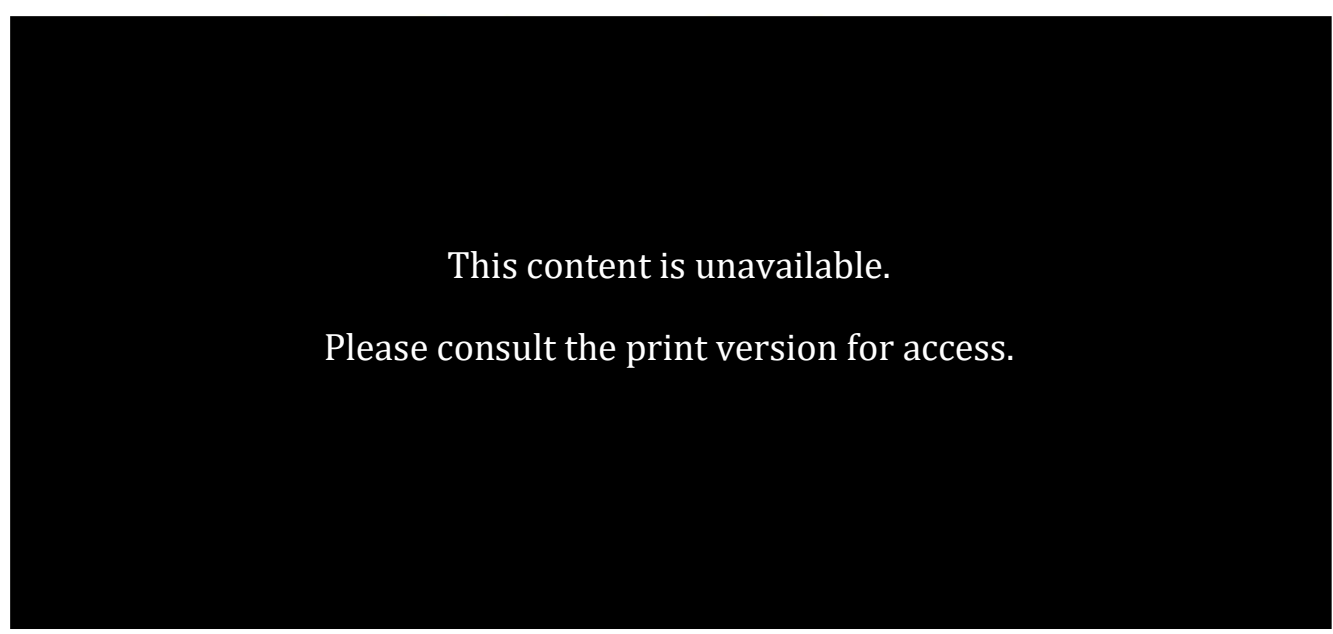

Source: https://dialogflow.com, n.d.

The initial prototype was developed catering only for requesting consumption data or meter reads for a specific date and comparing it with day, week, month or year ago. Initial user testing came back with suggestions for two additional features described in the previous section. The first was to provide the electricity spot market price, another for comparing reads for any arbitrary date specified by the user. The spot market price query feature was implemented as a different intent within DialogFlow as the web resource is different, but still uses the same Heroku API. It is also important to highlight that this study does not attempt to elaborate how smart metering works with regards to data collection. The system data flow of the messaging bot is presented in Figure 3.6. 


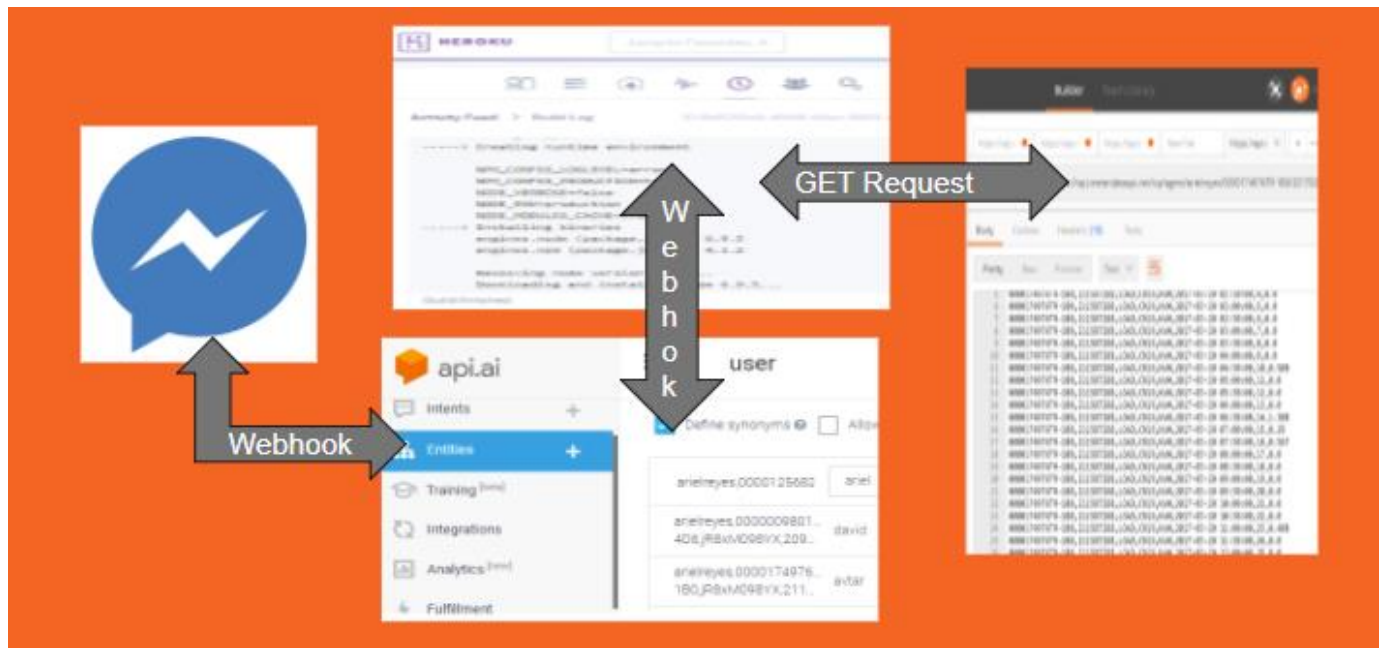

Source: Author. Interface and component diagram. 2017

The application model and technical references are available in Appendix D.

\subsubsection{Versions of the Conversation User Interface}

Recalling the insights given by consulted design experts, and the finding of Fitzsimons, et al. (2008) and Jeong, Wang and Lee (2012), the combination of emotional (emoji) and intellectual messages (electricity consumption data) provide for better visual persuasion. The designers consider emoji alone is insufficient and is adjunct to pro-environmental messages, while the latter views visual messages, if used in the right context is sufficient. Having both approaches in mind, it was considered worthwhile to test as well if the degree of visualness of a message can influence consumption.

It is necessary to reiterate, that processed electricity usage information in both text and emoji form is the key Eco-Feedback message. What the user testing can also provide is a comparison if a text with supplementary visual message is more effective than a purely visual one. In order to test if Eco-Feedbacks message were motivating enough, the researcher developed three versions of the chatbot.

The first version of the chatbot will be primarily text based, supplemented with an emoji representing positive or negative consumption. For the second version, the user provides data parameters as emoji, but the chatbot will respond in text and the resulting consumption would contain both text and emoji. The third version was purely emoji, the user would provide the chatbot emoji as data parameters and the bot will respond in emoji. For the third version the resulting consumption will again be an emoji. 
The first version will be tested by the users for two weeks, the second version for a week, the third version again for another week

By design, the AI service, DialogFlow, categorizes conversation topics as "intents", theses "intents" can be viewed as a map between what the user says and what action should be taken by the chatbot. As the chatbot needs to collect information from the user, the bot prompts the user with questions or emoji, and extracts data parameters from the user natural language inputs as "entities". These "intents" and "entities" are preconfigured within the application in DialogFlow. If in case a user deviates from expected response, the bot will continue to reiterate the question or prompt. If in case the user provides a response considerably distant from the "meter reading intent", the bot will respond using fallback "intents". Figures 3.8 and 3.9 are samples of conversations that have deviated.

Figure 3.8 Deviation of User Responses
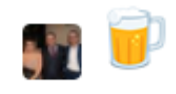

what to eat?

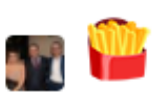

what to eat?

9 SEPTEMBER $11: 13$

Reads please

I'm afraid I don't understand.

Source: Author. User Responses, 2017 


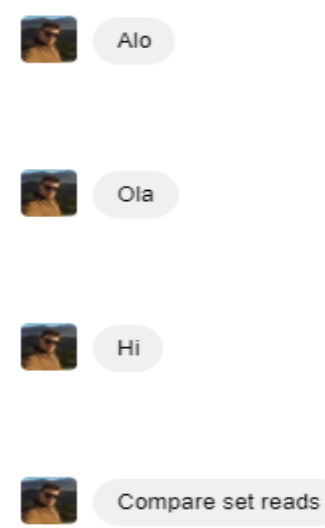

Compare set reads

\section{I'm not sure I follow.}

I'm not totally sure about that

Source: Author. User Intent, 2017

Prior to user testing, pre-testing was conducted wherein individual consumption data was extracted and provided to the users. With two weeks of user testing for the first version of the chatbot, the testing duration was evaluated to be suitable enough to observe if electricity usage would change compared to previous year's consumption. It is also important to note that users did not have a view of each other's consumption during the two weeks period. Each user was comparing his or her current consumption against historical information. If consumption differentiates significantly, then this is can be taken as a measure of the effectivity of Eco-Feedback.

In addition to post-testing by comparing consumption changes, the insights that can be derived from the second and third versions of the chatbot were geared toward determining visual persuasion, which type of messages --- text and emoji or purely emoji would be more effective. This can be probed in detail through a Focus Group Discussion after testing the third version of the bot. A sample conversation using the second version of the bot is shown in Figure 3.10.

Figure 3.10 Second Version of the Messaging Bot
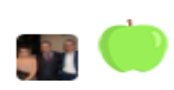

A day, a week, a month, a year

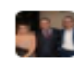

Meter read requested for 2017-10

11 and comparing it to meter read for 2016-10-11. Read for

for 2016-10-11. Read for
Requested Date: $35.213 \mathrm{KwH}$ and

Previous Read:32.753KwH

Sentiment:

Source: Author. Second version of the chatbot, 2017 
The third version of the bot is presented in Figure 3.11.

Figure 3.11 Third Version of the Messaging Bot

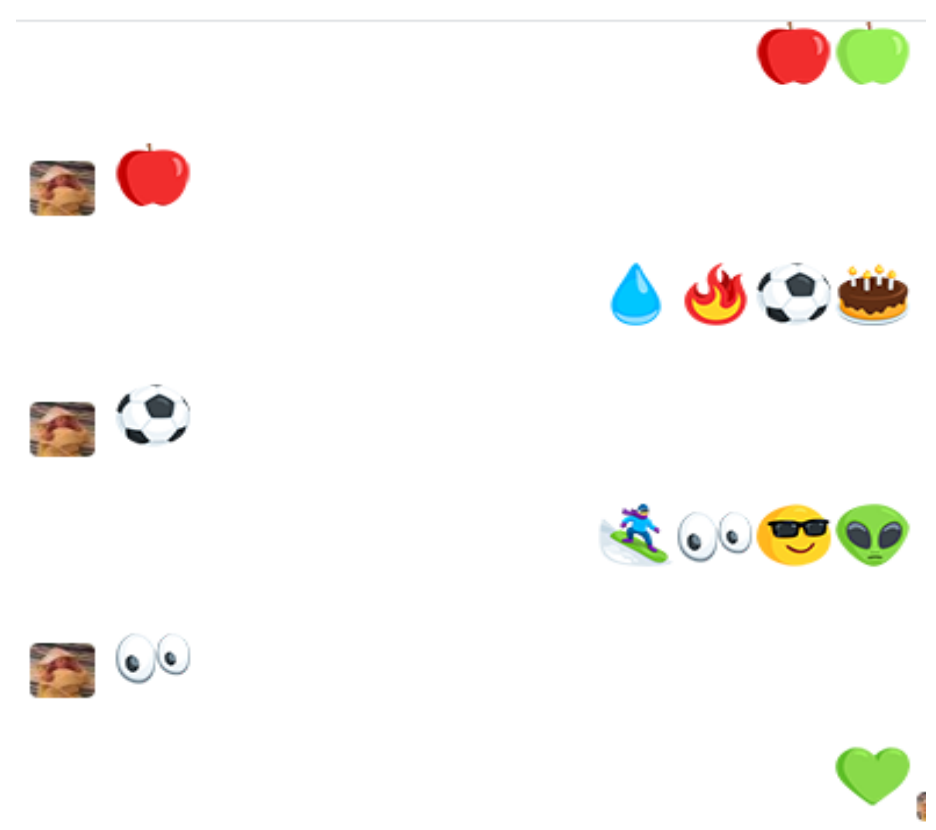

Source: Author. Third version of the chatbot, 2017

For each version user instructions were provided as guidelines on how to interact with the bot. Refer to Appendix E for details.

\subsubsection{Focus Group Discussion}

As discussed in the previous section, aside from measuring changes in consumption, it was necessary to probe perceptions on using the chatbot and how users thought if it has benefitted them or otherwise. A semi-structured Focus Group Discussion (FGD) with guide questions was developed asking about impression, observations and recommendations from the user and general questions on how effective the chatbot was presenting a concept like electricity consumption.

Given that an FGD provides qualitative observations, it was considered fitting to use the same method to gather descriptive observations on the different versions of the chatbot. These insights can help inform future studies seeking to explore CUI as an avenue to enable better human to machine interaction. Basically, capturing characteristics that work or not. 


\section{Results}

This research follows the model of Research Through Design (RtD). First coined by Frayling (1993) and described as taking the practice of creation as research. It is necessary to describe the model, as the research problem aims to determine if a visual language such as emoji can be used to represent something other than emotions in Computer Mediated Communication (CMC). Prototyping is an essential practice in RtD, in this study the use of a chatbot and emoji as a visual language, was tested for providing Eco-Feedback. The three versions or prototypes of the chatbot featured varying degree of visualness of the Eco-Feedback messages.

In addition to design and prototyping, and due to privacy and regulatory requirements (Electricity Authority, 2007), the researcher had to find electricity retailers that were interested in supporting this research. As mentioned in Chapter 2, the Electricity Authority mandated that electricity consumption data is private information which consumers can request from their electricity retailers. Still, electricity consumption data cannot be gathered without the consumer's consent. In addition to compliance, the researcher also needed to find a method for extracting meter usage information in a timely manner to allow for a real-time or close to real-time Eco-Feedback.

The following electricity retailers--- Contact Energy, Powershop and Flick Electric Co. were initially approached as possible research partners. Meetings and follow-up communications were sent, but only Flick Electric Co. agreed to participate in the study.

As discussed in Chapter 3, the researcher had to send out a participant fit survey to find prospective users or testers who would fit the following criteria of 1) being an existing customer of Flick Energy, 2) is energy aware, uses 3) Facebook Messenger and 4) emoji when communicating online.

The participant fit survey was sent out to Victoria University Wellington design students and alumni, and to family and friends of the researcher. From this initiative, a total of 36 people responded. The results of the participant fit survey are discussed in the next section.

\subsection{Participant Fit Survey Results}

The participant fit survey was done to help identify possible research participants or chatbot testers. The survey questions were initially presented to the research program coordinator, and the main recommendation was to reorder the survey guide questions to establish a flow. It was also suggested that the questions should be grouped according to topic which were demographic, interest in emoji and energy consciousness. For energy consciousness, the questions focused on environmental awareness and economic benefits derived from reduction of energy use. In the following section are some of the demographic results of the participant fit survey. 


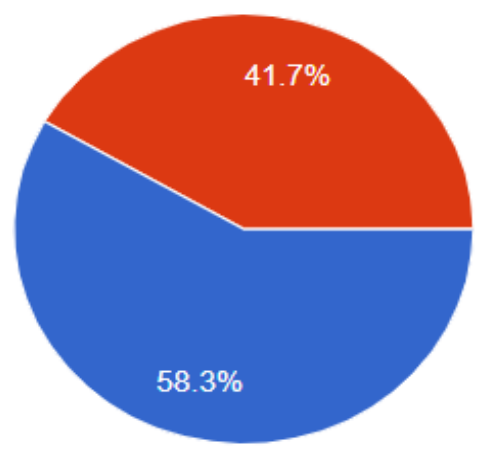

Female

Figure 4.2 Age

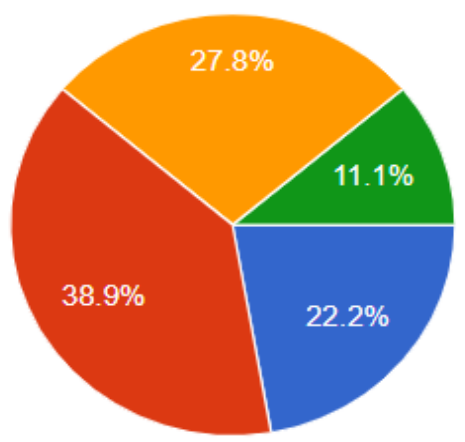

Under 26 years

26 - 35 years

36 - 45 years

Over 45 years

Figure 4.1.3 Occupation

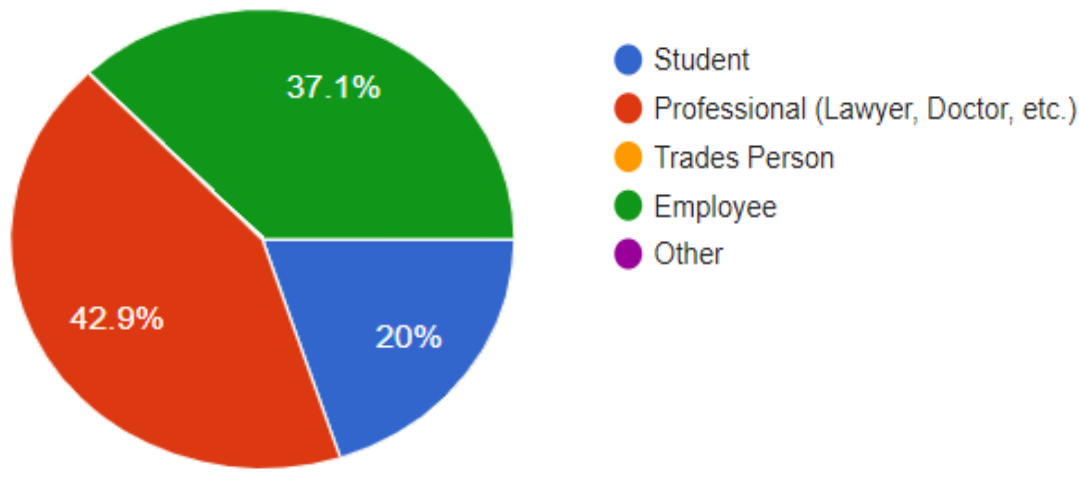

Source: Author. Participant Fit Survey Results, 2016 


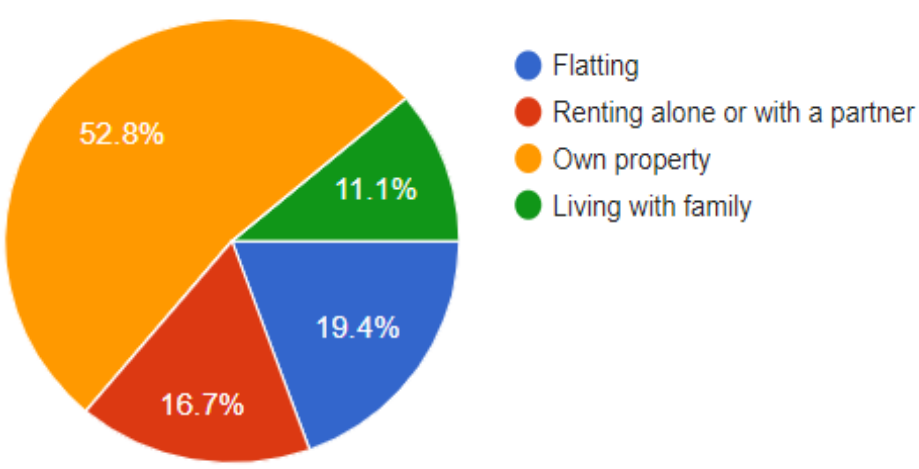

Source: Author. Participant Fit Survey Results, 2016

The respondents were asked if they were active on social media. This theory of using social media as a communication channel follows the study done by Petkov et. al, (2008) wherein social media channels were used to promote domestic energy conservation. The same question also helps inform the researcher how many of the 36 respondents could be potential testers. With user familiarity comes greater acceptance.

Figure 4.1.5 Active on Social Media

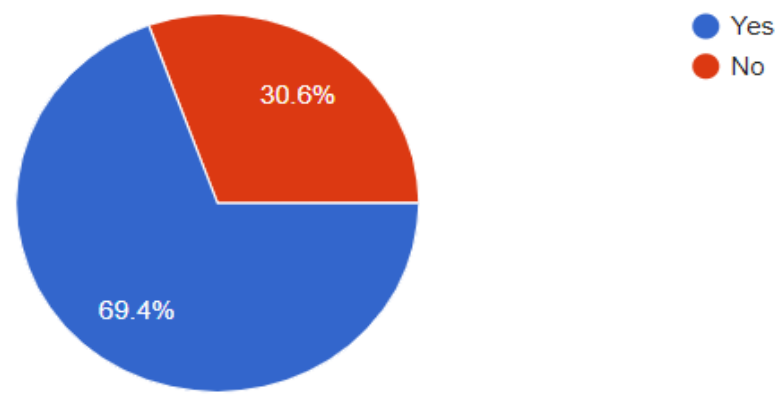

Source: Author. Participant Fit Survey Results, 2016

Focusing on popular social media services, Facebook is the top choice among the respondents. This is closely representative of the report given by Fyers and Cooke (2017) that $61 \%$ of New Zealanders have or are active on Facebook.

Figure 4.1.6 Social Media Services Used

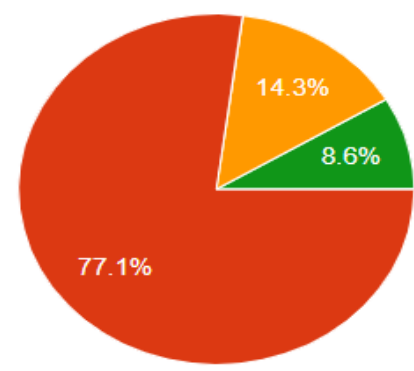

Twitter

Facebook

Instagram

Others

Source: Author. Participant Fit Survey Results, 2016 
With regards to emoji use when communicating in social media, $74.3 \%$ of the respondents use them.

Figure 4.1.7 Percentage Who Use Emoji

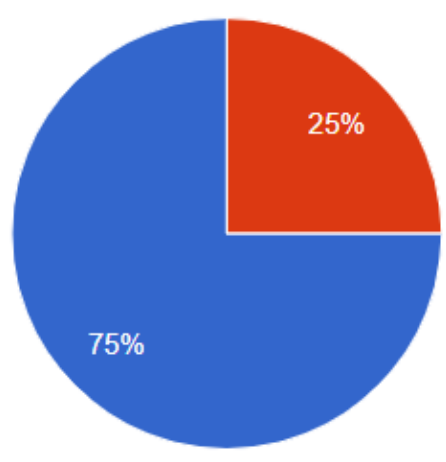

Source: Author. Participant Fit Survey Results, 2016

Following the study done by Instagram (Instagram, 2015), the top 6 emoji on EmojiTracker was presented to the respondents and they were asked which of these they preferred most. The most popular emoji was selected by 7 respondents, but majority selected the smiling face emoji.

Figure 4.1.8 Preferred Emoji

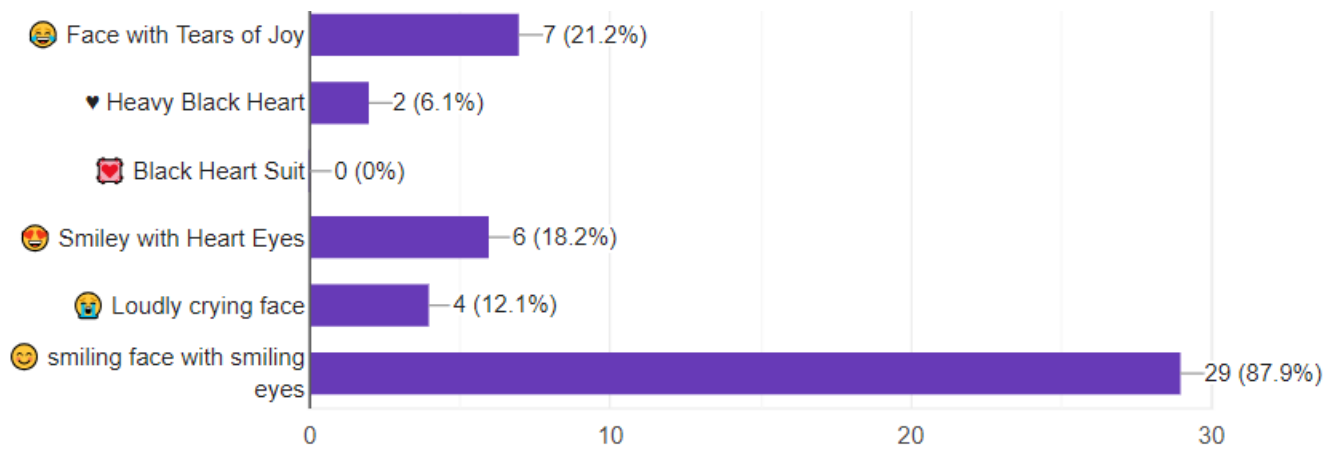

Source: Author. Participant Fit Survey Results, 2016

It is interesting to note that even if most respondents indicated they use emoji when communicating on social media, majority rated their emoji use as low.

Figure 4.1.9 Emoji Usage on Social Media

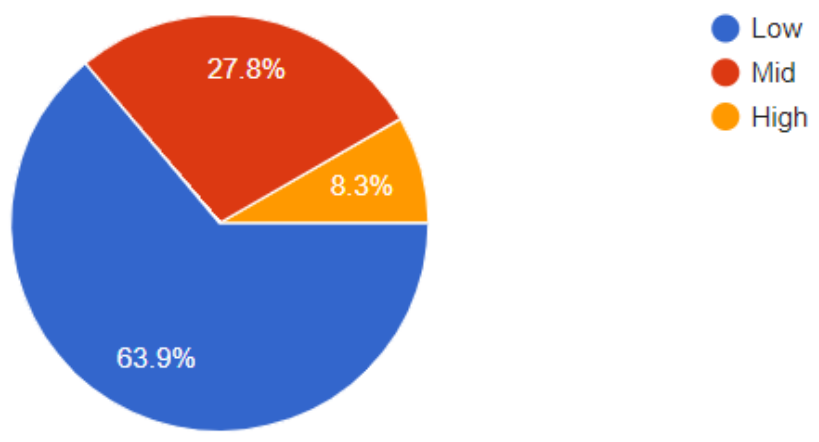

Source: Author. Participant Fit Survey Results, 2016 
Even if respondents indicated they had low use of emoji, they still provided standard emoji they thought would represent them. And majority or $66.7 \%$ expressed that if a tool was provided to personalize their emoji they would opt for it.

Figure 4.1.10 Prefer Personalized Emoji

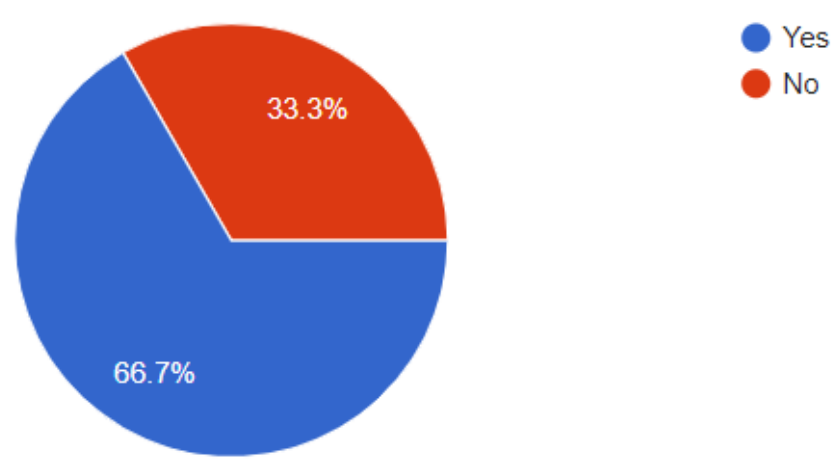

Source: Author. Participant Fit Survey Results, 2016

One constraint, as provided in Chapter 3, was the requirement of finding respondents who were consumers of Flick Electric Co. Only if such condition is passed can the researcher request for meter consumption data for the consumer. Of the respondents, $50 \%$ were consumers of other electricity retailers.

Figure 4.1.11 Electricity Retailers

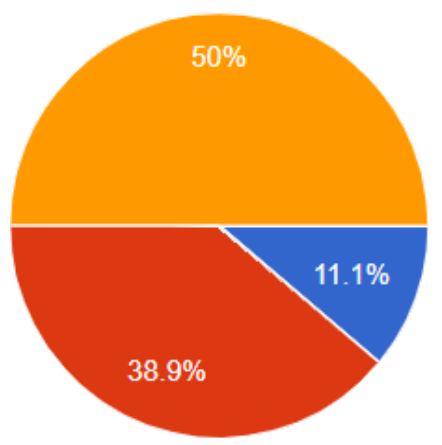

Powershop

Flick Electric Co.

Other

Source: Author. Participant Fit Survey Results, 2016

Most of the respondents also indicated they were aware of their electricity usage and considered themselves average electricity users.

Figure 4.1.12 Energy Awareness

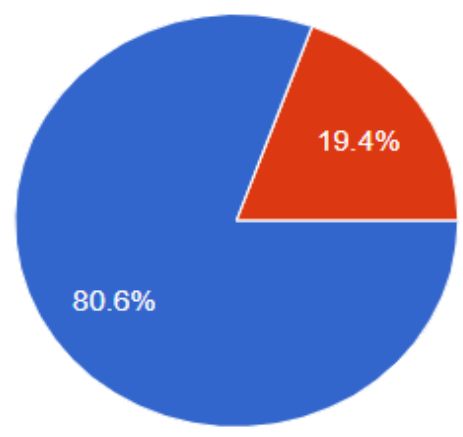

Yes

Source: Author. Participant Fit Survey Results, 2016 


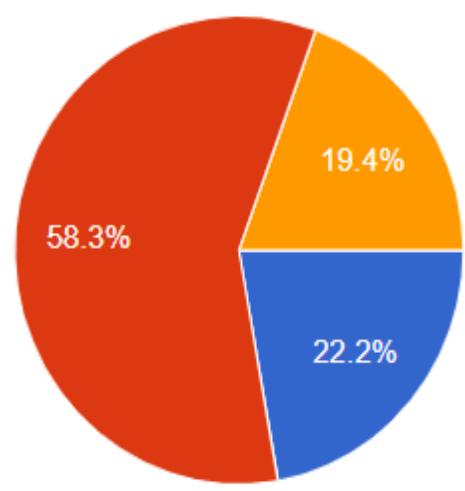

Low

Average

High

Source: Author. Participant Fit Survey Results, 2016

The respondents were also asked if they were satisfied with the energy information provided by their retailers and $75 \%$ said yes. Energy information in this context would be in the form of periodic electric bills provided in either paper or digital format.

Figure 4.1.14 Satisfied with Existing Retailer Energy Information
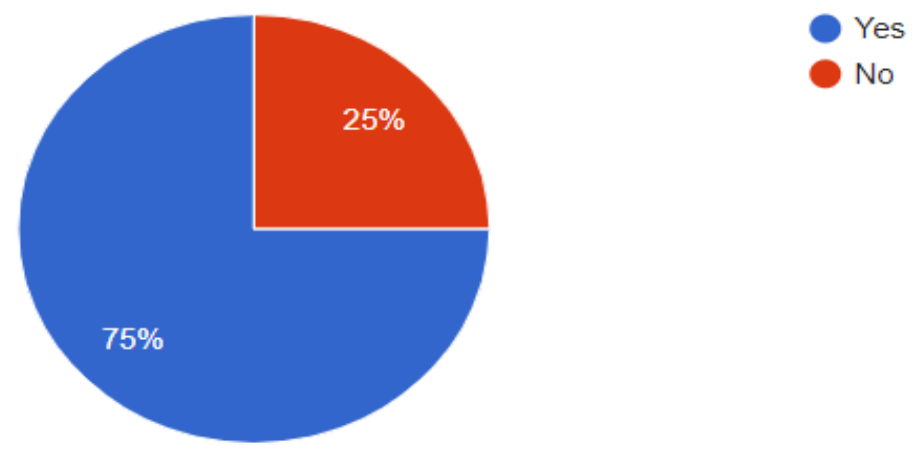

Source: Author. Participant Fit Survey Results, 2016

One final note on the Participant Fit survey results, even if several respondents fit the selection criteria, the thesis of this research was to determine if energy information could be presented through an alternative channel as visual messages. With the alternative channel being Facebook Messenger, 65.7\% of the respondents were not interested in receiving their energy usage information on Facebook Messenger. The responses reduced the number of prospective testers even further.

Figure 4.1.15 Interest in Receiving Energy Information on Facebook Messenger

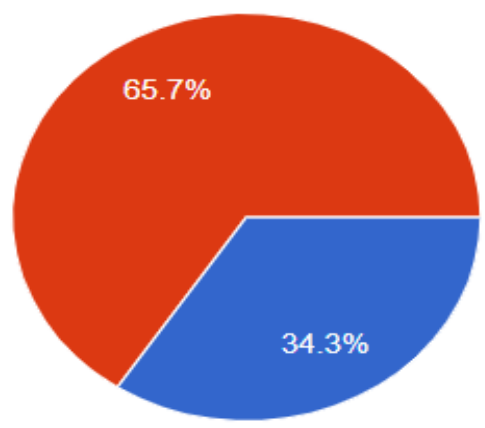

Source: Author. Participant Fit Survey Results, 2016 
Essentially, the results of the Participant Fit survey gave the primary investigator a suitable set of research participants that were familiar with the tools, message and were interested in the research. The next two phases of the research - additional data gathering and user testing, provides more insights on characteristics of Eco-Feedback using a social media channel and its relationship to energy reduction.

Refer to Appendix C for Participant Fit Survey questions and results.

\subsection{Situational Survey Results}

With the list of potential research participants identified, the primary investigator intended to conduct a face to face interview and profile the household electricity usage. Evaluating the potential participants living conditions following the survey done for the New Zealand Household Energy End-use Project (BRANZ, n.d.). But due to some participants being unavailable and with time constraints, this was again implemented as another online survey. The situational survey allowed for selecting participants with similar living conditions.

When this research was initially proposed, one of the aims was to find participants who were consumers of either Flick Electric Co. or Powershop, the only two retailers that have expressed interest in supporting this research. With consumers having similar household profiles and coming from different retailers, this could have provided the opportunity to promote competitive energy reduction between Flick Electric Co. and Powershop consumers.

Of the 36 respondents, 6 were selected to complete the situational survey as they were the only participants that were either with Flick Electric Co. or Powershop. The 6 participants were given the research information sheet and asked to sign the research consent forms. The same consent forms were then furnished to Flick Electric Co. and Powershop signifying that they allowed the researcher to request for their meter consumption data.

With research consents signed, the primary investigator proceeded with providing the 6 participants the situational survey. Results from this survey gave the following insights: the household size ranged from 1 to 5 persons, and only one had a fully insulated home. Heating varied from oil fan heaters, heat pumps and gas radiator central heating. All participants had standard appliances, except for 2 participants having electric hedge trimmers and lawn mowers that they only used fortnightly. Generally, all participants indicated that most heavily used appliance they have at home is the television, which was used between 4 to 6 hours. The longest period any of the participants lived away from home for last year was 40 days. Such length of time being away would only have material impact if comparison was done between current consumption and for periods where the participant was away. The period of data-gathering and user testing was not in the same period when the participant was away. 
In follow-up to the Participant Fit Survey on personalizing emoji use, the question about what emoji represented their high or low usage, comparison was on specific dates provided. The respondents gave the following:

Figure 4.2.1 Emoji to Represent Low or High Usage

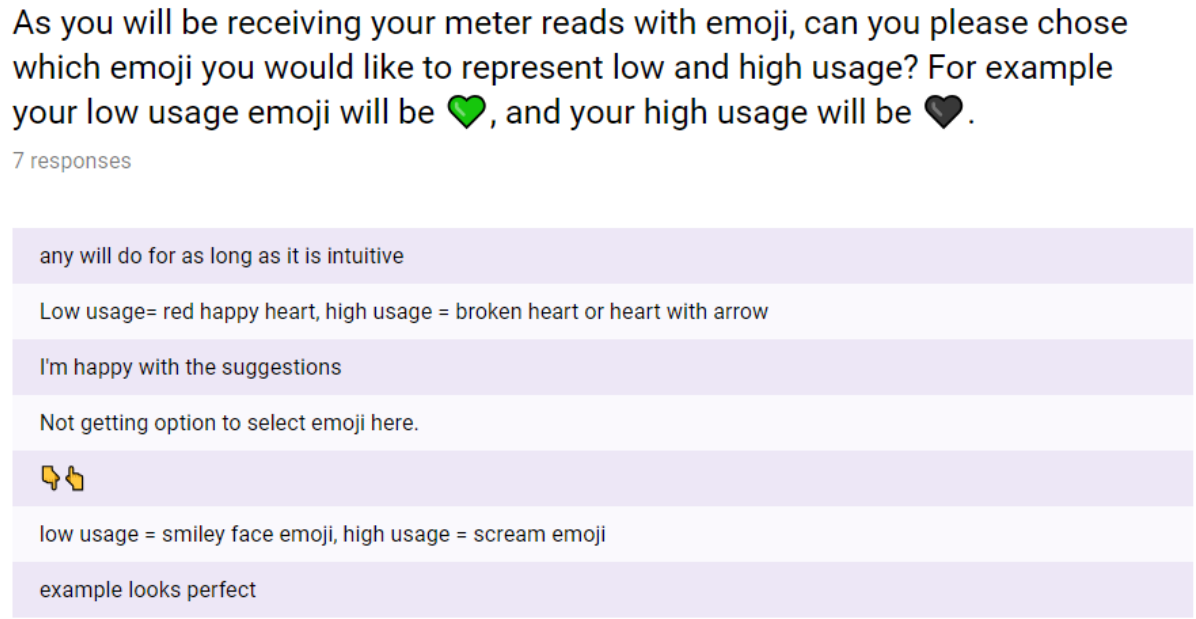

Source: Author. Situational Survey Results, 2017

After the situational survey was completed, the next step was to conduct user testing. Even with the consent forms submitted, user testing could not proceed unless the electricity retailers allowed for requesting user consumption data. After several followups with both retailers, only Flick Electric Co. gave its approval for requesting meter usage information. Only 5 out of the 6 qualified were with Flick Electric Co., the list was further reduced to 4 as one of the research participant's smart meter did not belong to the MEP Vector Advanced Metering Services (VAMS). VAMS is the MEP that provides the web API for extracting meter interval data, or half hourly consumption. The other MEP does not have an equivalent web API, preventing integration with the chatbot.

The situational survey was also meant to aid in normalizing the usage profiles. Normalization would allow for competitive comparison among the research participants. But due to one participant having centralized heating, peer comparison would skew the results to his favour. It is important to note though that by design the messaging chatbot allowed for comparing usage between dates for a user. The intention of comparing consumption was to the model the work done by Odom, Pierce and Roedl (2008) called the Energy Challenge, where students from 10 dormitories in the Indiana University Bloomington campus competed for consuming the least electricity and water.

With the constraint of only being able to conduct user testing for participants that are Flick Electric Co. costumers, and central heating for one participant, competitive comparison was no longer feasible. An alternative is to compare between a participant's recent and historical consumption, with consideration of having a chatbot provide consumption feedback.

Refer to Appendix F for Situational Survey questions and results. 


\subsection{User Consumption Profiles}

Prior to conducting user testing, as part of pre-testing, the consumption profiles of each participant's household was requested from the MEP. The method for data extraction is discussed in Chapter 3. The same consumption profiles were compared with the New Zealand average households based on the same cost and unit of measure as of the second quarter of 2016. This period was selected as this was the latest measured data made available by the Ministry of Business, Innovation and Employment or MBIE (2016) during pre-testing.

Figure 4.3.1 New Zealand Average Annual Expenditure on Electricity in 2016

\section{Average Annual Household Electricity Spend in New Zealand for 2016 is \$2065.86 (GST Inclusive)}

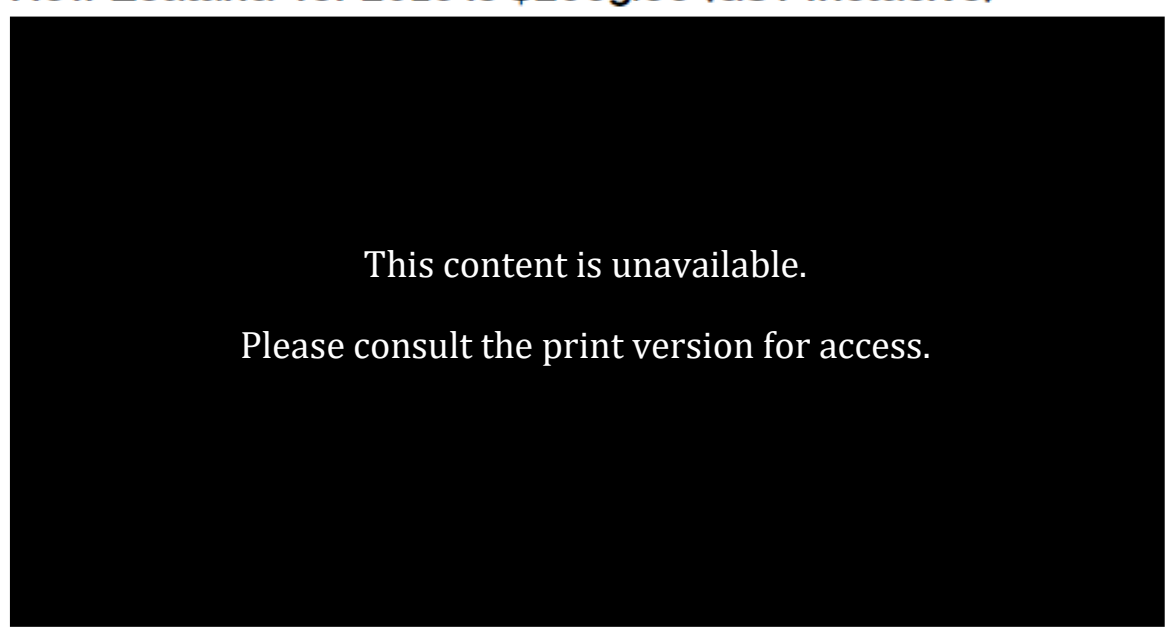

Source: https://figure.nz, 2017

Figure 4.3.2 New Zealand Average Expenditure on Electricity in 2016 Q2

\section{Average expenditure on Electricity per household in NZ for 2016 Q2 is NZD \$501.69.}

This content is unavailable.

Please consult the print version for access.

Source: https://figure.nz, 2017 
The New Zealand average consumption for the second quarter of 2016 is 1728.966 KWh. This was compared with the consumption of each participant's household for the same period, and the results showed one participant was consuming $40 \%$ higher than the New Zealand average for the same period.

Figure 4.3.3 Comparison of Participant's Electricity Usage Against New Zealand Average for Q2 2016

\section{Comparison of Participant's Usage Against NZ Average}

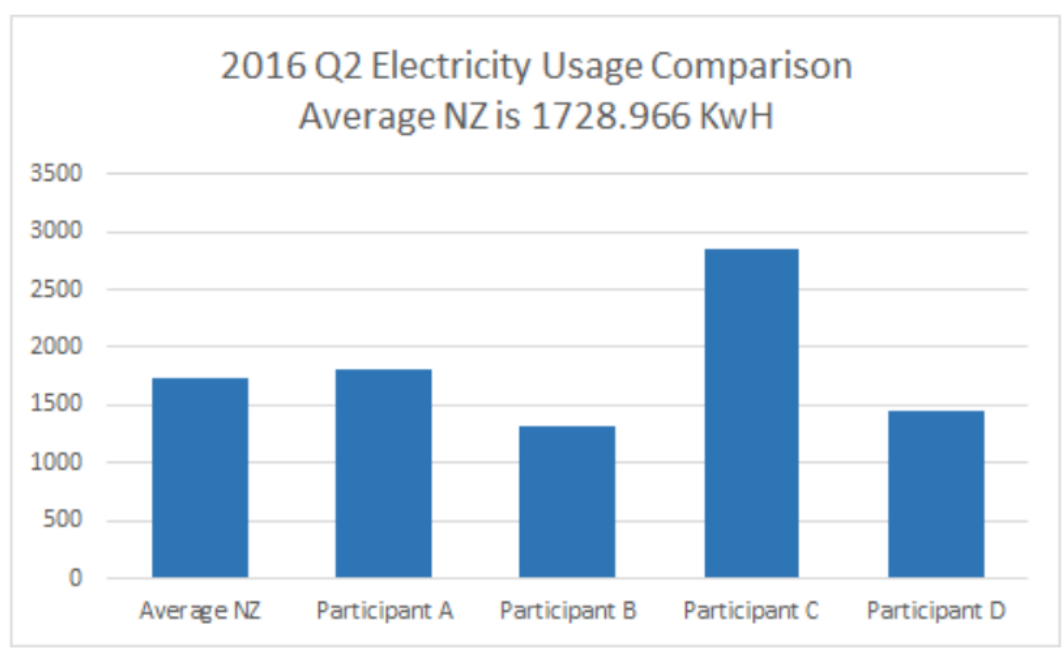

Reference: https://api.meterdataapi.net

Source: Author. Comparative Analysis of Participants Usage Data, 2017

As presented in Figure 4.18, the average expenditure per household in New Zealand on electricity for the Q2 in 2016 was $\$ 501.69$. Comparing this with the participant's usage in KWh multiplied against the average price per KWh for the same period shows similar results.

Figure 4.3.4 Comparison of Research Participant's Electricity Spending for Q2 2016 Compared to New Zealand Averages

\section{Comparison of Participant's Spend Against NZ Average}

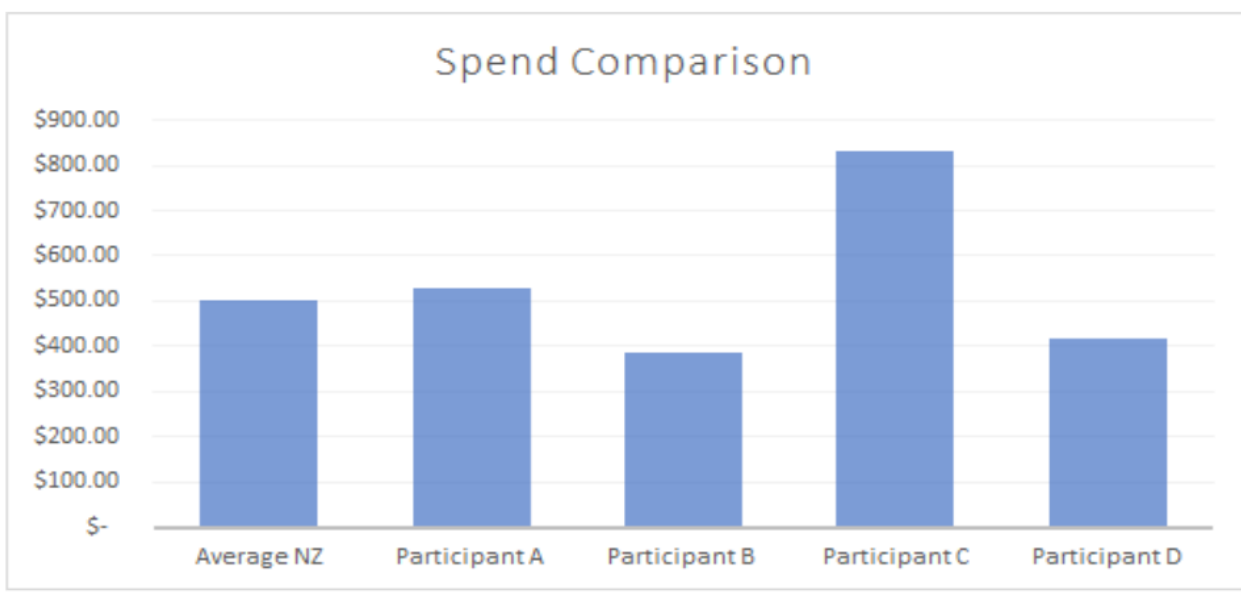

Reference: $\underline{\text { https://api.meterdataapi.net }}$

Source: Author. Comparative Analysis of Participants Usage Data, 2017 
The results from the pre-testing using 2016 Q2 data already shows one participant in particular consumes significantly more than the others. This reinforces the point that peer comparison will not be valid due to such outlier. Further giving weight to the necessity of comparing current against historical consumption for each participant.

\subsection{Chatbot Interactions}

As discussed in Chapter 3, the chatbot is an application which uses a combination of APIs published on different cloud platforms. For user testing there were 3 versions of the chatbot that were tested. The first version was used by the participants for two weeks, while the second and third versions were used a week each.

It is common practice that cloud providers tear down servers to save on computing resources. Cloud subscriptions that fall under free tiers are pooled together to save on computing resources. Applications under these tiers do not have dedicated servers allocated to them. The servers are torn down and spun up only when there are application requests. This was evident during user testing. The participants would at times send a meter read request with the chatbot not providing the reads in the first instance, but would respond appropriately on the following requests. With the chatbot published on Facebook it is constrained by the timeout limits on Webhooks. This was compounded by the regular server shutdowns on DialogFlow and Heroku.

Additional factors that also contributed to timing out of responses was the availability of the meter reading API, the aggregation and comparison of half hourly meter reads. If the participant would like to compare reads, the Heroku application sends two asynchronous requests for half hourly reads for two dates. Once responses are received, it then sums up and compares the reads for each date. Again, the AI interface on DialogFlow, Heroku and MeterDataAPI uptimes plus the compute needed to do meter read comparisons are contributors to non-responsiveness.

With the limitations defined above, it is necessary to present user interactions with the chatbot. This gives us further insights on what elements are important when developing a CUI. The table below shows frequency of interaction, grouped by intent.

The participants were given a guide on how they can request for meter reads, compare meter reads and check for the latest prices on the electricity spot market . Content analysis was applied across all the conversations between the participants and the chatbot. From the analysis, the primary investigator grouped the conversations as follows: 1) Successful Meter Read Requests, 2) Unsuccessful Meter Read Requests (system timeouts, unrecognized user inputs), 3) Out of Scope Requests (greetings, queries or comments not related to meter read requests), 4) Spot Market Price Requests. With the categories set, conversations were coded and tabulated. 
Table 4.1 Participant Chatbot Interactions by Category

\begin{tabular}{|l|l|l|l|l|}
\hline Category & $\begin{array}{l}\text { Participant } \\
\text { A }\end{array}$ & $\begin{array}{l}\text { Participant } \\
\text { B }\end{array}$ & $\begin{array}{l}\text { Participant } \\
\text { C }\end{array}$ & $\begin{array}{l}\text { Participant } \\
\text { D }\end{array}$ \\
\hline $\begin{array}{l}\text { Total Number of chatbot } \\
\text { Interactions }\end{array}$ & 65 & 39 & 78 & 113 \\
\hline $\begin{array}{l}\text { Successful Meter Read } \\
\text { Requests }\end{array}$ & 19 & 6 & 34 & 45 \\
\hline $\begin{array}{l}\text { Unsuccessful Meter Read } \\
\text { Requests }\end{array}$ & 18 & 5 & 19 & 25 \\
\hline Out of Scope Requests & 26 & 13 & 18 & 34 \\
\hline $\begin{array}{l}\text { Spot Market Price } \\
\text { Requests }\end{array}$ & 2 & 5 & 7 & 9 \\
\hline
\end{tabular}

Source: Author. Tabulated Chatbot Interactions, 2017

User testing span across 59 days, the text only version was tested for 20 days, while the other versions were tested over a week each. Participants were provided instructions on how to use each version and the users were reminded to request reads daily. Still, not all participants complied. That is the reason for extending the data gathering for each version.

One of the observations made during user testing was that even with Unicode standards, the interpretation of emoji varies across platforms. One example is the emoji "Woman with Turban" which exists on iPhones but not on Android phones. As a result, it is rendered instead as "Man with Turban" combined with the female sign as follows 8 . Even with the "Man with Turban" emoji alone, there are also six skin tones available to use, which adds more complexity. One participant chose the "Man with Turban" with a light skin tone as his identifier while the chatbot was expecting a dark skin toned "Man with Turban", this resulted into multiple failed meter read requests. These details came out when chatbot interactions became more visual.

Figure 4.4.1 Woman and Man with a Turban

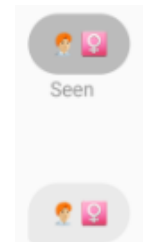

Source: Author. Facebook Messenger Screen Capture. 2017

Figure 4.4.2 Man with Turban and Different Skin Tones

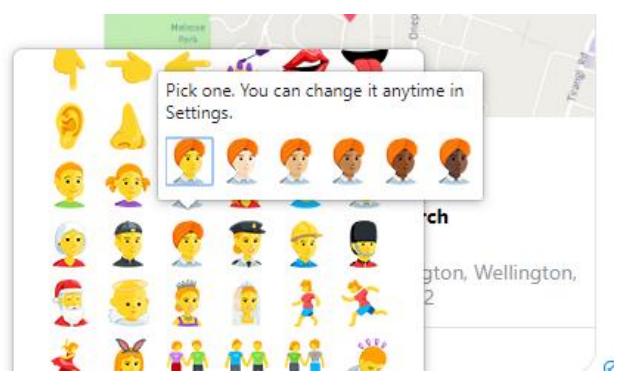

Source: Author. Facebook Messenger Screen Capture. 2017 
Another observation was one participant would request for multiple reads in a single session with the bot, comparing the requested read to different historical dates. This was done until he received an emoji that represented low electricity usage. While another participant would usually provide greetings and salutations to the chatbot when initiating a conversation.

There is no real pattern on how the participants interacted with the chatbot, but one can deduce from Table 4.1 that knowing the spot market price does not have any correlation on a participant's desire to request for his consumption. It is more interesting to note that one participant was actually interested in another participant's reads, but failed to request for the reads as he did not have the valid participant identification.

Messaging bots by design attempt to provide humanlike interaction, it responds to any user input. There are no restrictions on what inputs a user or participant can give, hence the occurrence of multiple "Out of Scope Requests". The chatbot will only shift to a preset conversation flow when a trigger phrase like "compare reads" or an emoji like 0 is given. These "Out of Scope Requests" are mostly greetings, random and vulgar comments wherein the chatbot has no interaction flow for.

Refer to Appendix G for participant's Facebook Messenger interactions with the chatbot.

\subsection{Comparative Consumption}

After gathering all meter consumption data points for each participant for the periods 9 September 2016 to 9 October 2016 and comparing it with meter consumption data points for 9 September 2017 to 9 October 2017, summaries showed that 3 out of the 4 participants consumed less electricity in 2017. Table 4.2 below shows the total consumption in KWh for each participant in 2016 and 2017.

Table 4.2 KWh Consumption by Participant for the Period 9 Sep. to 9. Oct. in 2016 and 2017

\begin{tabular}{|c|c|c|c|c|}
\hline & $\begin{array}{c}\text { Participant } \\
\text { A }\end{array}$ & $\begin{array}{c}\text { Participant } \\
\text { B } \\
\end{array}$ & $\begin{array}{c}\text { Participant } \\
\text { C }\end{array}$ & $\begin{array}{c}\text { Participant } \\
\text { D }\end{array}$ \\
\hline $\begin{array}{l}\text { Total KWh } \\
\text { Consumed from } \\
\text { 9 Sep. 2016 to } 9 . \\
\text { Oct. 2016 }\end{array}$ & 653.465 & 550.629 & 3022.271 & 611.882 \\
\hline $\begin{array}{l}\text { Total KWh } \\
\text { Consumed from } \\
\text { 9 Sep. 2017 to 9. } \\
\text { Oct. 2017 }\end{array}$ & 887.685 & 533.923 & 2859.515 & 602.388 \\
\hline
\end{tabular}

Source: Author. Comparative Analysis of Participants Usage Data, 2017

It is important to highlight that there are a few data gaps and variances in how interval data is recorded. For any missing interval data either from 2016 or 2017, these intervals were excluded from the summaries. Providing equivalent data and time points for both periods. To further illustrate, in 2016 Day Light Savings occurred on 25 Sep. while in 2017 it shifted on 24 Sep. So instead of 48 intervals for 24 Sep. only 46 intervals were compared. The same applied for $25 \mathrm{Sep}$.

Based on the cumulative daily interval reads, only Participant A had 3 days wherein reads for the period in 2017 were less than 2016. All other participants had at least 16 days. This requires further investigation on Participant A's living situation as some details could have been missed during the Situational Survey. Even though Participant A's 
consumption increased in 2017, usage is still lower than the New Zealand monthly average of $753.29 \mathrm{KWh}$ as Q3 of 2016 (Figures, 2017).

The succeeding graphs provide visualization of the comparative consumption for 28 observed days for each participant.

Figure 4.5.1 Participant A Comparative Consumption Graph

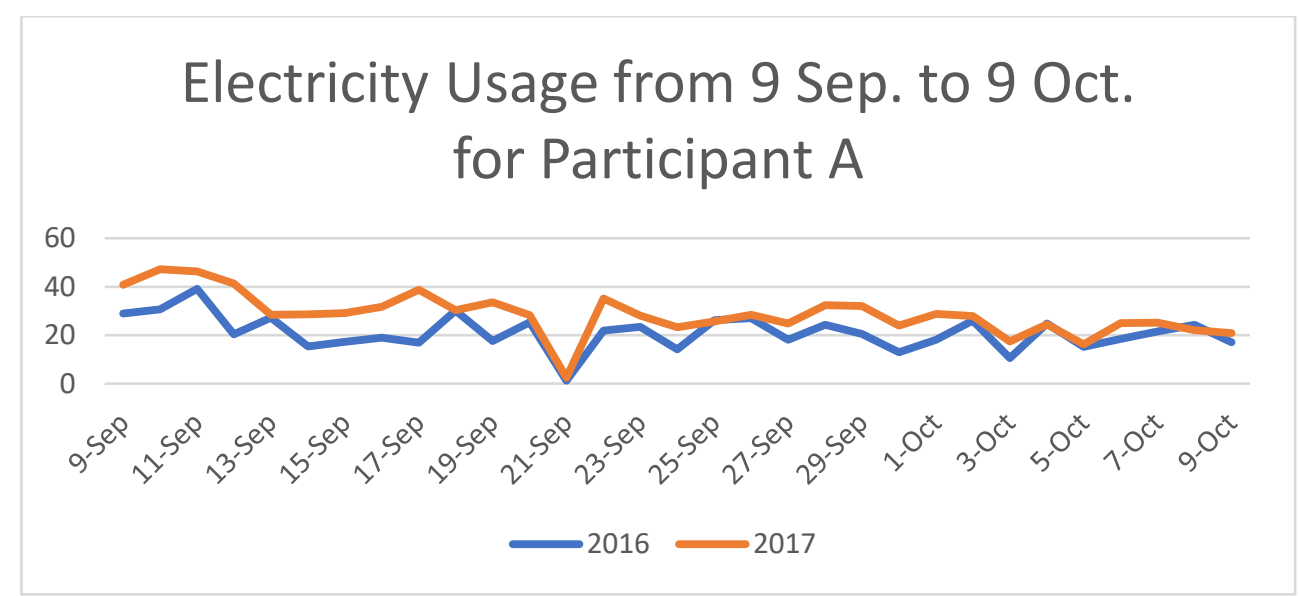

Figure 4.5.2 Participant B Comparative Consumption Graph

\section{Electricity Usage from 9 Sep. to 9 Oct. for Participant B}

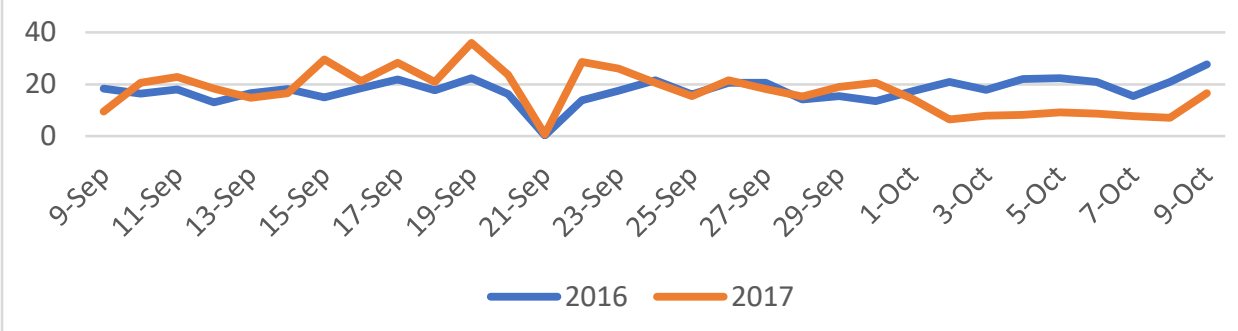

Figure 4.5.3 Participant C Comparative Consumption Graph

\section{Electricity Usage from 9 Sep. to 9 Oct. for Participant C}

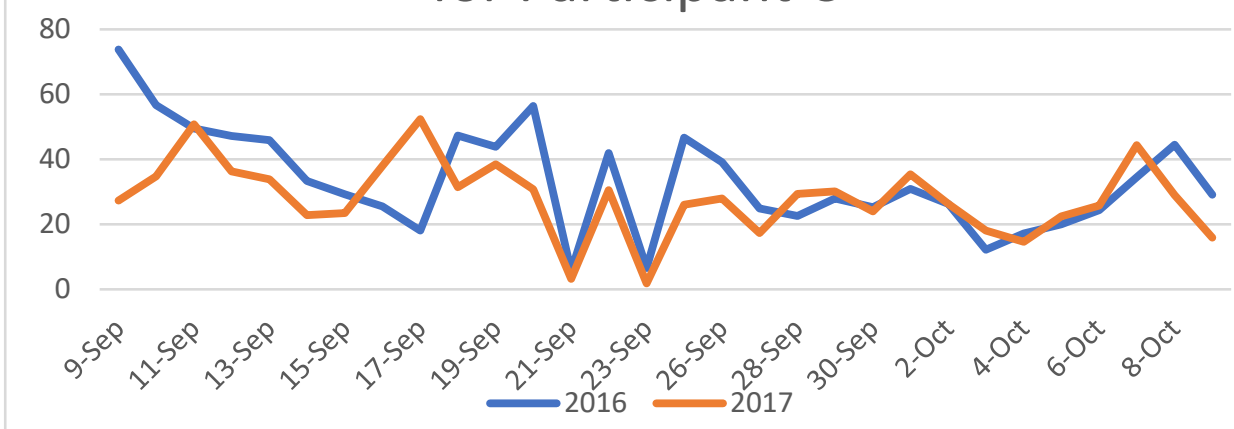

Source: Author. Comparative Analysis of Participants Usage Data, 2017 


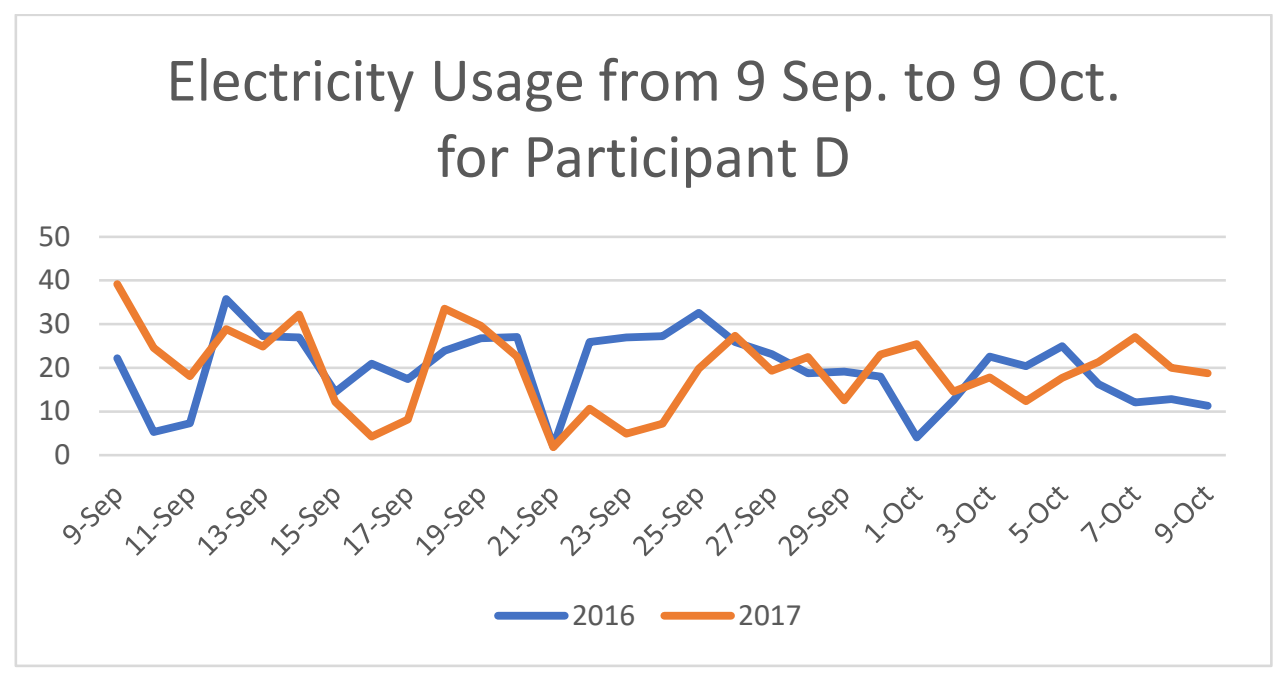

Source: Author. Comparative Analysis of Participants Usage Data, 2017

Refer to Appendix $\mathrm{H}$ for details on each participant's cumulative interval reads.

\subsection{Focus Group Discussion}

With this research being both qualitative and quantitative, post user testing warranted gathering feedback on the effectivity of emoji aided by the chatbot in providing EcoFeedback. It was necessary to probe participant's opinions on the positive and negative attributes of the prototype, to this objective the following guide questions were prepared:

Question 1: What was your general impression on using the chatbot to retrieve your electricity consumption data?

Question 2: What were the good and bad points using the 3 versions of the chatbot namely: text only, text and emoji, emoji only?

Question 3: With emoji being an emotive visual language, what emotions did you feel while using the chatbot (e.g. frustration, uncertainty, happiness)?

Question 4: What were the work arounds or hacks that you had to do to get the chatbot to provide you with your electricity consumption data?

Question 5: Working in the energy sector, aside from providing electricity consumption data, in what other areas or ways do you see a conversation user interface or bots can be practicable?

Question 6: If this design experiment was extended to a larger group, what would be your recommendations?

Most of the responses to questions 1 and 2 were leaning towards user experience. The general opinion was the first version of the chatbot prompted them what to key in, and not requiring any memory retention. While the second version for them was "quicker and 
easier", one participant even opined that "It flows in a way that surprised me...I thought I was too old for this, I will not be using emojis...but I can see something there". For the participants second version provided the same ease of use as the first version, but eliminated the need of typing lengthy information. The comment on the third version, which was all emoji based, was that it was "illegible" and there was a "learning curve to it". For them, the third version was difficult to learn as it required the user to remember what emoji to use. What stood out from the responses was that it was important for the participants to get their measurements or KWh used. Specifically commenting that "numbers actually mean something to us". If the prototype would have to stick with emoji, a participant opined that emoji could be used to represent quantity for example "...400KWh you could get four green squares".

One theme that came out four times was comparison. This was first mentioned in response to question 1 where it would be helpful if the chatbot provided insight on how the consumption compared to New Zealand averages, for example if the usage for the day is $10 \%$ above average. The next was on question 3, wherein a participant indicated they were happy when they received a low usage emoji. Still, there was a desire to be able to compare usage with others, like their friends. Another participant shared a need to profile household per suburb depending on the number of rooms in a house, which in turn can be used to compare with their profile. Last, with the recommendations if the prototype was presented to a larger group, it can help if the consumption data was shared with the group. For one participant, this would prompt him to act "I do nothing or maybe from the lowest I would feel super happy or if on the highest I would feel compelled to change something". Indicating that only with competition can there be behavioural changes.

Another important theme that came out was the chatbot initiating the conversation. In the chatbot's current state, a conversation will only flow when triggered by a user's input. Given that energy information is already collected, participants expressed the desire for the chatbot to trigger the conversation with alerts such as "the last 5 days has been awful, what have you been doing?" or "hey your usage is a bit up at the moment, you might want to have a think about whether or not you left your towel rail on...". Even extending the idea to having a "personal assistance" that would not only alert you but can also provide recommendations on what to change. This theme opens up opportunities for future research.

Finally, when the participants were asked about what emotions they felt during user testing, one participant shared "I kinda still feel it's a computer...".

Transcriptions on the Focus Group Discussion are presented in Appendix I. 


\section{Conclusion}

The research problem presented was to determine if emoji could be used to visualize electricity usage information. The primary investigator considered Captology as a highly effective model for promoting pro-environmental behaviour. As presented in Chapter 2, Section 2.1 where tools, media and social actors were all encapsulated in a Conversation User Interface (CUI) or a chatbot. The chatbot functions as an agent that will provide energy information visualized as emoji. Emoji was selected due to its wide adoption in Computer Mediated Communication (CMC). With the emoji (Face With Tears of Joy) being considered as the Oxford dictionary 2015 word of the year, it would be of interest to test if it could be used for something other than emotive expressions. As Lebduska (2014) argued, emoji are similar to Pitman's shorthand, with the exception that shorthand being familiar to only a technical few. While emoji is learned through casual use, "the universality of emojis, which, like any communication, is both materially and culturally bound". She further stresses that the struggles in using emoji are similar to the alphabetic language as posited by T.S. Eliot and Italo Calvino that text can be limiting when expressing emotions. There are also opposing arguments on the premise that emoji can now be considered as a visual language. For Azuma and Ebner (2008), they considered graphic emoticons as an auxiliary visual language and have proven the digital pictographs can break language barriers. While Gretchen McCulloch (SwiftKey, 2016) doesn't consider emoji as a language, but recognizes it as the "fourth quadrant" in non-verbal online communication. The primary investigator sought to determine if visual persuasion in the form of emoji, as explained in Chapter 2 Section 2.8, would be effective in motivating pro-environmental behaviour. Specifically, to reduce electricity consumption.

A review on Eco-Feedback research done by Froelich, et. al. (2010) documented the different techniques for motivating pro-environmental behaviour. Three of the six techniques, which are information, comparison and feedback were utilized in the design of the Eco-Feedback prototype. Again, the prototype being presented is a Facebook Messenger chatbot. In their research, they emphasized the need to detail salient design factors like the frequency of feedback, appropriateness of presenting consumption, the level of granularity, the accessibility and medium of the information (push vs. pull), and the ability to make comparisons. Pointing out these attributes needed to be considered and evaluated.

\subsection{Design Consideration}

Any research on Eco-Feedback cannot exist without considering Human-Computer Interaction ( $\mathrm{HCl}$ ) as well as environmental psychology. With the former focused on technological artefacts, and the latter on behavioural changes. Still, as pointed out by Froelich, et. al. (2010), both fields have insufficient details on what effective visual elements contribute to good Eco-Feedback design. It was considered that with ubiquitous computing like instant messaging and emoji, developing Eco-Feedback using these tools was a novel idea. At the time of this writing, the primary investigator did not find any Eco-Feedback prototypes implemented as a Conversation User Interface (CUI), specifically a Facebook Messenger chatbot where energy information is presented as emoji. 
There were three design iterations of Facebook Messenger bot, each iteration having different degrees of "visualness". "Visualness" in this context is the way emoji is used when requesting and receiving Eco-Feedback as detailed in Chapter 3, Section 3.4.1. After going through the design iteration, changes in consumption and user's feedback were analysed.

\subsection{Design Implications}

Like most studies on Eco-Visualization and Eco-Feedback, a lot of focus is given towards reducing energy consumption. Reduction in energy use is only one segment in the field of environmental management. Considering both environmental and behavioural psychology, when designing Eco-Feedback is necessary as there are multiple elements that need to converge to facilitate pro-environmental action, spanning across natural and built environments, social settings, learning and information environments. As Kollmuss and Agyeman (2010) argued, having environmental information alone does not warrant behavioural change. For any design to have material impact, it needs to overcome barriers like individuality (attitude and temperament), responsibility ("locus of control", lack of efficacy) and practicality (lack of resources, social and institutional constraints).

Even if the prototype had the key attributes of good Eco-Feedback design, testing supports the argument presented by Fitzsimons, et. al. (2008, p. 33) that through behavioural priming visual messages can affect behavioural changes but it requires semantic association, commonality of objects in relation to a situation, and social influence. In which case, emoji alone do not have any semantic association or commonly understood relation to energy information. On social influence, the research participants stated they needed to see how they compare not only with their friends but with the average New Zealand consumer as well.

Tying back to the argument that reducing consumption is only one aspect, if an EcoFeedback design works effectively to reduce consumption, the same design could then be replicated and tested in other disciplines like waste management, environmental preservation and conservation.

\subsection{Design Research}

Through prototyping, a new method for Eco-Feedback was developed. It proved to be suitable for providing comparison of individual's past consumption behaviour. Based on feedback from the end users, social comparison is considered a motivating factor.

Through user feedback, it was determined emoji alone is insufficient for visualizing energy information. It was even proven that with instructions, users have mental models which they fall back on to when using software systems, and CUI is no exception. Chapter 4, Section 4.6 detailed user difficulties interacting the Facebook Messenger chatbot using emoji exclusively. Furthermore, the participants pointed out in the feedback sessions, numbers are essential to them.

Interaction design is centred around maximising usability and user experience. There is emphasis on how information is accessed, mostly requested by the end user. Design review sessions gave insight that with ubiquitous computing, pushing information is a preferred option. With information being provided to the user whenever there are significant changes in consumption patterns. 
Also, the availability of spot market prices did not prove to be an effective motivator as it was initially thought to be. Participants shared that they tried it, but when they noticed the prices hardly changing they stopped using it. One participant opined that it needed more granularity as it only gave prices for the Upper, Lower North Island and the South Island. While another stated that he was already using the Flick Electric Co. mobile application for his price notification, but would appreciate if he was provided a way to set thresholds on his consumption, combining price and usage, and notified if he was nearing his threshold. These insights reinforce the need to evaluate existing environments when designing CUIs.

Like any interface, good CUI design translates to better user experience. CUI which stems from Natural Language Processing (NLP), has the potential of providing a richer user experience through Machine Learning. As Sheth (2015) argued the application paradigm (be it mobile, web or desktop) is now reaching its saturation point. Even with a multitude of applications available on mobile devices, consumers tend to use only a few repeatedly. Adoption of CUI has the potential of leap frogging over traditional application as Machine Learning can help tailor user experience. According to Hollbrook (2017), Machine Learning can be utilized to gather in situ feedback when designing interaction flow. Current practice with traditional applications is to gather and evaluate user feedback after prototyping or full development. While CUI is not constrained by the materiality of visual elements, any changes in the conversation can be integrated without disrupting the interaction flow.

\subsection{Future Studies}

Results from this study have shown that CUI can be a suitable platform for Eco-Feedback. It has also been proven through prototyping and testing that emoji in its simplest form is insufficient for data visualization. This then opens up opportunities for future studies as energy usage information can be collected and then analysed using Predictive Analytics or Machine Learning models, better understanding of consumption behaviour could be discovered.

In the area of environmental psychology, other techniques like commitment, goal settings and incentives could also be tested if they are effective as motivators for Eco-Feedback implemented as a CUI.

Another opportunity identified is to explore if changing the way energy information is received, would be effective in motivating pro-environmental behaviour. To reiterate, feedback from testing indicate that receiving consumption information along with recommendations is preferable than users having to request for it. It necessary follows that recommendations be appropriate to the users living situation.

One final opportunity is to determine if emoji can be used to improve Human to Computer Interaction. With the aide of the emoji keyboards most recently used function, users can conveniently send emoji with less key strokes. As the prototype has proven, computer programs can take these emoji as instructions. This opens up the possibility of using emoji in other areas like home or work place automation. Furthermore, with emoji being adopted in other fields, like even the United States Library of Congress accepting a transliteration of Moby Dick as Emoji Dick (Allen, 2013) there is still opportunities to discover other uses of these digital pictographs. 


\section{Reference List}

Adler, J. (n.d.). Smile, Frown, Grimace and Grin - Your Facial Expression Is the Next Frontier in Big Data. Retrieved March 29, 2018, from https://www.smithsonianmag.com/innovation/rana-elkaliouby-ingenuity-awards-technology-180957204/

Allcott, H., \& Mullainathan, S. (2010). Behavior and Energy Policy. Science, 327(5970), pp. 12041205.

Allen, E. (2013, February 22). A Whale of an Acquisition | Library of Congress Blog [webpage]. Retrieved March 29, 2018, from //blogs.loc.gov/loc/2013/02/a-whale-of-an-acquisition/

Azuma, J., \& Ebner, M. (2008, June). A stylistic analysis of graphic emoticons: Can they be candidates for a universal visual language of the future. In Proceedings of World Conference on Educational Multimedia, Hypermedia and Telecommunications (pp. 972-979).

Barba, R. (2016, April 14). B of A's New Customer Reps: 'Chat Bots' on Facebook Messenger. American Banker, 1(71). Retrieved from http://link.galegroup.com.helicon.vuw.ac.nz/apps/doc/A453047257/AONE?u=vuw\&sid=AONE \&xid=1ec6a161

Bargh, John A., Mark Chen, and Lara Burrows (1996), "Automaticity of Social Behavior: Direct Effects of Trait Construct and Stereotype Activation on Action," Journal of Personality and Social Psychology, 71 (2), 230-44.

Bargh, John A., Peter M. Gollwitzer, Annette Lee-Chai, Kimberly Barndollar, and Roman Tro"tschel (2001), "The Automated Will: Nonconscious Activation and Pursuit of Behavioral Goals," Journal of Personality and Social Psychology, 81 (6), 1014-27.

Beckel, C., Sadamori, L., \& Santini, S. (2012, November). Towards automatic classification of private households using electricity consumption data. In Proceedings of the Fourth ACM Workshop on Embedded Sensing Systems for Energy-Efficiency in Buildings (pp. 169-176). ACM.

Bolt, G. (2015, August 15). Smart meters. Retrieved from https://www.consumer.org.nz/articles/smart-meters

BRANZ (n.d.). HEEP | The Household Energy End-Use Project. Retrieved March 29, 2018, from https://www.branz.co.nz/cms_display.php?sn=80\&st=1\&pg=18593

Brown, F. A., Miller, T. M., Wooters, C. C., Culley, B. M., \& Snavely, E. D. (2015, December 29). US9223537B2. United States. Retrieved from https://patents.google.com/patent/US9223537B2/en

Brownlee, J. (2016, April 4). Conversational Interfaces, Explained. Retrieved March 29, 2018, from https://www.fastcodesign.com/3058546/conversational-interfaces-explained

Burgoon, J. K., Buller, D. B., \& Woodall, W. G. (1996). Nonverbal communication: The unspoken dialogue (2nd ed.). New York, NY: McGraw-Hill.

Burke, M. \& Kraut R. (2011). Social Capital on Facebook: Differentiating Uses and Users. HumanComputer Interaction Institute, Carnegie Mellon University. 5000 Forbes Ave., Pittsburgh, PA 15213

Chin, D., Zappone, A., \& Zhao, J. (2016). Analyzing Twitter Sentiment of the 2016 Presidential Candidates. News \& Publications: Stanford University. 
Cohn, N. (2015, October 13). Will emoji become a new language? Retrieved March 29, 2018, from http://www.bbc.com/future/story/20151012-will-emoji-become-a-new-language

Crystal, D. (2005, February). The scope of Internet linguistics. In Proceedings of American Association for the Advancement of Science Conference; American Association for the Advancement of Science Conference, Washington, DC, USA(pp. 17-21).

Darby, S. (2006) The effectiveness of feedback on energy consumption. University of Oxford, Environmental Change Institute. Retrieved from http://www.eci.ox.ac.uk/research/energy/downloads/smart-metering-report.pdf

Dimson, T. (2015). Emojineering part 1: Machine learning for emoji trends. Instagram Engineering Blog, 30 .

Durante, C. (2016). Adapting Nonverbal Coding Theory to Mobile Mediated Communication: An Analysis of Emoji and Other Digital Nonverbals. Masters Theses. Retrieved from http://digitalcommons.liberty.edu/masters/408

Electricity Authority (n.d.). My usage. Retrieved March 29, 2018, from https://www.ea.govt.nz/consumers/your-power-data-in-your-hands/my-usage/

eMarketer (2014, December 11). 2 Billion Consumers Worldwide to Get Smart(phones) by 2016. Retrieved from https://www.emarketer.com/Article/2-Billion-Consumers-WorldwideSmartphones-by-2016/1011694

Fitzsimons, G. M., Chartrand, T. L., \& Fitzsimons, G. J. (2008). Automatic effects of brand exposure on motivated behavior: how apple makes you "think different". Journal of consumer research, 35(1), 21-35.

Foster, D., Linehan, C., Lawson, S., \& Kirman, B. (2011, May). Power ballads: deploying aversive energy feedback in social media. In CHI'11 Extended Abstracts on Human Factors in Computing Systems. ACM.

Froehlich, J., Findlater, L., \& Landay, J. (2010). The Design of Eco-feedback Technology. In Proceedings of the SIGCHI Conference on Human Factors in Computing Systems (pp. 1999-2008). New York, NY, USA: ACM. https://doi.org/10.1145/1753326.1753629

Full Emoji List (n.d.). Retrieved March 27, 2018, from http://unicode.org/emoji/charts/full-emojilist.html

Fyer, A and Cook, H. (2017, March 23). Facebook is New Zealand's second-favourite leisure activity I Stuff.co.nz. Retrieved March 29, 2018, from https://www.stuff.co.nz/technology/90005751/Facebook-is-New-Zealands-second-favouriteleisure-activity

Galloway, P. (2016, October 26). The Original Emoji Set Has Been Added to The Museum of Modern Art's Collection. Retrieved March 29, 2018, from https://stories.moma.org/the-original-emoji-sethas-been-added-to-the-museum-of-modern-arts-collection-c6060e141f61\#.q4bnskcs5

Garra, G., Singer, A. J., Taira, B. R., Chohan, J., Cardoz, H., Chisena, E., \& Thode, H. C. (2010). Validation of the Wong-Baker FACES pain rating scale in pediatric emergency department patients. Academic Emergency Medicine, 17(1), 50-54.

GSMA Mobile Economy 2018. (n.d.). Retrieved from https://www.gsma.com/mobileeconomy/

Hallsmar, F. \& Palm, J. (2016). Multi-class Sentiment Classification on Twitter using an Emoji Training Heuristic. Retrieved from http://kth.divaportal.org/smash/get/diva2:927073/FULLTEXT01.pdf 
Hanington, B., \& Martin, B. (2012). Universal methods of design: 100 ways to research complex problems, develop innovative ideas, and design effective solutions. Rockport Publishers.

Harris, J. E. (2016). The Use of Emojis With Adolescents in the Therapeutic Context. Pacifica Graduate Institute.

Hern, A. (2016, June 20). Rifle emoji blocked from phones "after pressure from Apple." Retrieved March 29, 2018, from http://www.theguardian.com/technology/2016/jun/20/apple-rifle-emojiphones-unicode

Holbrook, J. (2017, July 10). Human-Centered Machine Learning. Retrieved March 29, 2018, from https://medium.com/google-design/human-centered-machine-learning-a770d10562cd

Holmes, T. G. (2007). Eco-visualization: combining art and technology to reduce energy consumption. In Proceedings of the 6th ACM SIGCHI conference on Creativity \& cognition (pp. 153162). ACM. Retrieved from http://dl.acm.org/citation.cfm?id=1254982

Instagram (2015, May 1). Emojineering Part 1: Machine Learning for Emoji Trends. Retrieved March 29, 2018, from https://engineering.instagram.com/emojineering-part-1-machinelearning-for-emoji-trendsmachine-learning-for-emoji-trends-7f5f9cb979ad\#.1o1ivbd0r

Jeong, J.-W., Wang, X.-J., \& Lee, D.-H. (2012). Towards Measuring the Visualness of a Concept. In Proceedings of the 21st ACM International Conference on Information and Knowledge Management (pp. 2415-2418). New York, NY, USA: ACM. https://doi.org/10.1145/2396761.2398655

Kaplan, R. (2013, March 21). Beyond the GUI: It's Time for a Conversational User Interface | WIRED. Retrieved March 29, 2018, from https://www.wired.com/2013/03/conversational-userinterface/

Kelly, C. (2015). Do you know what I mean > :(: A linguistic study of the understanding of emoticons and emojis in text messages. Retrieved from http://urn.kb.se/resolve?urn=urn:nbn:se:hh:diva27611

Kollmuss A. \& Agyeman J. (2002). Mind the Gap: Why do people act environmentally and what are the barriers to pro-environmental behavior? Environmental Education Research, 8:3, pp. 239-260

Kovacs, M. (2017, January 27). Smart Meters NZ: The Guide Energy Efficient Homes. Retrieved March 29, 2018, from https://www.canstarblue.co.nz/energy/electricity-providers/smartmeters-changing-electricity-market/

Ljubešić, N., \& Fišer, D. (2016). A global analysis of emoji usage. In Proceedings of the 10th Web as Corpus Workshop(pp. 82-89).

Love, D. (2015, August 4). An anti-gun organization is calling on Apple to ban the gun emoji from the iPhone. Retrieved from https://www.dailydot.com/irl/disarm-the-iphone-gun-emoji/

M. S. Pallak, and W. Cummings. (1976). Commitment and Voluntary Energy Conservation. Personality and Social Psychology Bulletin. 2(1), pp. 27-30. Available: http://psp.sagepub.com/content/2/1/27.short

McTear, M. F. (2002). Spoken Dialogue Technology: Enabling the Conversational User Interface. ACM Comput. Surv., 34(1), 90-169. https://doi.org/10.1145/505282.505285

Ministry of Business, Innovation and Employment (2017, June). Unlocking our energy productivity and renewable potential - NEW ZEALAND ENERGY EFFICIENCY AND CONSERVATION STRATEGY 2017 - 2022. Retrieved from: http://www.mbie.govt.nz/info-services/sectorsindustries/energy/documents-image-library/NZEECS-2017-2022.pdf 
Myers, B., \& Ko, A. (2009). The Past, Present and Future of Programming in HCI. Institute for Software Research. Retrieved from http://repository.cmu.edu/isr/782

Nicholson-Cole, S. A. (2005). Representing climate change futures: a critique on the use of images for visual communication. Computers, Environment and Urban Systems, 29(3), 255-273. https://doi.org/10.1016/j.compenvurbsys.2004.05.002

Novak P, Smailović J., Sluban B. \& Mozetič, I. (2015). Sentiment of Emojis. Retrieved from: http://journals.plos.org/plosone/article?id=10.1371/journal.pone.0144296\#abstract0

Odom, W., Pierce, J., \& Roedl, D. (2008). Social Incentive \& Eco-Visualization Displays: Toward Persuading Greater Change in Dormitory Communities. In workshop proceedings of Public and Situated Displays to Support Communities. OZCHI '08.

Olsen, C. S. (2014). Visualization of energy consumption: Motivating for a sustainable behaviour through social media. In 2014 International Conference on Collaboration Technologies and Systems (CTS) (pp. 641-646). https://doi.org/10.1109/CTS.2014.6867642

Persuasive Tech. (n.d.). Psychology of Facebook. Retrieved May 22, 2016, from http://captology.stanford.edu/projects/psychology-of-facebook.html

Pierson, D. (2016, October 26). Emojis join Van Gogh and Picasso at Museum of Modern Art. Los Angeles Times. Retrieved from http://www.latimes.com/business/la-fiemojis-moma-20161026snap-story.html

Rodrigues E., Souza F. and Chan W. (2016). United States Patent No. US20160092173A1. Oracle International Corporation, Redwood Shores, CA (US): United States Patent Office.

Schnoebelen, T. (2012). Do you smile with your nose? Stylistic variation in Twitter emoticons. University of Pennsylvania Working Papers in Linguistics, 18(2), 14.

Sears, A., \& Jacko, J. A. (2007). The Human-Computer Interaction Handbook: Fundamentals, Evolving Technologies and Emerging Applications, Second Edition. CRC Press.

Sheth, B. (2015). Forget Apps, Now The Bots Take Over | TechCrunch. Retrieved March 29, 2018, from https://techcrunch.com/2015/09/29/forget-apps-now-the-bots-take-over/

Smith, C. (2018, February 3). 65 Amazing WhatsApp Statistics and Facts (February 2018). Retrieved from https://expandedramblings.com/index.php/whatsapp-statistics/

Stern, J. (2015, May 19). How I Learned to Love Writing With Emojis. Retrieved March 29, 2018, from http://graphics.wsj.com/how-i-learned-to-love-writing-with-emojis/

Štolfa, T. (2016, March 10). The Future of Conversational UI Belongs to Hybrid Interfaces. Retrieved March 29, 2018, from https://medium.com/the-layer/the-future-of-conversational-uibelongs-to-hybrid-interfaces-8a228de0bdb5

SwiftKey (2016). The Linguistic Secrets Found in Billions of Emoji - SXSW 2016 present.... Technology. Retrieved from https://www.slideshare.net/SwiftKey/the-linguistic-secrets-foundin-billions-of-emoji-sxsw-2016-presentation-59956212

Tchokni, S. E., Séaghdha, D. O., \& Quercia, D. (2014, May). Emoticons and Phrases: Status Symbols in Social Media. In ICWSM.

Unicode Consortium. (n.d.). Retrieved March 27, 2018, from https://unicode.org/

United Nations Foundation. (2013). What We Do: Improving Energy Efficiency. Retrieved from http://www.unfoundation.org/what-we-do/issues/energy-and-climate/improving-energyefficiency.html 
USwitch (n.d.). Gas and electricity: what type of user are you? Retrieved March 29, 2018, from https://www.uswitch.com/gas-electricity/guides/gas-and-electricity-user-groups/

Venables, M. (2007). Smart meters make smart consumers [Analysis]. Engineering Technology, 2(4), 23-23. https://doi.org/10.1049/et:20070401

Williams K. and George, D. (2017, July 7). Thousands consider changing power companies as spot price bills skyrocket | Stuff.co.nz. Retrieved from https://www.stuff.co.nz/business/money/94359384/thousands-consider-changing-powercompanies-as-spot-price-bills-skyrocket

Wong, D. L., \& Baker, C. M. (1988). Pain in children: comparison of assessment scales. Pediatric Nursing, Vol.14 No.1, pp. 9-17. Retrieved from: http://www.pediatricnursing.net/interestarticles/1401_Wong.pdf 


\section{List of Figures and Tables}

\section{List of Figures}

Figure 2.1 Comparison Between Conventional and Advanced Metering Data Flows .......................... 7

Figure 2.2 Energy Usage in New Zealand Homes .................................................................................... 9

Figure 2.3 Environmental Knowledge Linear Progression Model ............................................................. 9

Figure 2.4 Kollmuss and Agyeman Pro-Environmental Consciousness ............................................... 10

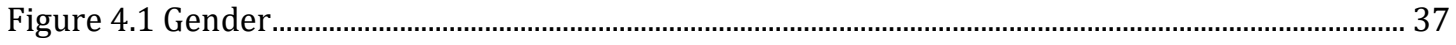

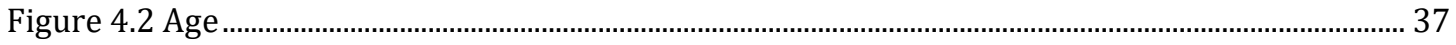

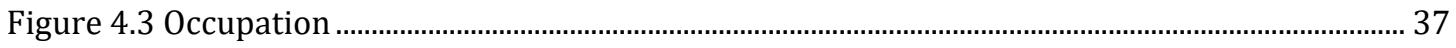

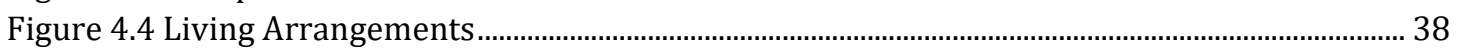

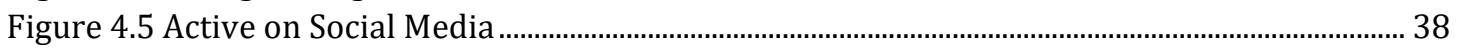

Figure 4.6 Social Media Services Used................................................................................................ 38

Figure 4.7 Percentage Who Use Emoji........................................................................................................... 39

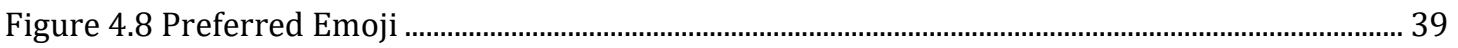

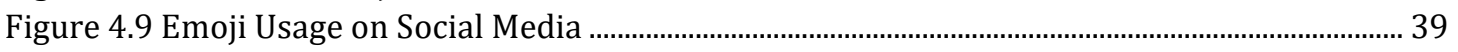

Figure 4.10 Prefer Personalized Emoji............................................................................................................. 40

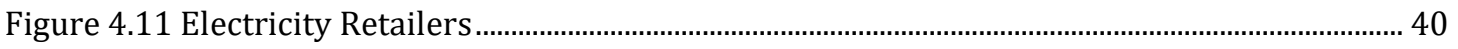

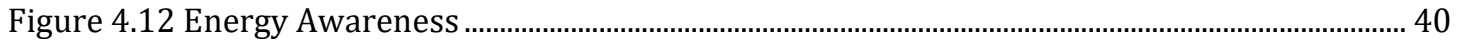

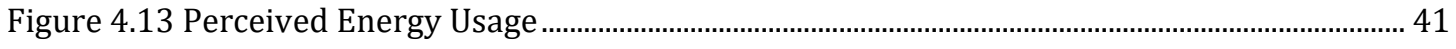

Figure 4.14 Satisfied with Existing Retailer Energy Information ........................................................... 41

Figure 4.15 Interest in Receiving Energy Information on Facebook Messenger ............................... 41

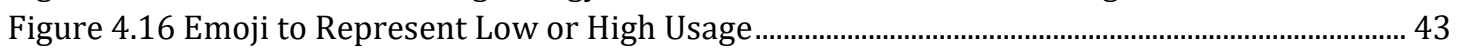

Figure 4.17 New Zealand Average Annual Expenditure on Electricity in 2016.................................. 44

Figure 4.18 New Zealand Average Expenditure on Electricity in 2016 Q2 ........................................... 44

Figure 4.19 Comparison of Participant's Electricity Usage Against New Zealand Average for Q2

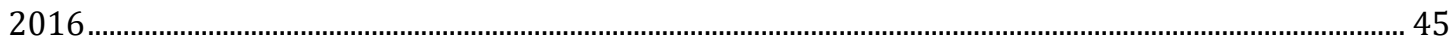

Figure 4.20 Comparison of Research Participant's Electricity Spending for Q2 2016 Compared to

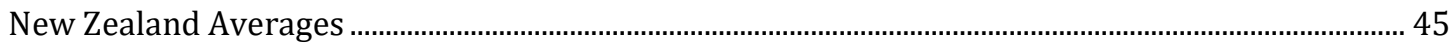

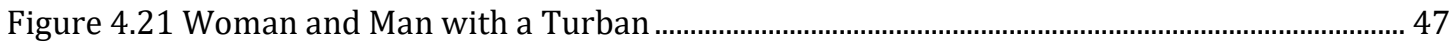

Figure 4.22 Man with Turban and Different Skin Tones .......................................................................... 47

Figure 4.23 Participant A Comparative Consumption Graph.................................................................. 49

Figure 4.24 Participant B Comparative Consumption Graph.................................................................. 49

Figure 4.25 Participant C Comparative Consumption Graph ................................................................. 49

Figure 4.26 Participant D Comparative Consumption Graph ............................................................... 50

\section{List of Tables}

Table 4.1 Participant Chatbot Interactions by Category .................................................................................4 47

Table 4.2 KWh Consumption by Participant for the Period 9 Sep. to 9. Oct. in 2016 and 2017 ...... 48 


\section{Appendix A: Questions and Responses from First Design Expert}

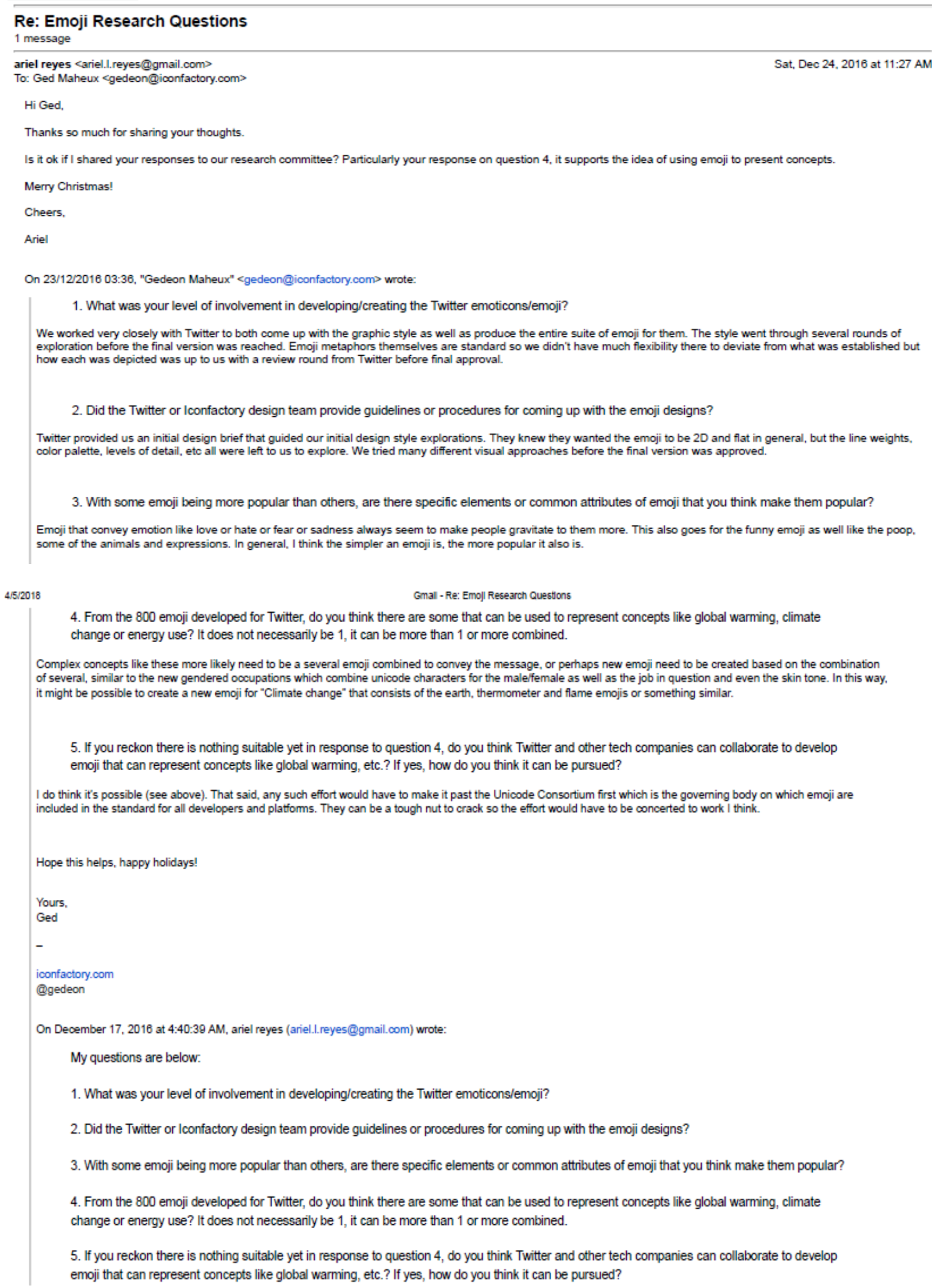




\title{
9. Appendix B: Questions and Responses from Second Design Expert
}

\author{
1. What emojis are you most fond of? What are the ones you dislike? Why? \\ Fond of: \\ I think I'm fond of the emoji that I use most often and find most useful. Here's my top 5: \\ - 目 Thumbs up sign. I use this all the time as a shorthand and more personable way \\ of saying "ok", "yes", "done", "gotcha" etc. Super common and useful in a work
} context.

- :- Grimacing face. Useful in all kinds of contexts, like showing sympathy for something bad happening to someone else, or in awkward-funny situations.

- Waving hand sign. We use this a lot at Atomic for acknowledging when people come online or are signing off for the night etc. Also use it for greeting new people into our customer Slack group.

- Person bowing deeply. A shorthand way of showing gratitude/thanks.

- Face with tears of joy. Everyone's favourite. For lols, but also when someone does something that you're extremely happy about - like that ship a feature you've really been waiting for.

Dislike:

I don't think there's any emoji I especially dislike, but there are a lot that I don't use. I'd guess out of the hundreds of emoji available I regularly use only 10-20, and may have only ever used about 100. One emoji that kind of annoys me in its execution is "Tired face" - just because that's not the expression people have on their face when they're tired, and if it looked like an actual tired face l'd be able to use it more.

2. Do you use emojis for work and when communicating with family and fried?

To what extent?

- Work: Yes. We use Slack for internal team communication and also have a Slack group for customers. Slack makes it easy to add emoji to messages and give emoji-only responses. I'd say roughly $10 \%$ of all my message contain emoji. Here's an example:

- Family \& friends: Yes, mainly in SMS messages and in responses to Instagram Appendix B: Questions and Answers from Second Design Expert posts. I'm not sure how much I use them, but definitely daily. More for messages and responses that are emotional, and less for purely practical stuff - like planning/coordinating things.

3. With research studies indicating emojis have now replaced Internet slang , what are your thoughts on emojis becoming accepted as a formal internet language?

I don't think emoji will be accepted as a formal language, because they're not yet very usefu for communicating anything but very simple concepts. But I do think they're be accepted as being included in other formal communication. For example, I read a lot of Medium posts from industry peers and commentators on topics such as UX, product design and entrepreneurship, and it's not uncommon to see emoji used sparingly to help communicate humour or emotion as part of an otherwise serious article for a professional audience.

4. Looking at emojis from a designer's point of view, what visual characteristics of emojis do you consider essential for making it gain wide acceptability?

I assume this is about acceptability in a formal context. Perhaps the main issues are around cultural and situational appropriateness. Some visual characteristics that could support this are:

- Cultural appropriateness - where objects, clothing and other symbols are relevant to the context. For example, there might be a "farming" emoji, but farming may look very different in different countries, cultures and industries.

- Racial diversity - where emojis depict appropriate depictions of race.

- Sexual diversity - where emojis reflect and support modern views on sexual diversity especially in terms of female representation in professional contexts, and emoji that work for the LGBT community.

- Universality of aesthetics - where the visual treatment of emoji is appropriate for usage in professional and formal contexts, and appeals to as many people as possible. This probably means that the quality needs to be very high yet avoid being overly stylistic / adhering to one particular visual style.

5 . We know emojis are effective in communicating emotions digitally, what are your thoughts of it being used to represent data? Some what similar to how the bar code and QR code have evolved.

I find this question quite hard to answer, maybe simply because I have not seen (or imagined) many ways emoji can be used for data. My instinct is that they are unlikely to be 
useful in communicating anything but very simplistic data sets (e.g. binary yes/no, hot/cold, or broad groupings like high, medium low etc). I think the primary intended use case of emoji, in providing a smallish \& finite set of commonly understood and shared visual symbols is at odds with usage in bar/QR code contexts, where very large unique (many millions) variations are necessary that can be quickly and reliably distinguished from each other by machines.

6. If you were given the challenge to interpret numerical data as emojis, for example inflation or interest rates, how would you do it?

If I was given a choice, I wouldn't, because I can't think of a way that emoji could effectively communicate numerical data. But if I had to use here's some things I'd try:

- Using them in an infographic way, where a single emoji represented a unit of data so, for example, to express a number like 3.5 you could display three and a half emoji (where the emoji used represented the subject matter as closely as possible e.g.

using human figures when communicating population).

- Inflation and interest rates are tricky because there's often a need to communicate their change over time, which would usually be represented using a line graph. Emoji could be used for the data points along a graph. Or which a bar chart they could be stacked on top of each other to form a solid bar.

- They could also be used in a supplementary way to help express how a value has changed over time or compares to a previous period:
$\circ 110 \% \mathrm{~W}$
$0-10 \%$
$\circ 0.03$
$00.03 \%$
0120
03.5 \&

7. If applied to education, how do you think emojis can be used in teaching new concepts or telling a story?

If we can remember some books taught us how to read using text interlaced with graphics.

In a way, I'm not sure that they have anything too significant to add here because - as you suggest - visual symbols are already used where they are thought to aid learning. Emoji are unique in that they can go anywhere digital text can go, unlike images, so I suspect they will mainly be useful in digital contexts.

8. How do you think emojis can be used to represent abstract concepts like energy usage?

I don't know! Emoji are essentially icons or small and simple illustrations, so they should be able to be used wherever those two things are already being used. Looking at a collection of infographics about energy usage

( https://www.google.co.nz/search?q=energy+usage+infographics\&tbm=isch ) you can see many situation where icons or simple illustrations are already used - emoji could be used here. This combined with the data usages (as mentioned above) provide a range of ways they can be used. There's no doubt many more I haven't thought of too.

9. Unlike its formal counterpart, digital communication using emojis is highly prone to misinterpretation, as a designer what elements do you think can help prevent this from happening?

- Careful selection of the appropriate emoji for your audience

- Using them sparingly when they truly aid communication

- Using them in a supportive way along with text and other more traditional forms of communication

10. Do you think emojis are here to stay or are they just a fad? Why?

I think they're here to stay - well as long as we continue to use digital text at least. As mentioned, emoji are unique in that they can go only where digital text can go, and digital text is probably already the most prevalent form of communication we have, so it makes sense that people will seek ways to improve the quality and range of things we can communicate using text - and emoji is one of those. In this light, emoji may become a small subset of a larger range of ways digital text can be augmented to communicate 
10. Appendix C: Participant Fit Survey Questions and Results

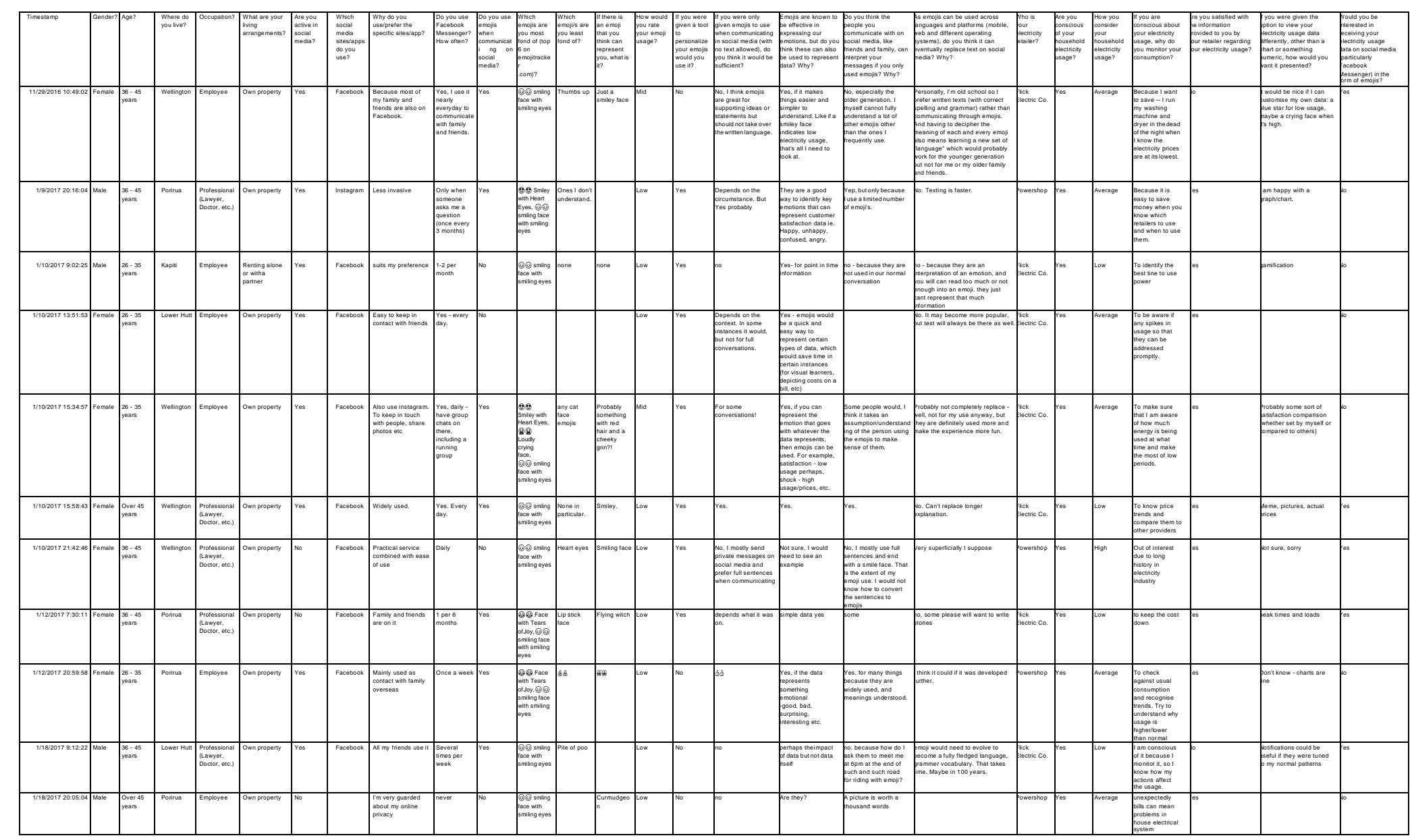




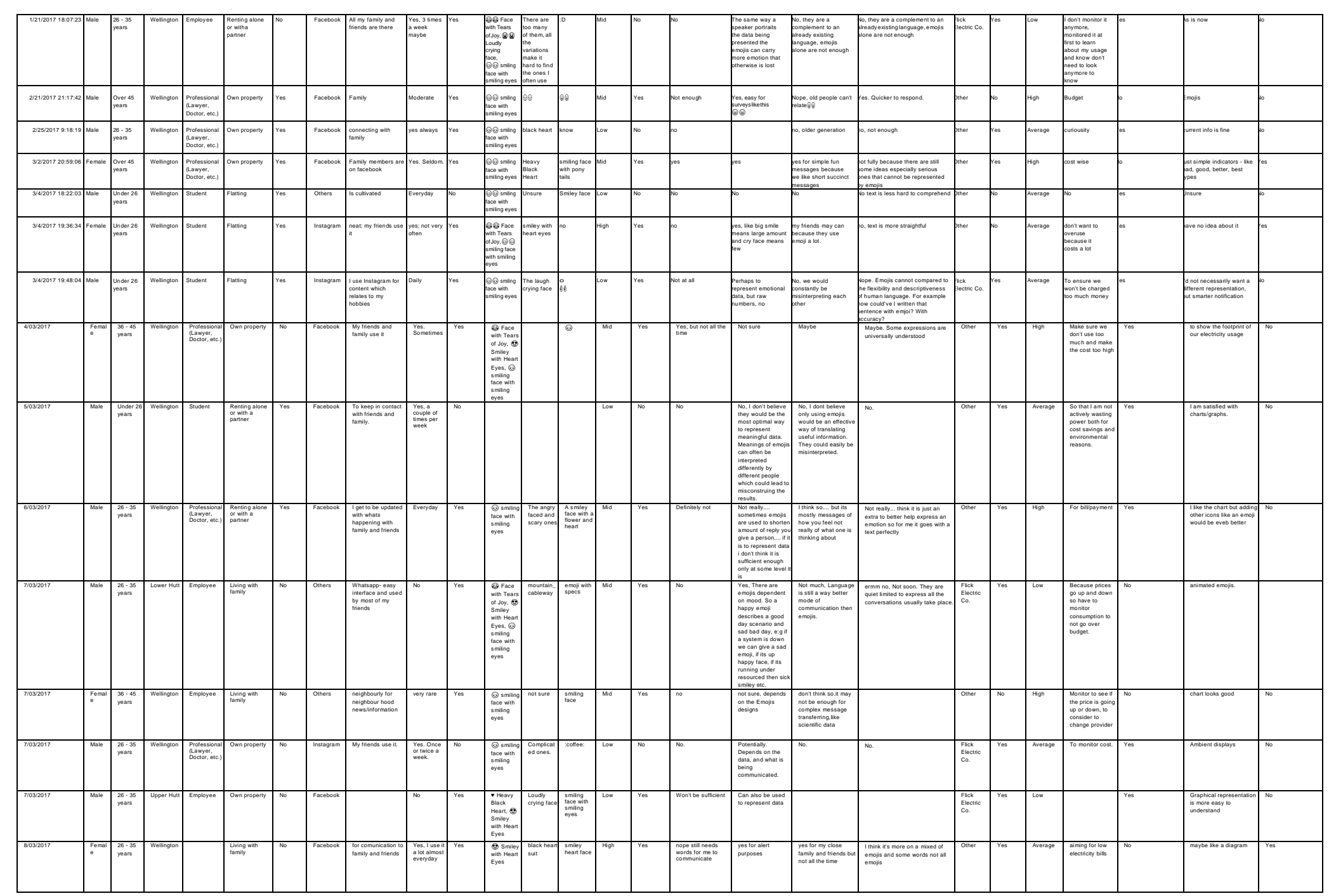




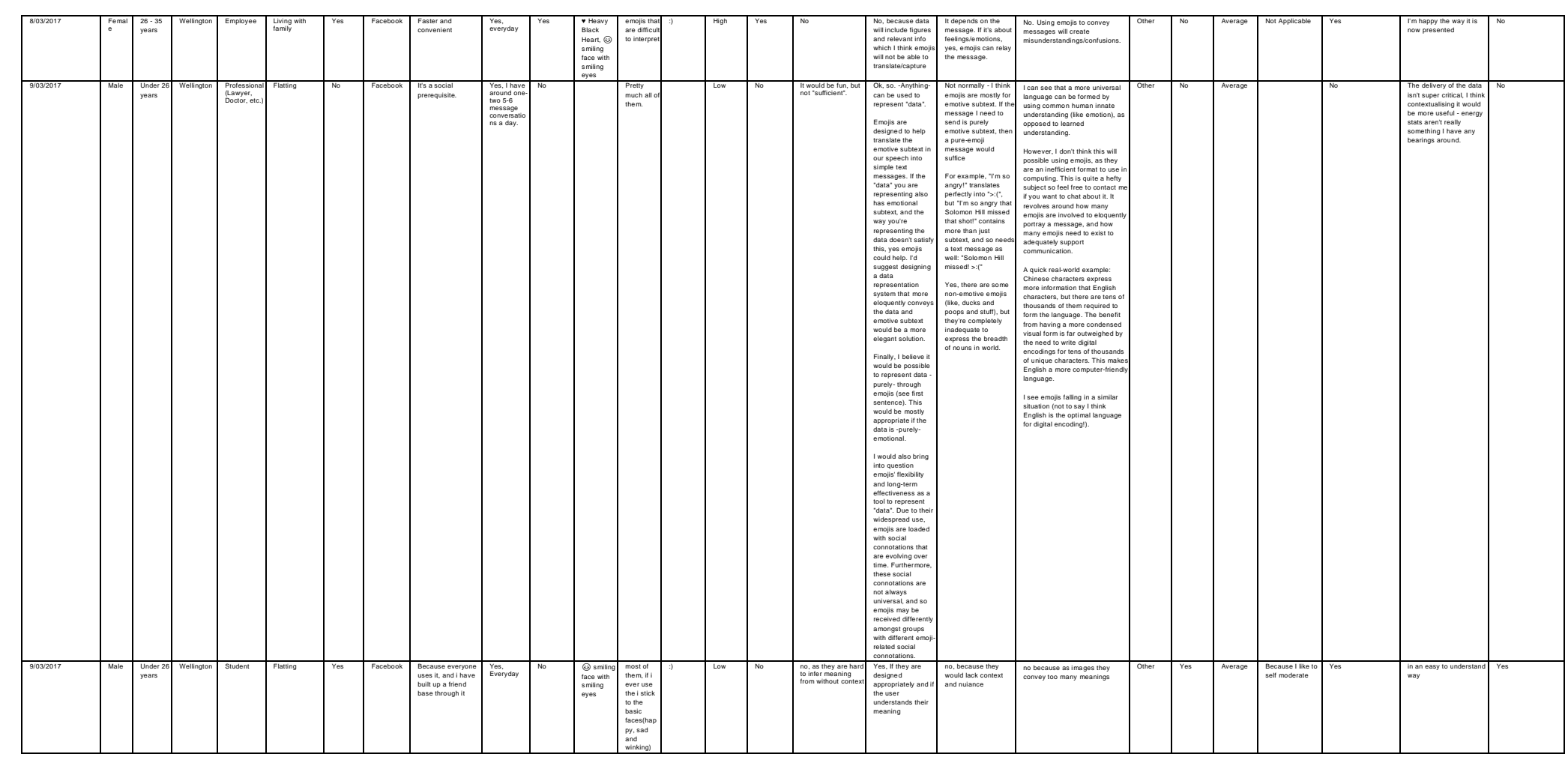




\section{Appendix D: Application Architecture and Technical References}

There are four main application components that work together to enable the chatbot to retrieve the meter reads and spot market prices. Each application component is described below:

Facebook Messenger Application - The user interface made available to the research participants.

DialogFlow Artificial Intelligence Service - The cloud hosted Artificial Intelligence (Al) service that provides human like responses to the messages coming from the user interface.

Node.js Application - The backend application that packages the data sent by the Al service to the Meter Data API and processes the data coming back from the same API. The backend application is hosted on Heroku.

MeterData API - The commercial web API provided by the Meter Equipment Provider to retrieve stored half hourly meter reads.

The application architecture is modelled as follows:

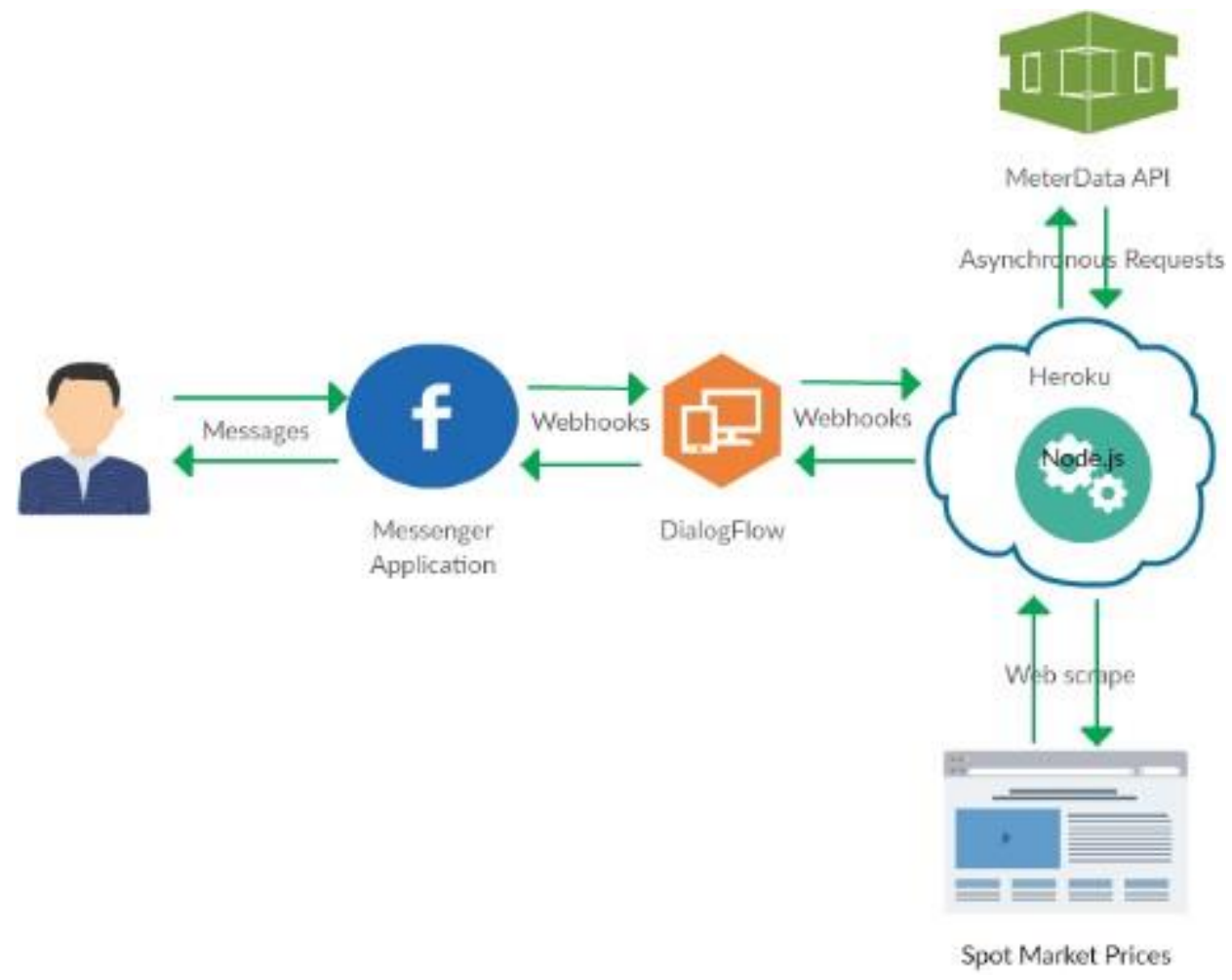

\section{Application build references and artefacts:}

Guide for creating a chatbot: https://dialogflow.com/docs/integrations/facebook

DialogFlow chatbot project: https://1drv.ms/u/s!AhUxHtn2CfQtxS5Gcf GqKGI4xh

Guide for hosting on Heroku: https://devcenter.heroku.com/categories/nodejs-support

Node.js project source code: https://github.com/alr888/mddm emoji research 
Note: In the DialogFlow project, the intents used for meter reading are in the red square, while the spot market price intent is in the green square.

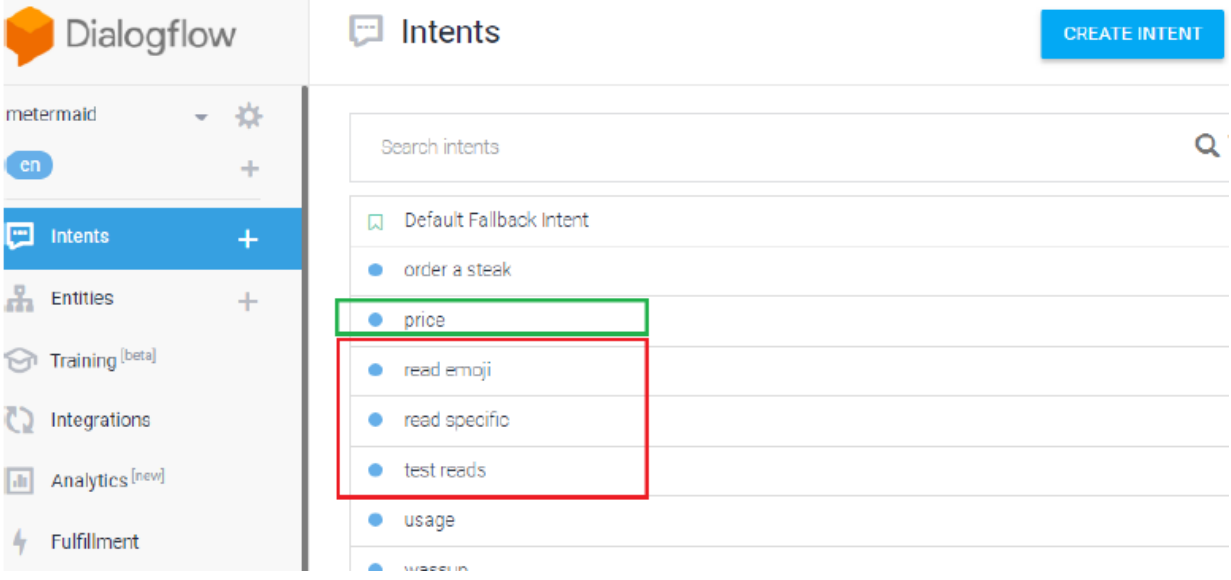

\section{Meter Data API - End User Documentation}

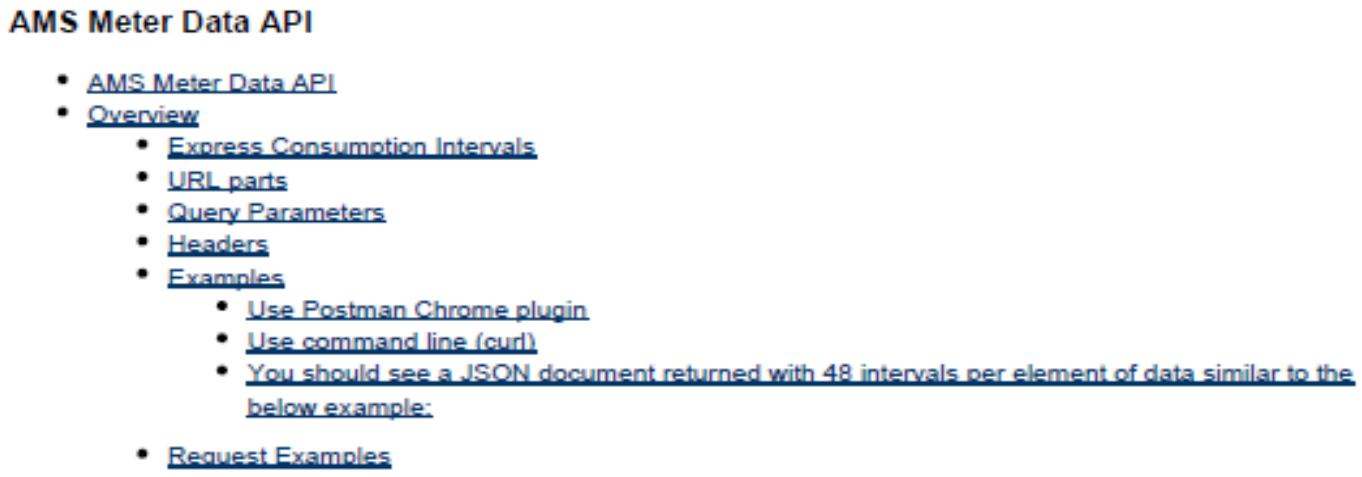

\section{Overview}

AMS has a Meter Data Service to provide fast and early access to Meter Data to meet a variety of use cases. This Meter Service is known as the Meter Data API

The AMS Meter Data API is intended to provide fast, scalable and secure access to Meter data for:

- Display in web and mobile applications

- Ad-hoc data transfers

- Regular small scale data transfers

- On demand viewing of latest data

The API is keyed on ICP.

Express Consumption Intervals

This is interval (30 minute) consumption data from the meter(s) at an ICP.

- Requests a single day or a date range, even several years is fine.

- Consumption data for a given day will generally be available for consumption by a client the day after the meter has recorded the information, likely in the morning.

- Reconciliation data quality processes have not been performed on this data. 
URL parts

\begin{tabular}{|l|l|l|}
\hline Name & Notes & Example \\
\hline user-type & A user type, can be & \\
& - retailer & \\
\hline - distributor & agent & \\
\hline
\end{tabular}

\begin{tabular}{|c|c|c|}
\hline user-id & $\begin{array}{l}\text { A user identifier. For Retailer or } \\
\text { Distributor this is the } 4 \text { letter code. } \\
\text { For a 3rd Party this is what ever } \\
\text { was assigned. }\end{array}$ & $\begin{array}{l}\text { GENE } \\
\text { UNET } \\
\text { VECT }\end{array}$ \\
\hline ICP & $\begin{array}{l}\text { An ICP to request data for } \\
\text { Must be hyphenated }\end{array}$ & $0006799558 \mathrm{RN}-\mathrm{B} 12$ \\
\hline start-date & $\begin{array}{l}\text { - The start date is inclusive. } \\
\text { - Data returned for intervals after } \\
\text { the start (00:00:00 NZST/NZDT) } \\
\text { of the day specified } \\
\text { - AMS meters use NZ time. }\end{array}$ & 20130227 \\
\hline end-date & $\begin{array}{l}\text { - The end date is inclusive } \\
\text { - Data returned for intervals before } \\
\text { (midnight NZST/NZDT) of the day } \\
\text { specified } \\
\text { - To request a single day the start- } \\
\text { date and end-date should be the } \\
\text { same and will return } 48 \times 30 \text { min } \\
\text { intervals }\end{array}$ & \\
\hline
\end{tabular}

\section{Query Parameters}

\begin{tabular}{|l|l|l|}
\hline Name & Notes & Example \\
\hline format & $\begin{array}{l}\text { Optional: Format can be one of } \\
\text { json, csv }\end{array}$ & \\
\hline tz & $\begin{array}{l}\text { Mandatory: The only tz allowed } \\
\text { currently is Pacific/Auckland }\end{array}$ & \\
\hline
\end{tabular}

Headers

\begin{tabular}{|l|l|l|}
\hline Name & Notes & Example \\
\hline Authorization & $\begin{array}{l}\text { Mandatory: The API uses basic } \\
\text { authentication over https only }\end{array}$ & $\begin{array}{l}\text { Authorization: Basic } \\
\text { YkxDGzpmMIZpJm1TMVL5 }\end{array}$ \\
\hline
\end{tabular}

Accept
Format can be specified through headers or the format option

The Accept header takes precedence over the format option
Accept:application/json

Accept:text/csv 
12. Appendix E: User Guides and Instructions First Version - Text Only

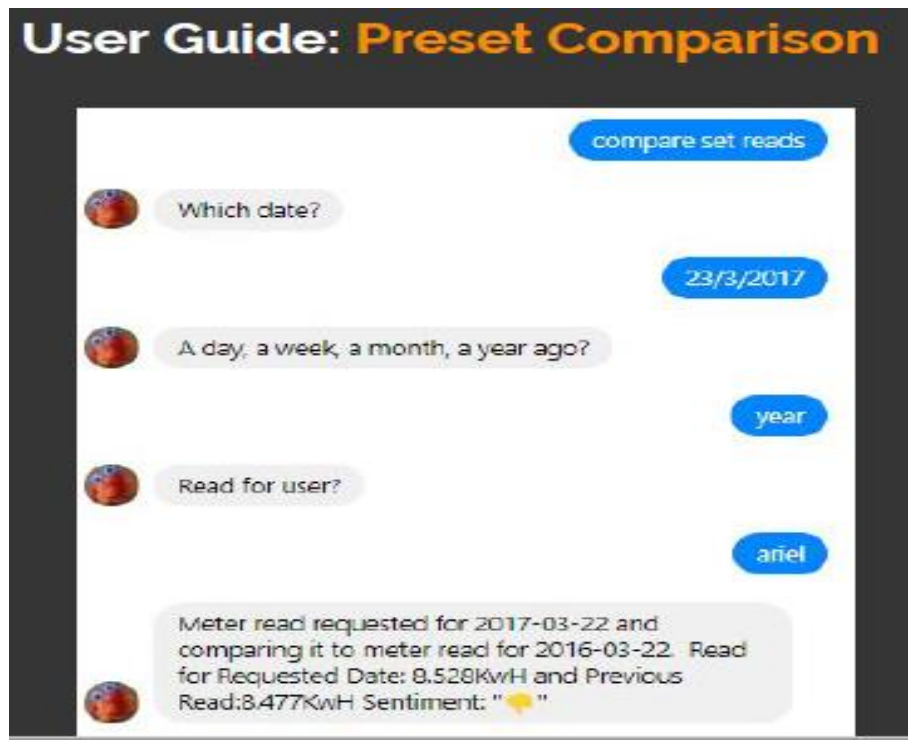

\section{User Guide: Arbitrary Comparison}

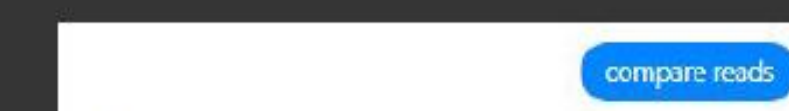

For which date?

Compare with which date?

For user? 


\section{Second Version - Text and Emoji}

[F.

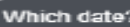

स्:

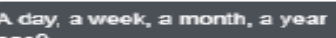

ago?

[F.

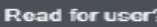

중

Meter read requested for $2017-10-$
o4 and comparing it to meter read
for $2017-09-27$. Read for
Roquostod Dato: $12.387 \mathrm{KwH}$ and
Previous Read:19.331Kw/H
Sentiment:

Third Version - Emoji Only

Here is the final design experiment wherein interaction with the bot will be purely emoji based. Definition is as follows:

Request for reads:

Start date either today: 0 or yesterday:

Compared with date range day: 4 , week: 8 , month: year: 17 ,

User IDs (names withheld): it ac ey

\section{Guides for Requesting the Spot Market Price}

How can I help?

Spot Market Price as of 2017-09-02 ..- New Zealand:

$7.2131 \mathrm{c} / \mathrm{kWh}$, Upper North Island: $7.26 \mathrm{c} / \mathrm{kWh}$, Lower

North island : $7.1088 \mathrm{c} / \mathrm{kWh}$, South Island: 7.1918

(1) $\mathrm{ckWh}$

Hi Team,

The spot price market utility is now working again.

You can still request for the spot market price using text (inputting "price" as the intent and "price" as the info requested).

Or using emoji by using $\$$ (high voltage as intent) and 8 (flying dollars as the info request).

Cheers,

Ariel 
13. Appendix F: Situational Survey Questions and Results

\begin{tabular}{|c|c|c|c|c|c|c|c|c|c|c|c|c|c|c|c|}
\hline imestamp & Address? & Occupation? & Household size? & $\begin{array}{l}\text { How many housenold } \\
\text { members stay at home } \\
\text { during the day? }\end{array}$ & $\begin{array}{l}\text { Is your home } \\
\text { fully insulated? }\end{array}$ & $\begin{array}{l}\text { What method of } \\
\text { haeating, ventlation } \\
\text { and coling do you } \\
\text { have athome? you }\end{array}$ & 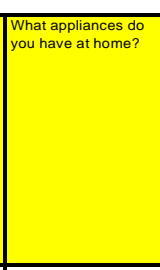 & $\begin{array}{l}\text { How offen do you use } \\
\text { these a papiances and } \\
\text { tor how long? }\end{array}$ & $\begin{array}{l}\text { What appliances or } \\
\text { devices do you have } \\
\text { that are always ove } \\
\text { standby? }\end{array}$ & 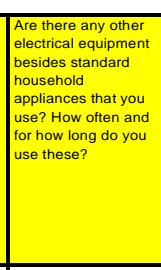 & 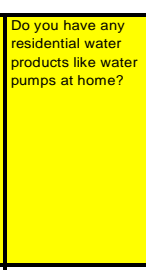 & \begin{tabular}{|l|}
$\begin{array}{l}\text { an you provide an } \\
\text { estimate of how long } \\
\text { housenold members } \\
\text { stay at home? }\end{array}$ \\
\end{tabular} & 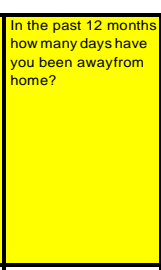 & 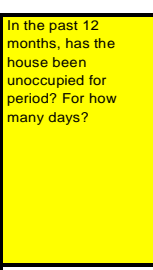 & 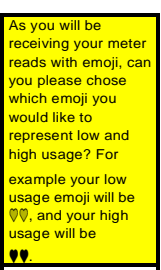 \\
\hline 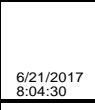 & \begin{tabular}{|l|l|l|l} 
Wellington \\
\end{tabular} & IT & & & Yres & Heat pump & 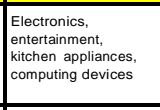 & everyday $4.6 \mathrm{hrs}$ & $\begin{array}{l}\text { Eniterainmont, } \\
\text { kitchen appliances }\end{array}$ & no & yes & $8.12 \mathrm{hrs}$ & 4 weeks & 4 weeks & 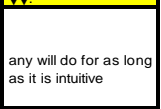 \\
\hline 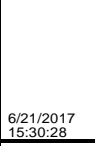 & 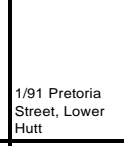 & IT Engineer & & & Noo & Electricity & 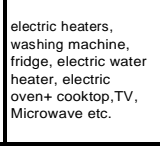 & \begin{tabular}{l|} 
everyday, some run \\
all day long and \\
some for thus and \\
some nunder 1 hour or \\
so.
\end{tabular} & $\begin{array}{l}\text { Tr, Washing } \\
\text { machine, milorowave, } \\
\text { water heater }\end{array}$ & 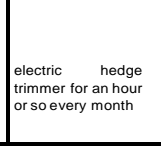 & no & all day & around 40 days & around 40 days & 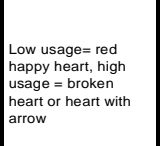 \\
\hline 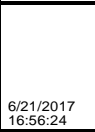 & $\begin{array}{l}\text { 2/135 Austin St, } \\
\text { atv Vitis } \\
\text { wellington }\end{array}$ & 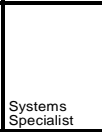 & & & No & Electric oil heaters & 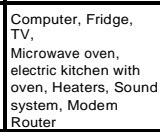 & $\begin{array}{l}\begin{array}{l}\text { All hin time rm at } \\
\text { home }\end{array} \\
\text { he }\end{array}$ & $\begin{array}{l}\text { TV, Microwave oven, } \\
\text { Computer, Sound } \\
\text { system, Modem } \\
\text { Router }\end{array}$ & $\begin{array}{l}\text { Tablet and S Smatrt } \\
\text { phono, } 2 \text { hours }\end{array}$ & Hot Water Cylinder & & 2 months & 2 months not in a row & $\begin{array}{l}\text { Im nappy with hie } \\
\text { suggestions }\end{array}$ \\
\hline 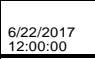 & 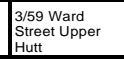 & 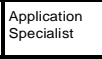 & 2 bedroom house & & Yres & Gas Heater, HAV & 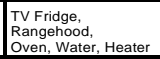 & Everyday & Water Heater Fridge & \begin{tabular}{|l} 
Lawn Mover every \\
fortnight
\end{tabular} & No & 24 hours & 2 months & Around 2 months & 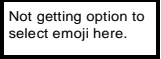 \\
\hline 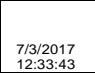 & 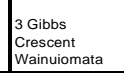 & $\begin{array}{l}\text { Product } \\
\text { Oonner }\end{array}$ & $\begin{array}{l}\text { 2Aumans, } 3 \\
\text { Antimals }\end{array}$ & 3 Animals & No & $\begin{array}{l}\text { Heat ump and } \\
\text { eco panel heater }\end{array}$ & 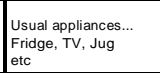 & 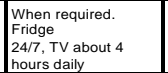 & TV, Fridge & na & naa & 8 hrs & $\begin{array}{l}\text { Work days someme } \\
\text { weeknend days }\end{array}$ & na & $\$ \$ 9 Q$ \\
\hline $\begin{array}{l}712012017 \\
20.0406\end{array}$ & 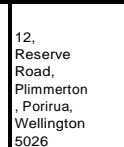 & Administrator & & $\begin{array}{l}1 \text { person some days. (20\% } \\
\text { of the time) }\end{array}$ & No & $\begin{array}{l}\text { Heat pumpssitr } \\
\text { Conddionin plus } \\
\text { wood burner }\end{array}$ & 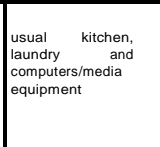 & $\mid \begin{array}{l}\text { every day } 2-3 \text { hours } \\
\text { per day }\end{array}$ & $\begin{array}{l}\text { tv, microwave, oven, } \\
\text { computers }\end{array}$ & 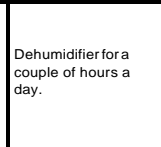 & no & 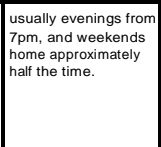 & & 14 days & \begin{tabular}{|l} 
low usage = smiley \\
tace emoji, high \\
unsage e scream \\
emoji
\end{tabular} \\
\hline $\begin{array}{l}\text { 10:16:2017 } \\
\text { 8:13:37 }\end{array}$ & $\begin{array}{l}2 \text { Stramird } \\
\text { (riove, Avalon }\end{array}$ & $\begin{array}{l}\text { Sesvive } \\
\text { Deilivery } \\
\text { Manager }\end{array}$ & & & No & \begin{tabular}{|l|} 
Gas radiato central \\
neating
\end{tabular} & 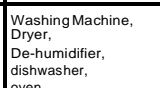 & $\mid \begin{array}{l}\text { Every day, } 1 \text { hour or } \\
\text { longer }\end{array}$ & Laptop & Laptops ‘2, TV's ‘2 & Infinity hot & 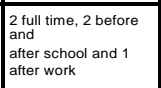 & 2 weeks & 7 days & \begin{tabular}{|l} 
example looks \\
perfect
\end{tabular} \\
\hline
\end{tabular}


14. Appendix G: Chatbot Interactions

Participant A

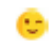

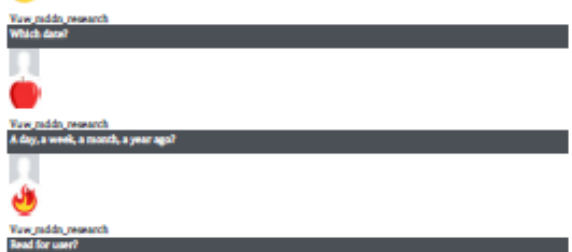

Fimatuman

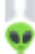

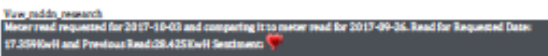

10

;

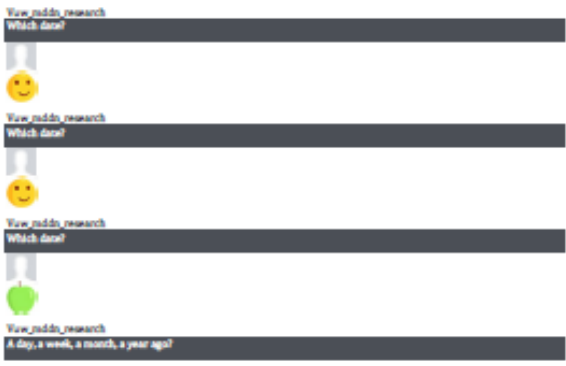

Participant A

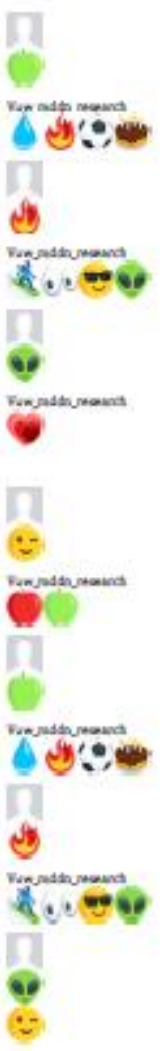

Participant A

$\therefore$

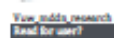

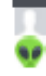

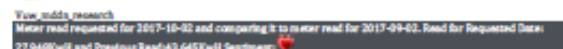

증

$\because$

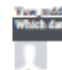

C.

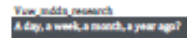

(i)

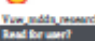

8

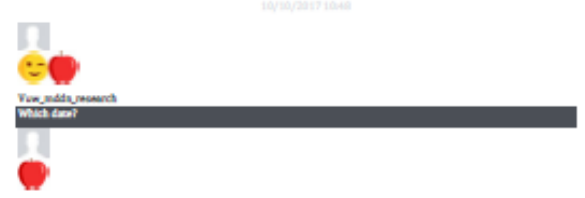

Participant A

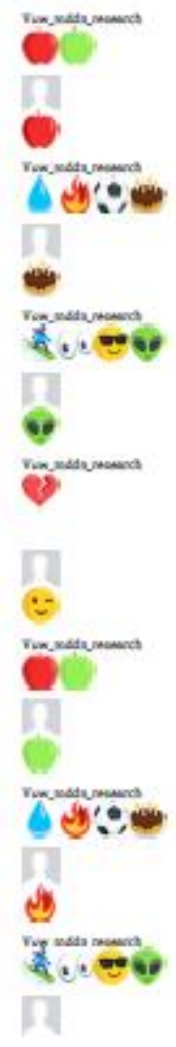




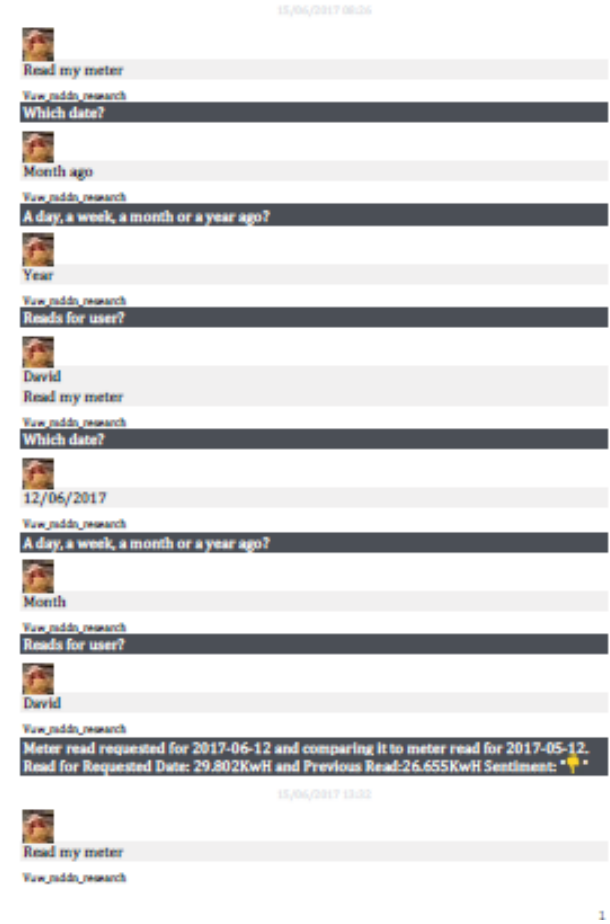

Participant B

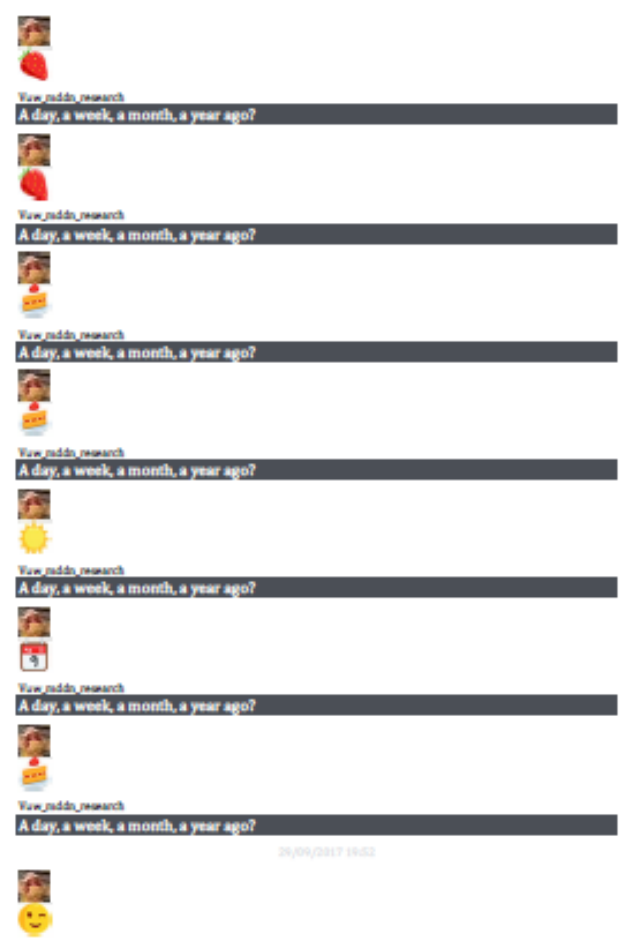

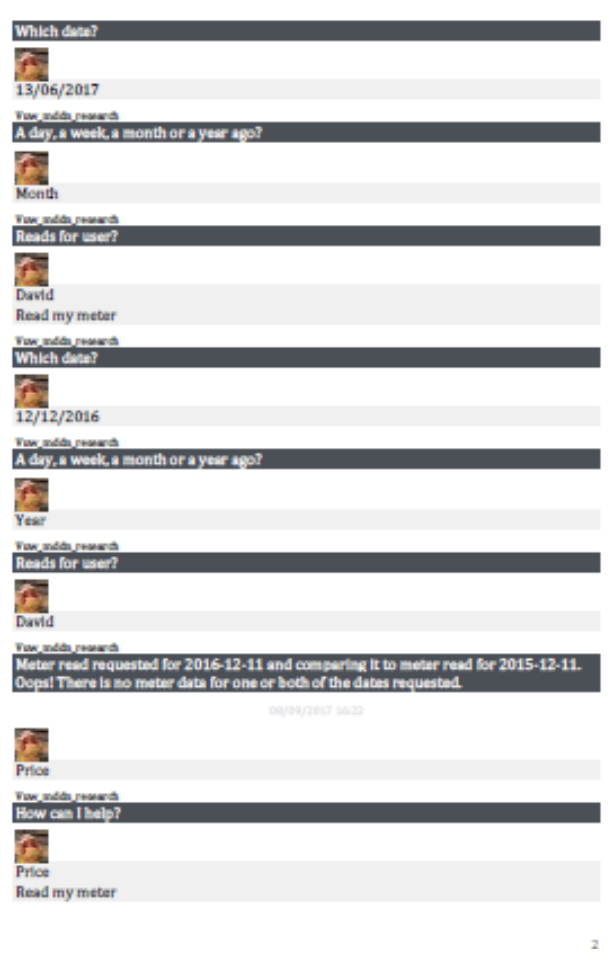

Participant B

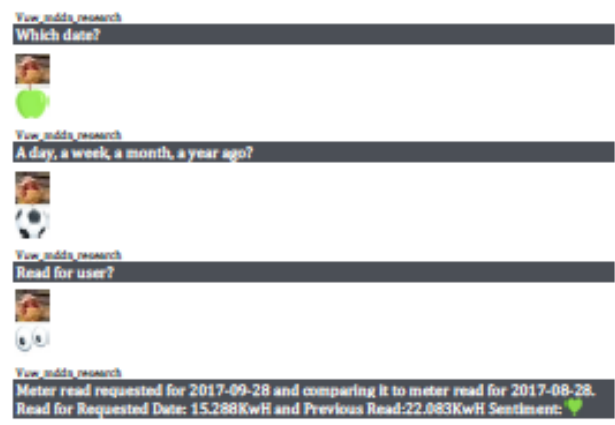

A

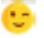

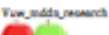

C

a

(1)

$00 \%$

E

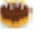

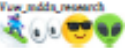

a

4. 

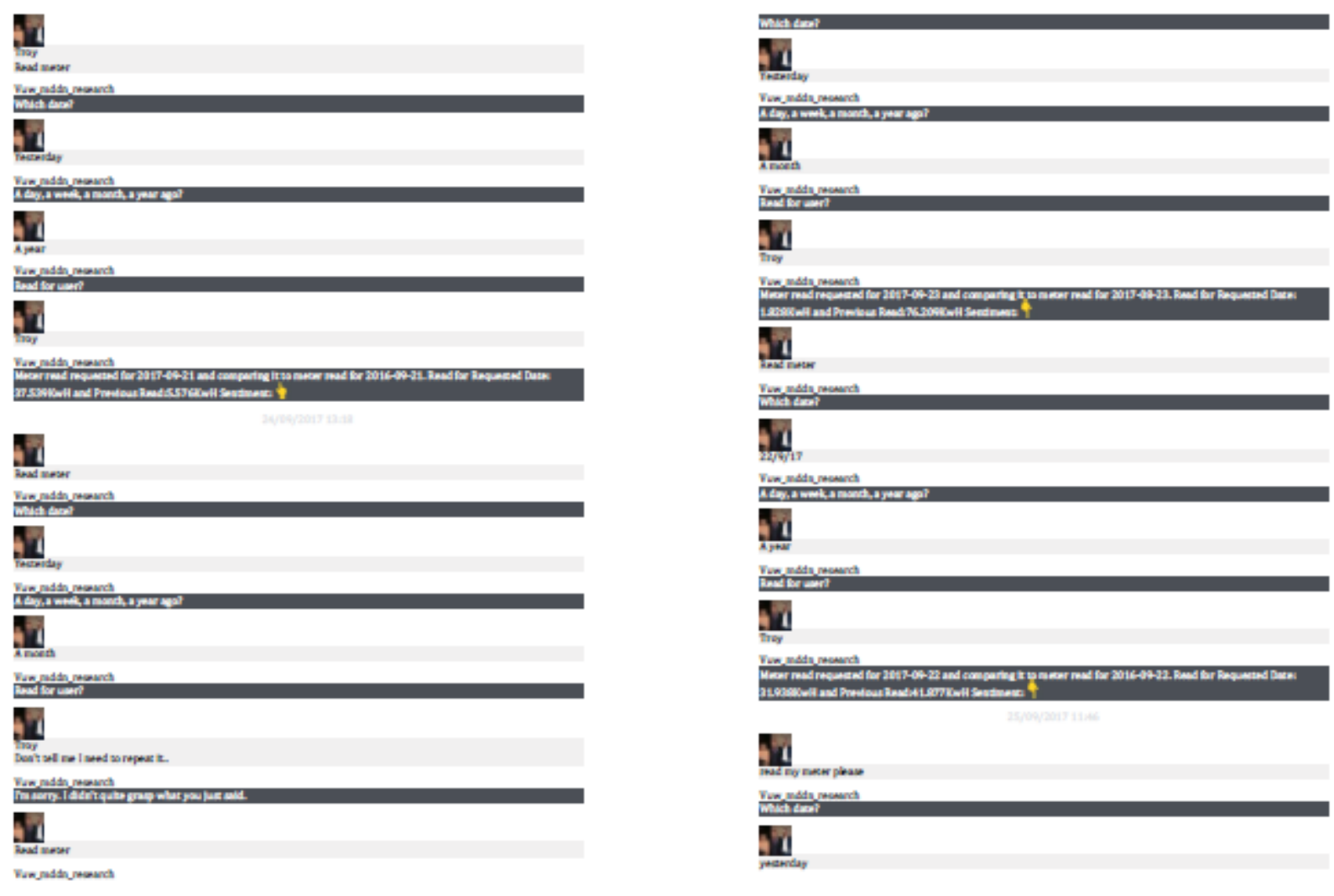

II Vinendengouna

II

Participant C

Participant C

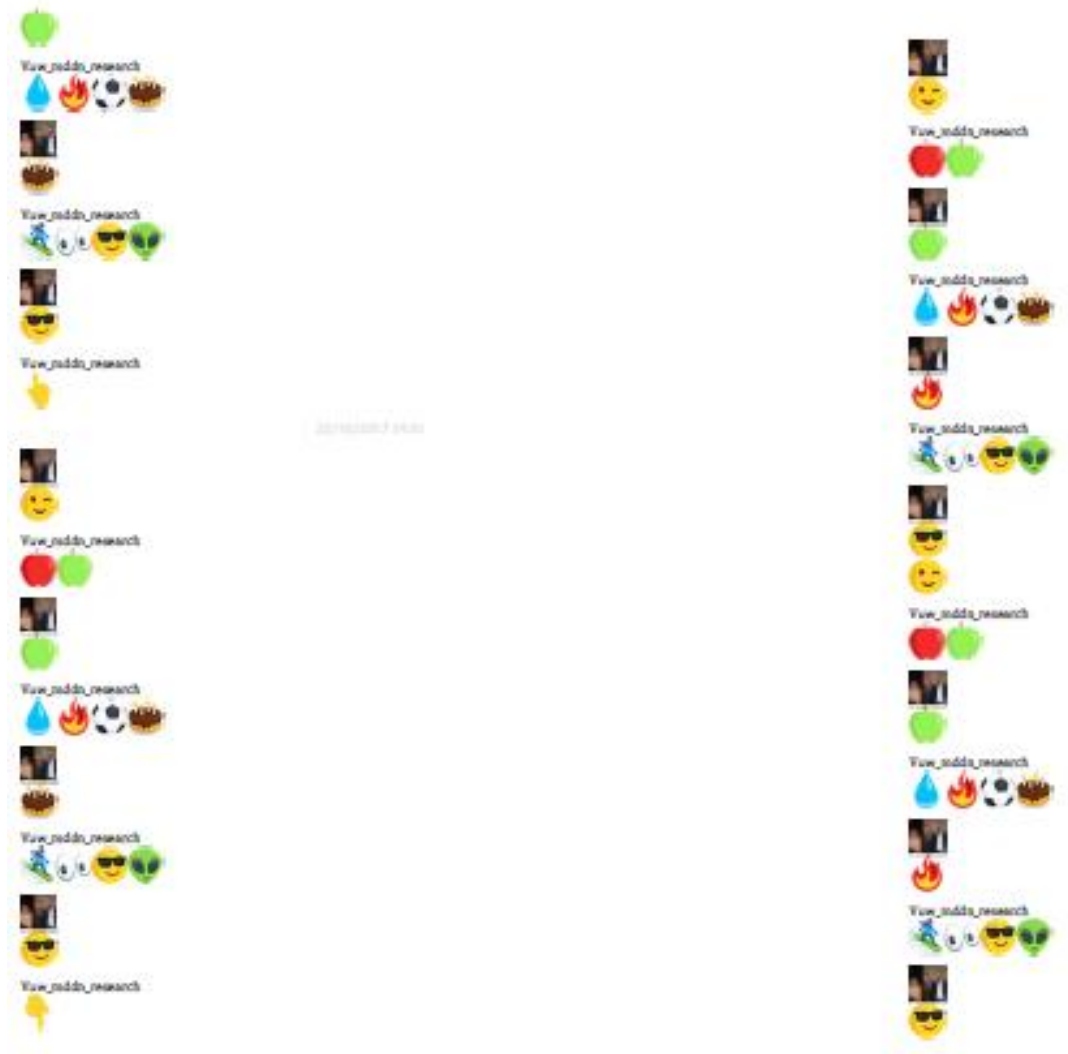




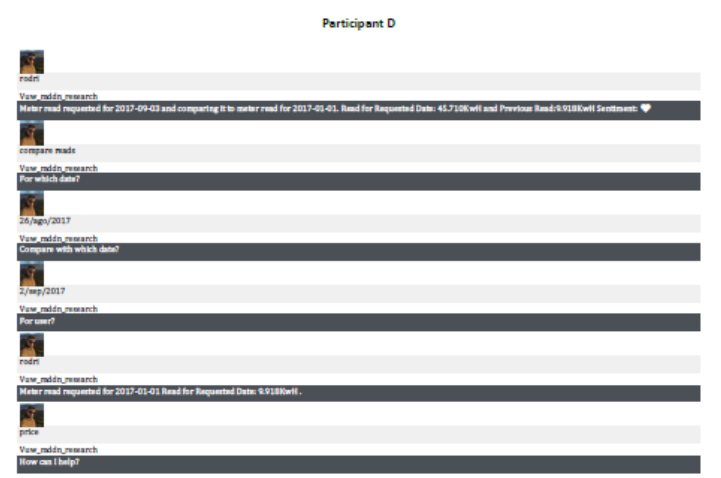

Participant D
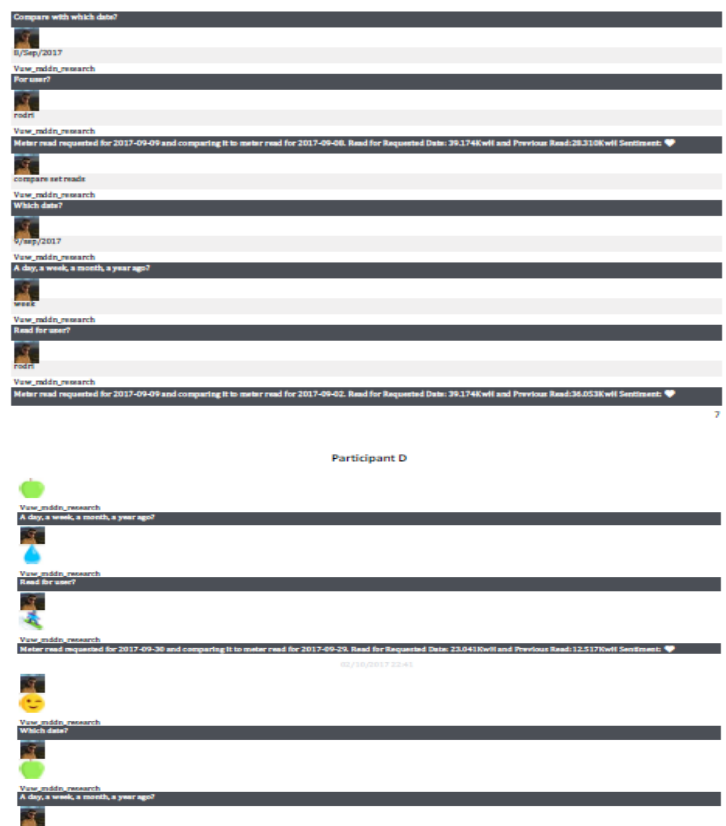

Fin
国

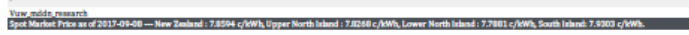

国

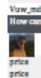

西

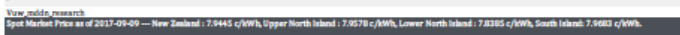

A.

(n)

Fin
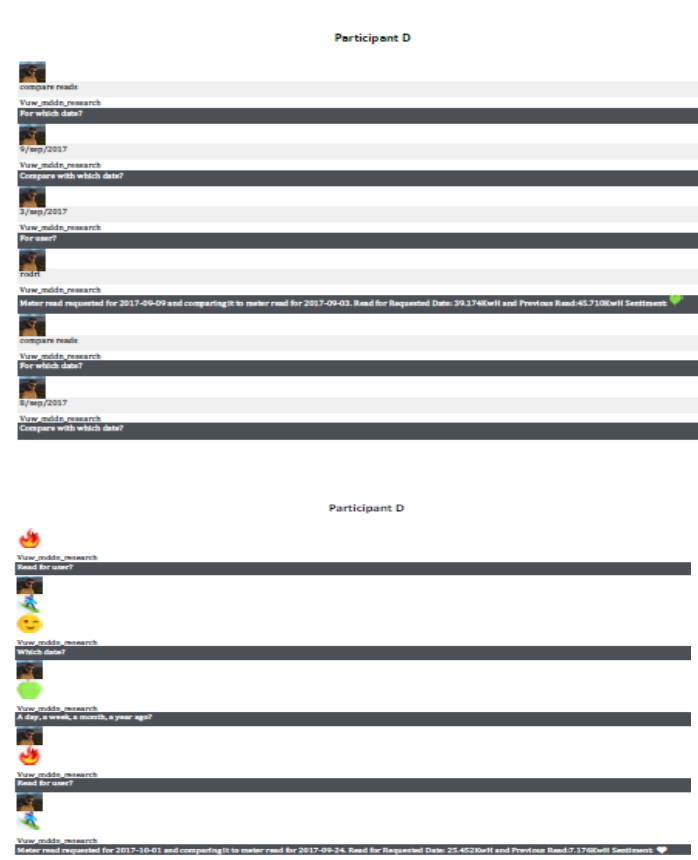

Porticipant $D$

Participant D
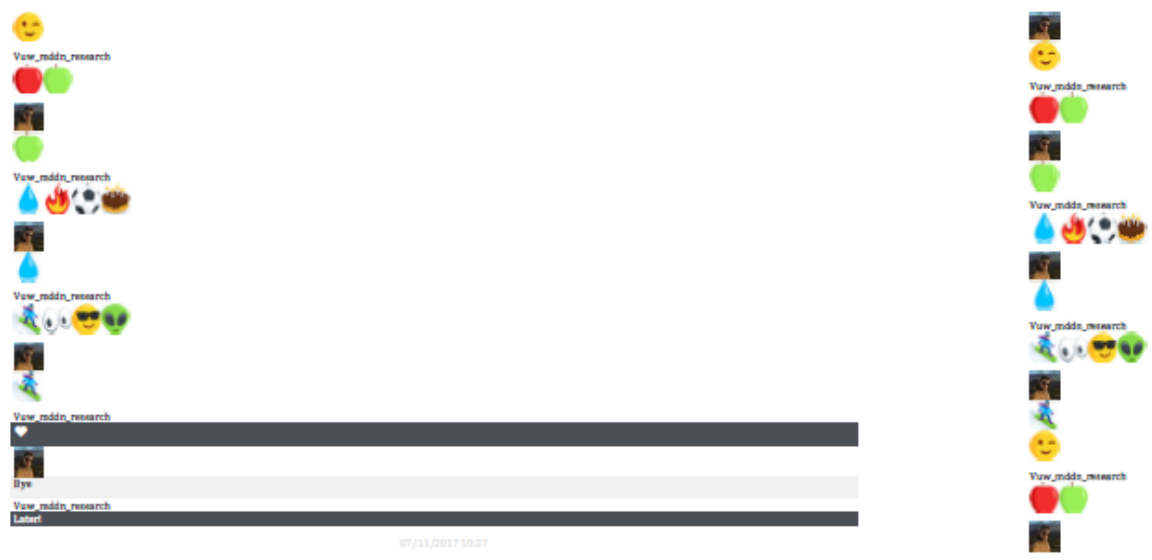

Note: All messaging bot interactions can be retrieved from: https://1drv.ms/b/s!AhUxHtn2CfQtxS9UD-

$6 \mathrm{~s} 7 \mathrm{fb} 6 \mathrm{qz} 5 \mathrm{~g}$ 
15. Appendix H: Comparison of Participants Daily Cumulative Reads

\begin{tabular}{|l|r|r|}
\hline \multicolumn{3}{|c|}{ Participant A } \\
\hline Date & 2016 & 2017 \\
\hline 9-Sep & 28.932 & 40.846 \\
\hline 10-Sep & 30.693 & 47.202 \\
\hline 11-Sep & 39.116 & 46.261 \\
\hline 12-Sep & 20.334 & 41.347 \\
\hline 13-Sep & 27.196 & 28.47 \\
\hline 14-Sep & 15.41 & 28.544 \\
\hline 15-Sep & 17.271 & 29.097 \\
\hline 16-Sep & 18.946 & 31.681 \\
\hline 17-Sep & 16.837 & 38.692 \\
\hline 18-Sep & 30.08 & 30.32 \\
\hline 19-Sep & 17.601 & 33.581 \\
\hline 20-Sep & 25.335 & 28.277 \\
\hline 21-Sep & 1.192 & 2.447 \\
\hline 22-Sep & 21.851 & 35.038 \\
\hline 23-Sep & 23.385 & 28.017 \\
\hline 24-Sep & 14.092 & 23.33 \\
\hline 25-Sep & 26.161 & 25.709 \\
\hline 26-Sep & 27.098 & 28.425 \\
\hline 27-Sep & 18.124 & 24.749 \\
\hline 28-Sep & 24.325 & 32.335 \\
\hline 29-Sep & 20.445 & 31.978 \\
\hline 30-Sep & 12.877 & 23.856 \\
\hline 1-Oct & 18.104 & 28.732 \\
\hline 2-Oct & 26.054 & 27.948 \\
\hline 3-Oct & 10.518 & 17.359 \\
\hline 4-Oct & 24.847 & 24.42 \\
\hline 5-Oct & 15.229 & 16.111 \\
\hline 6-Oct & 18.499 & 24.899 \\
\hline 7-Oct & 21.591 & 25.118 \\
\hline 8-Oct & 24.315 & 22.112 \\
\hline 9-Oct & 17.007 & 20.784 \\
\hline Total & 653.465 & 887.685 \\
\hline & & \\
\hline
\end{tabular}

\begin{tabular}{|l|r|r|}
\hline \multicolumn{3}{|c|}{ Participant B } \\
\hline Date & 2016 & 2017 \\
\hline 9-Sep & 18.283 & 9.399 \\
\hline 10-Sep & 16.431 & 20.537 \\
\hline 11-Sep & 18.057 & 22.833 \\
\hline 12-Sep & 12.967 & 18.316 \\
\hline 13-Sep & 16.564 & 14.822 \\
\hline 14-Sep & 18.083 & 16.487 \\
\hline 15-Sep & 14.863 & 29.599 \\
\hline 16-Sep & 18.417 & 21.261 \\
\hline 17-Sep & 21.906 & 28.325 \\
\hline 18-Sep & 17.701 & 20.963 \\
\hline 19-Sep & 22.279 & 35.963 \\
\hline 20-Sep & 16.203 & 23.64 \\
\hline 21-Sep & 0.234 & 0.608 \\
\hline 22-Sep & 13.855 & 28.673 \\
\hline 23-Sep & 17.585 & 26.046 \\
\hline 24-Sep & 21.603 & 20.555 \\
\hline 25-Sep & 16.015 & 15.441 \\
\hline 26-Sep & 20.516 & 21.546 \\
\hline 27-Sep & 20.58 & 18.112 \\
\hline 28-Sep & 14.215 & 15.288 \\
\hline 29-Sep & 15.429 & 19.009 \\
\hline 30-Sep & 13.576 & 20.498 \\
\hline 1-Oct & 17.359 & 14.238 \\
\hline 2-Oct & 20.921 & 6.375 \\
\hline 3-Oct & 17.803 & 7.922 \\
\hline 4-Oct & 21.959 & 8.2 \\
\hline 5-Oct & 22.262 & 9.102 \\
\hline 6-Oct & 20.948 & 8.667 \\
\hline 7-Oct & 15.47 & 7.784 \\
\hline 8-Oct & 20.875 & 7.113 \\
\hline 9-Oct & 27.67 & 16.601 \\
\hline Total & 550.629 & 533.923 \\
\hline & & \\
\hline
\end{tabular}

\begin{tabular}{|l|r|r|}
\hline \multicolumn{3}{|c|}{ Participant C } \\
\hline Date & 2016 & 2017 \\
\hline 9-Sep & 73.799 & 27.367 \\
\hline 10-Sep & 56.691 & 34.699 \\
\hline 11-Sep & 49.469 & 50.808 \\
\hline 12-Sep & 47.199 & 36.345 \\
\hline 13-Sep & 45.929 & 33.8 \\
\hline 14-Sep & 33.311 & 22.782 \\
\hline 15-Sep & 29.305 & 23.43 \\
\hline 16-Sep & 25.518 & 37.952 \\
\hline 17-Sepp & 18.072 & 52.373 \\
\hline 18-Sep & 47.308 & 31.457 \\
\hline 19-Sep & 43.872 & 38.501 \\
\hline 20-Sep & 56.371 & 30.829 \\
\hline 21-Sep & 5.576 & 3.219 \\
\hline 22-Sepp & 41.877 & 30.548 \\
\hline 23-Sep & 6.57 & 1.828 \\
\hline & & \\
\hline 25-Sep & 46.638 & 26.078 \\
\hline 26-Sep & 39.054 & 28.013 \\
\hline 27-Sepp & 24.906 & 17.326 \\
\hline 28-Sep & 22.618 & 29.372 \\
\hline 29-Sep & 27.936 & 30.08 \\
\hline 30-Sep & 25.285 & 23.963 \\
\hline 1-Oct & 30.962 & 35.338 \\
\hline 2-Oct & 26.274 & 26.316 \\
\hline 3-Oct & 12.142 & 18.026 \\
\hline 4-Oct & 17.135 & 14.623 \\
\hline 5-Oct & 19.958 & 22.477 \\
\hline 6-Oct & 24.344 & 25.722 \\
\hline 7-Oct & 34.511 & 44.355 \\
\hline 8-Oct & 44.467 & 28.985 \\
\hline 9-Oct & 29.174 & 15.903 \\
\hline Total & 3022.271 & 2859.515 \\
\hline & & \\
\hline
\end{tabular}

\begin{tabular}{|l|r|r|}
\hline \multicolumn{3}{|c|}{ Participant D } \\
\hline Date & 2016 & 2017 \\
\hline 9-Sep & 22.194 & 39.174 \\
\hline 10-Sep & 5.28 & 24.551 \\
\hline 11-Sep & 7.287 & 18.055 \\
\hline 12-Sep & 35.764 & 28.914 \\
\hline 13-Sep & 27.294 & 24.889 \\
\hline 14-Sepp & 26.976 & 32.186 \\
\hline 15-Sep & 14.466 & 12.182 \\
\hline 16-Sep & 20.946 & 4.259 \\
\hline 17-Sep & 17.389 & 8.16 \\
\hline 18-Sep & 23.944 & 33.589 \\
\hline 19-Sepp & 26.744 & 29.669 \\
\hline 20-Sep & 27.047 & 22.602 \\
\hline 21-Sepp & 1.955 & 1.816 \\
\hline 22-Sep & 25.882 & 10.643 \\
\hline 23-Sep & 26.975 & 4.912 \\
\hline 24-Sep & 27.22 & 7.176 \\
\hline 25-Sep & 32.595 & 19.828 \\
\hline 26-Sepp & 25.896 & 27.345 \\
\hline 27-Sep & 23.128 & 19.331 \\
\hline 28-Sep & 18.726 & 22.515 \\
\hline 29-Sep & 19.112 & 12.517 \\
\hline 30-Sep & 17.961 & 23.041 \\
\hline 1-Oct & 4.078 & 25.452 \\
\hline 2-Oct & 12.552 & 14.569 \\
\hline 3-Oct & 22.598 & 17.838 \\
\hline 4-Oct & 20.374 & 12.387 \\
\hline 5-Oct & 24.997 & 17.696 \\
\hline 6-Oct & 16.238 & 21.307 \\
\hline 7-Oct & 12.064 & 27.045 \\
\hline 8-Oct & 12.848 & 19.972 \\
\hline 9-Oct & 11.352 & 18.768 \\
\hline Total & 611.882 & 602.388 \\
\hline & & \\
\hline
\end{tabular}

Note: Missing reads are attributed to no collection for the day. 


\section{Appendix I: Focus Group Discussion Transcription}

Q: What were your general impression on using the bot to retrieve electricity consumption data? How did it feel...? Just your thoughts.

A: I don't know...I guess...the second phase...it felt like quicker and easier...because it was asking the same question...they go to your recently used box or whatever...more agile. It flows in a way that surprised me...I thought I was too old for this, I will not be using emojis...but I can see something there, like yeah, it could be useful. But uhm...yeah you have to remember that maybe...when bots reply back...

Q: To give everybody a reminder that it's all text-based, you have to type in you request, then we move to emoji inputs but the bot was also responding text-based and then the third iteration it was all emoji-based. So those are the three design iterations that we did.

A: I like the first one because it gave us what we needed to put in, so it's like prompting (inaudible) day, year and month. It requires no memory retention for doing anything. And then on the second one when it was uh emoji would text back, that was probably the one that I found easier (inaudible)...I don't know, I guess I just...I like to see the numbers...

A: (Indian)...it makes more sense...sometimes I could be just (inaudible)

A: I didn't realise what my numbers were until (inaudible)

Q: Did it make you more conscious about your consumption or in general being aware of your usage?

A: I might just compare it to the...it would be nice if there was something in there which would say, "this is $10 \%$ above the New Zealand average or this $95 \%$ of the New Zealand average."

Q: So there needs to be a comparator...

A: When I moved to Flick I already have the behaviour change where I knew the numbers and all... what's the latest on where you've got different appliances so...outside of all of that stuff, I don't think it changed a bit...I don't know, I should take a look (inaudible)...maybe I should send it to my wife.

Q: We have a month's worth of consumption data that we can compare with. I know not everybody's been religiously checking but we know that facility is available and I can see everybody requesting it from time to time.

A: You almost need to remind me to say hey do you want to know something about your behaviour? Get a prompt, you know?

Q: Let the bot trigger the conversation?

A: yeah...like would you like ti...average literally just have a two-weekly hey (inaudible)

A: ...change the behaviour, for my case the - alert (inaudible)

Q: It needs to have push notifications, so to speak, on your consumption.

A: It could send a message first right (inaudible) facebook chat basically. I'd get the message..

A: ...the last 5 days has been awful, what have you been doing?

Q: So what were the good and bad points using the 3 versions of the bot?

A: The first one had instructions and text only...that...that took away (inaudible) and...text response...(inaudible)

A: The second one was good because it saves me from typing everything else again so if I sort of type month...M-O-N-T-H...you kinda get tied up just typing my name into it so just...so... being able to tap the emoji button associated to it because you remember the emoji (inaudible)...uhm...made the second one real quick and stuff which is cool so it still got the benefits of the first one without the delays of having to re-type the information... whereas the third one is mostly illegible.

A: Yeah...the learning curve for that last one is (inaudible)

Q: Yeah...if you're just visual language...takes more effort.

A: The younger you are, the better you would be.

Q: They just communicate with emojis all the time.

A: It's another language...it's completely another language.

Q: Any other thoughts? Good and bad points?

A: The third one was difficult to learn because every time you might have to do some work to remember what that emoji meant.

Q: And then it wasn't as informative without the numbers. Just the emoji itself doesn't really have any emotional impact to you without the numbers.

A: And we're probably the worst audience for that because we all know metering and stuff...

Q: Yeah, true, true, true.

A: ...the number actually mean something to us...you know...if they're not meaningful for the general population...an emoji...you know up and down...(inaudible)

Q: Did you feel any emotions while using the bot? 'Cos that's what emojis are supposed to be, right? They're supposed to convey emotions.

A: Maybe the...because it was a conversation sometimes you feel compelled to say "hi,"..."goodbye." That kind of thing. Are you fucking kidding with me? (Laughter)

Q: Some frustrations talking to it.

A: (Inaudible comments) my emojis half the time, it pretty says I'm confused (laughter) 
A: Yeah sometimes when we get emoji like the heart, red heart, I know its I haven't spent that much then I felt, okay, happy. That was the only - emotional investment (inaudible).

Q: So there's a little emotional touches. And I guess that's the only way to convey a narrative...there's emotional connection that would make things more...your audience more attentive...that's the intention.

A: I kinda still see it as a computer...

$\mathrm{Q}$ : Yes, less person...it's still a machine.

A: This could be that the conversation could be the other way around, like ask the question, who is the person talking to the bot? So if it's me, they need to just ask me, would you like your usage compared to today's usage with...those options.

A: Or your friends or something...

A: Yup, and if I tell that I want this...

Q: So it's making the conversation more human-like, that it would initiate the conversation and even branch out, not just linear request for your usage...

A: Yeah, share with your friends...see theirs...that's something to think about...

Q: Did you apply any work-arounds or hacks that you had to get the bot to provide?

A: Well, in my case you had to do the whole query twice, everytime.

Q: The reason for that is because I'm using Heroku, an API.AI, it's all on AWS...it had to spin up the server each time if it's not used, so that's just a limitation....but that's the only hack that you had to apply?

A: So again I used the phone...predictive functionality, the bar on top which remembers the emojis because I don't use them when you're outside, you just log in and then you go one, two, three, four...and again one, two, three, four.

A: One other thing we can do is send all the emojis in one go and then it parse each individual emojis.

Q: So we just have to trigger one message with everything...it remembers what you use frequently.

A: I deactivate predictive text, like, a year ago and yeah man, it would have been useful for this.

Q: Ah...you disable this for...?

A: Yeah I took the foobar out or something yeah, yeah...

Q: So you always refer to the instructions...?

A: So I never did and, I mean, I didn't really know where to go with it...and that would be, probably (inaudible) with the use, 'cause, you know (inaudible)

Q: So, inputs...predictive texting and also the re-tries. So yeah, working in the energy sector, aside from providing electricity consumption data, in what other areas or ways do you see a conversation user interface or a bot can be used, where practical?

A: So it's, it's how frequent it's pulling data usage

Q: Whenever...only whenever you request it.

A: Oh okay...it would be useful to have maybe...so...half hourly (inaudible) but having something where it looks at your usage across the week and as you're getting toward the weekend it goes "hey your usage is a bit up at the moment, you might want to have a think about whether or not you left your towel rail on..." or you know, having something come through and prompt you when it goes above like that actual...hey just a heads up, thinking about just...it would be really useful to...okay so I might do anything about it (inaudible)...yeah, having it actually say something and go "oh your usage is down, paki paki."

A: Yeah, more like an assistant.

Q: So personalised assistant for your consumption?

A: Yeah (inaudible)

Q: It needs to have comparison with other friends and family or...

A: In that case yeah or you can use an average for your situation, like, I don't know... what bedroom or...

A: ...what did you turn on at 2:00?

A: Or just use your average for the last year right? Your power is up against what it was last year, you know, it's not gonna be (inaudible)...well your average for the week a year ago, you've gone above your average a year ago.

Q: But what Rodrigo pointed out, normally you don't recall what you did the previous year so you're mostly comparing what you did last week or last month, is that correct?

A: Yeah, that one I guess is more helpful as a summary like, during the cold corner, you're up or down you know but day, it's not that useful....yeah, you're spending much less than on the last year...I was on leave that day , I don't remember when was that...

A: ....with that data, like we could come up with averages...we could pick a street in a suburb and what appears on the map for a 3-bedroom or a 2-bedroom house or a 1-bedroom house and give seasonal pricing for a weekday and for a weekend usage.

A: .... 3-bedroom house in Karori uhm saves this consumer about this much on A Tuesday in winter...so you've gone above the Tuesday and then you just go, I live in a 3-bedroom house...I have a uhm...the date today and then, would you consider yourself a high or low power user...then set profiles right? Then once you got that profile you're always comparing against that profile.

A: We as a business could come up with that...

Q: That's the purpose of the situational interview survey that I sent out - how you're looking compared to wider New Zealand. But it shouldn't just be a one-off, it should be intuitive enough to give you your profile as you go...changing... A: ...tell you you're with the right reseller as well...since you've got a profile at home, you kinda wanna be prompted just, you know (inaudible)...flick energy....well you should switch 
A: ...those ones never pop up on the (inaudible) like flick or powershop (inaudible) then it's gonna be significantly cheaper but sorted's not gonna, or what's my number's not gonna figure out that you're a person that's gonna be that product...

A: But it would be good for them to suggest things you know...or if you were to say (inaudible)...this heater consumed so much power...it's an easy way to change your behaviour.

Q: It's cyclical - what you consume influences what your future consumption would be...like what you said, it will influence what you need to purchase, what you need to cut down on.

A: How many light bulbs have you got? I've got shitloads... maybe you should get some LEDs.

$\mathrm{Q}$ : One of the papers I'm looking at is the disaggregation, there's already an algorithm that's based on, this is only on a perminute recording of your consumption...you can potentially project which appliances are using more. But the problem we have in New Zealand is we only capture 30-minute intervals, we don't have that granularity so that algorithm doesn't really apply. Bigly (?) is doing it in Australia...the local company that gives information intelligence on consumption but they're not that big. That way you can record each appliance, how much they're using, 'cause even with the electric toothbrush, they'll show a sudden spike. We'll have a capture...this is my profile and changes in that because it's so granular it can really capture. Q: If this design experiment is extended to a larger group, what would your recommendations be?

A: You'd want to key inside of or have that, an emoji that works like a question mark emoji which gives you what each one needs (can't understand what they're saying here)...and if you full emoji, the ability to be able to request significant data, so whether I think you get like there's a green square and a red square emoji, it needs to have a key which tells you that a green square is 10 and a red square is 5 and it will give you your kwh in (inaudible)...400kwh you get 40 green squares, maybe something else...oh not yet...40 green square, the 4 green squares and that 100 ...comes to 100 emoji...(inaudible)....something to be able to put, like if you wanted to keep that you know, being emphatically emoji-fied, then using emojis to be able to give quantity.

A: (Inaudible)...yeah you've got that sort of cute little emoji thing that you've got and so ah you have to have a kind of...fully interactive and...

Q: 'Cause it can, API.Al can pick voice so it can tayke your...it's not perfect yet but it can receive voice requests.

$A$ : I reckon if you have another option to see how well that went on voice it would be very interesting (inaudible)

A: ...there's an emoji thing this morning about iphone $X$, stuff where you can record your face and it will do an emoji...or like that weird donkey sausage (???) on snapchat? Stuff that does shit like that...virtual...reacts to you.

Q: But going back to, it's just a representation of uh how you project or how you display and interpret consumption. If we want to stick to emojis, ah lexicon or a dictionary of what they mean.

A: I think publishing with the group, like getting that upfront, that would be quite cool 'cause then you would be able to...some comparative data against the...the rest of the group.

Q: So you mean, sharing where, the group will be ah...the group's consumption is compared?

A: ...you can see it ongoing, 'cause I don't think any of us had a problem with it.

A: That would really prompt you to action or, or...yeah I'm okay, I do nothing or maybe from the lowest I would feel super happy or if on the highest I would feel compelled to change something.

A: ...one creates competition and...real behaviour change...

Q: ...sort of dimifies (??? sounds like) the whole idea of monitoring consumption.

A: Yeah, remember the biggest reduction in power, people going on holiday yeah, unfair advantage...(lots of talking, end of recording).

Q: On the question...uhm...the bot has a utility right...for grabbing the spot market price. During the exercise, did you use it? What were your thoughts on that functionality?

A: I used a few times but ah because the rates are not for the specific area which I am already (inaudible) there weren't that helpful but it's always good to have something like that where we can just check and then uhm we can get back the results to see if like if I'm going to use a lot of electricity at this point of time, I could use that bot to check the prices. The only downside is those prices need to be specific uhm for all the specific areas.

Q: It should be more granular...

A: True

Q: What would your recommendation be for that functionality, will it...should be fed to you, pushed or should it be triggered on demand?

A: If it could be automatic, even the prices are high than the threshold then it would be great. But on demand is good too because yeah, on demand is fine to me.

Q: But it would be necessary, a requirement basically to have a threshold for your situation, your size of household.

Q: So ah, are you aware that there's a functionality for extracting spot market price through the bot?

A: Uh yeah I was aware but I don't really understand how to use it or the instructions (inaudible) yeah there was a spot price...I understood it when you could pass it, I think you could actually go to direct instructions on uh, couple of weeks back...uhm...yeah that's something that would really be useful. Actually I just forgot how to use it when it came to using the emojis and stuff, back when you can type in a thing I think...that worked fine for me.

$\mathrm{Q}$ : In the context of making it available to the end user, do you think there's some use for it?

A: Uhm...I think so, I think you'd have to be pretty uhm...or you'd be a diligent person if you're looking at spot pricing to make your decision around your power usage. What would be more useful is the app actually messaging you and telling you when 
spot prices are low or below pre-mentioned threshold so that way I could go, oh cool, I just had an alert from my the WNDD research and telling me that power is cheap right now, maybe I'll go and do my drying.

Q: So...recommendations are preferable given thresholds for your profile, your situation?

A: Yeah I think it would be, even I mean (inaudible) spot pricing according to your area right? But if you were to be asked by it uhm what would you consider a good spot price threshold and you said...I don't know how to price like you said $x$ cents per kilowatt hour uhm and it told you anything beneath that, or below, I think that would be really useful.

Q: You're aware that there's a facility for extracting spot marking price with the bot?

A: Yes I am.

Q: Did you find it useful?

A: I did initially uhm...I guess when the first time I became aware I started looking at quite uhm quite a bit until, I think you shared the stats with me and I came out as the lowest....and then I probably didn't...(Ariel: gain as much?) well I thought okay, what the hey it's quite good but it would have been...you know...I guess it was all up to... what things have meant to my, my sort of consumption...it was...I mean I guess because I've been with Flick for a while, I thought about making a lot of changes based $\mathrm{n}$ spot price but I've been useless at using their Facebook website as well, so..it was good, yeah I think that was actually quite a useful one, but it would be good to have a bit of a comparative view of spot prices right?

Q: Do you reckon, having a threshold and being notified...?

A: ... yeah through this I kinda figured out in our discussions that I want to be told how to change my behaviour through all of this...if the bot was uh....be able to be configured so it was always prompting you based on thresholds and useful information, I'd change my behaviour, no doubt

Q: Are you aware that there's this utility for getting the spot market price through the bot?

A: Yes

Q: How did you find it? Was it useful, did it give any additional value to influence your behaviour?

A: I guess it wasn't uh...I didn't had the need to use it at any point...yeah...so I tried it, it told me a price and okay, that't it but I didn't feel the need to keep checking the price. I guess the whole period I used the bot I didn't had any concerns about the price. I knew it was around 20 something, on the low 20 cents and it's good enough so the whole use of the bot, the way I was seeing it was uhm...trying to learn about my consumption, the amounts...detect my behaviour when it goes up and down and kinda see that impact. Yeah, for me the price was kinda constant the whole time so if I use much or less of the same thing...I didn't fall back to keep looking at the price.

Q: It had that facility or feature of you know, having a threshold notifying you if you were going above the threshold, would you think that would be more suitable?

A: Yeah, definitely. I think that's great, that you don't have to ask...it will tell you like hey it's spiking okay, and you change your behaviour right there...did you have a fan going or a heater and you're not that worried about temperature you would turn it off...or you will put off doing laundry. But...that would be good but I guess a good thing on the bot, maybe this is turning much more into like data mining or stuff...if it could tell me...because if you can see both trends, both dimension, the amount that I use, the units that I use on the meter and then the price dimension, then it can draw a parallel or draw conclusion of them both and tell me hey man, you're using the majority of your electricity when the price is high or are you aware that during this time usually is lower and yeah.

Q: So having your profile measured and...specific to your situation...more geared...'cause even with Flick's notification, the same data source for the bot is what it's using...for the upper north, lower north...but it does push that information to you. Whereas with the bot you have to demand for it.

A: Yeah, exactly so I can see the challenge but uh, I guess it's an opportunity...maybe like if it sees that the price is spiking and it sees that I usually don't use power during that time...you can just not tell me anything because...yeah...not useful for me. Q: Any other recommendations or thoughts along that line?

A: Yeah I guess it's playing around building prototype using both dimensions at the same time because you will say...it could be (inaudible) and I will be asking price to one bot and then consumption to another...

Q: It was basically two distinct conversations...

A: Exactly, so maybe it could tell me like uh, yeah this day you used more power and turns out that day anyway is cheap day you know on the spot price or...oh this day you used not a lot of power but turns out that uh the price was low so it would still be a green heart (???) for example, like a good thing. Rainbow's good...well whatever emoji you wanted. even if you went over the top on your consumption, if you happen to have done it with the low prices, oh good behaviour man, it should be rewarded you know. So my conclusion is they were so separated and the price was so static that I didn't, I think I asked for it 2 or 3 times and then I didn't find the need. 


\section{Appendix J: Ethics and Forms}

TE WHARE WĀNANGA O TE ŪPOKO O TE IKA A MĀUI

is

\section{Power Play: Visualising Electricity Use as Emojis \\ INFORMATION SHEET FOR PARTICIPANTS}

Thank you for your interest in this project. Please read this information before deciding whether or not to take part. If you decide to participate, thank you. If you decide not to take part, thank you for considering my request.

\section{Who am I?}

My name is Ariel Reyes and I am a Masters student in Design Innovation at Victoria University of Wellington. This research project is work towards my thesis.

\section{What is the aim of the project?}

My project is an attempt to provide an alternative to data visualization by interpreting energy data as emojis (digital pictographs used in electronic messaging). With emojis now replacing Internet slang (e.g. (3) $\approx$ lol, $\approx$ xoxo, 国 $\approx$ omg), and people using them for daily communication, this study investigates if emojis can also be used to represent data, particularly electricity usage data. Also explore the potential of promoting energy reduction use by presenting the interpreted energy data on social media. This research has been approved by the Victoria University of Wellington Human Ethics Committee [provide approval number].

\section{How can you help?}

If you agree to take part, your electricity usage data will be requested from your electricity retailer --which can be Flick Energy, Contact Energy or Powershop. Which will then be presented to you on social media, through Facebook Messenger. These messages will be a combination of text and emojis representing your energy use. You are encouraged to respond to these messages or you can choose to ignore them, without giving a reason. You can withdraw from the study up to four weeks after commencement on If you withdraw, the information you provided, electricity usage and any recorded messages, will be destroyed.

\section{What will happen to the information you give?}

This research is confidential. I will not name you in any reports, and I will not include any information that would identify you. Only my supervisors and I will read the messages. Any recordings will be kept securely and destroyed 3 years after the research ends. 


\section{What will the project produce?}

The information from my research will be used in my Masters thesis. You will not be identified in my report. I may also use the results of my research for conference presentations, and academic reports. I will take care not to identify you in any presentation or report.

\section{If you accept this invitation, what are your rights as a research participant?}

You do not have to accept this invitation if you don't want to. If you do decide to participate, you have the right to:

- $\quad$ choose not to answer any question or respond to any messages;

- $\quad$ withdraw from the study up until four weeks after your interview;

- $\quad$ ask any questions about the study at any time;

- $\quad$ receive a copy of your messages (if it is recorded);

- $\quad$ read over and comment on a written summary of your messages;

- be able to read any reports of this research by emailing the researcher to request a copy.

\section{If you have any questions or problems, who can you contact?}

If you have any questions, either now or in the future, please feel free to contact either:

\section{Student:}

Name: Ariel Reyes

University email address:

reyesarie@myvuw.ac.nz

\section{Supervisor:}

Name: Walter Langelaar

Role: Thesis Supervisor

School: School of Design

Phone: 044635512

\section{Human Ethics Committee information}

If you have any concerns about the ethical conduct of the research you may contact the Victoria University HEC Convener: Associate Professor Susan Corbett. Email susan.corbett@vuw.ac.nz or telephone +64-4-463 5480 . 


\section{Power Play: Visualising Electricity Use as Emojis CONSENT TO INTERVIEW}

This consent form will be held for 3 years.

Researcher: $\quad$ Ariel Reyes, School of Design, Victoria University of Wellington.

- I have read the Information Sheet and the project has been explained to me. My questions have been answered to my satisfaction. I understand that I can ask further questions at any time.

- $\quad$ I agree to take part in an audio recorded interview.

- I agree to share social media messages to the researcher that I have given and received. As long as it is within the context of this research project.

I understand that:

- I may withdraw from this study up to four weeks after the interview (and social media messages collection) by the $23^{\text {rd }}$ of October 2016, and any information that I have provided will be returned to me or destroyed.

- $\quad$ The information I have provided will be destroyed 3 years after the research is finished.

- $\quad$ Any information I provide will be kept confidential to the researcher and the supervisor. I understand that the results will be used for a Masters report and a summary of the results may be used in academic reports and/or presented at conferences.

- My name will not be used in reports, nor will any information that would identify me.

Signature of participant:

Name of participant:

Date:

Contact details: 


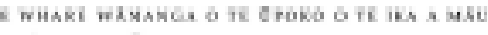

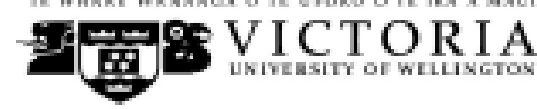

\section{MEMORANDUM}

\begin{tabular}{|c|c|}
\hline To & Ariel Reyes \\
\hline COPYTO & Walter Langelaser \\
\hline FROM & AProf Busan Cortett, Convener, Human Enics Committee \\
\hline DATE & 21 eeptember 2016 \\
\hline PAGES & 1 \\
\hline QUEJECT & $\begin{array}{l}\text { Ethloc Approval: } 23428 \\
\text { Power Play: Visuallaing Electricty Use as Emols }\end{array}$ \\
\hline
\end{tabular}

Thank you for your application for ethical approval, which has now been conaldered by the atanding Committee of the Human Eonica Committee.

Your applikation has been approved from the above date and this approval continue: untl 31 May 2017. If your data collection ls not completed by this date you should spply to the Human Ethics Commitiee for an extension to this approval.

Best wiahes with the research.

KInd regarda

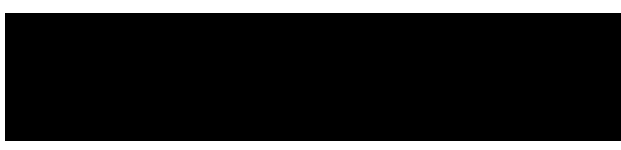

ausan Cortett

Convener, Vkctoria Unlversity Human Ethics Committec

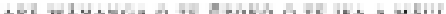

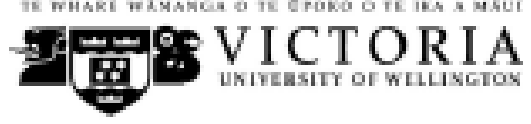

\section{MEMORANDUM}

Thane 0-4.451568

Prall mancorbettowuwers

\begin{tabular}{l|l}
\hline TO & Ariel Reyes \\
\hline COPY TO & Waiter Langelasr \\
\hline FROM & AProt Busan Cortett, Convener, Human Enics Committee \\
\hline DATE & 1 ANgust 2017 \\
\hline PAGES & 1 \\
\hline
\end{tabular}

Thank you for your request to extend your ethics approval. This has now been

Thank you for your request to extend your ethics approval. Thla has now been considered and

If your data collection la not completed by this daxe you ahould apply to the Human Ethics Commitree for an extension to this aporoval.

Best whes won the research.

Kind regarda

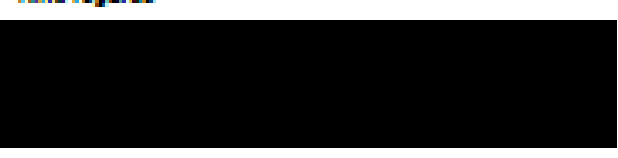

Susan Cortett

Convener, Victoria Unlveralty Human Ethics Committes 